\title{
Corrosion Fatigue Crack Propagation of Oil-Grade Alloy 718 in $\mathrm{NaCl}$ Solution
}

Jared S. Nutter

West Virginia University

Follow this and additional works at: https://researchrepository.wvu.edu/etd

\section{Recommended Citation}

Nutter, Jared S., "Corrosion Fatigue Crack Propagation of Oil-Grade Alloy 718 in NaCl Solution" (2013). Graduate Theses, Dissertations, and Problem Reports. 3398.

https://researchrepository.wvu.edu/etd/3398

This Thesis is protected by copyright and/or related rights. It has been brought to you by the The Research Repository @ WVU with permission from the rights-holder(s). You are free to use this Thesis in any way that is permitted by the copyright and related rights legislation that applies to your use. For other uses you must obtain permission from the rights-holder(s) directly, unless additional rights are indicated by a Creative Commons license in the record and/ or on the work itself. This Thesis has been accepted for inclusion in WVU Graduate Theses, Dissertations, and Problem Reports collection by an authorized administrator of The Research Repository @ WVU. For more information, please contact researchrepository@mail.wvu.edu. 


\title{
Corrosion Fatigue Crack Propagation of Oil-Grade Alloy 718 in NaCl Solution
}

\author{
Jared S. Nutter \\ Thesis submitted to the \\ Benjamin M. Statler College of Engineering and Mineral Resources \\ at West Virginia University \\ in partial fulfillment of the requirements for the degree of
}

\author{
Master of Science \\ in \\ Mechanical Engineering \\ Xingbo Liu, Ph.D., Chair \\ Konstantinos Sierros, Ph.D. \\ Bruce Kang, Ph.D. \\ Department of Mechanical and Aerospace Engineering \\ Morgantown, West Virginia \\ 2013
}

Keywords: Corrosion Fatigue Crack Growth, Ni-base Alloy 718, NaCl, Aging Treatment 


\title{
Abstract \\ Corrosion Fatigue Crack Propagation of Oil-Grade \\ Alloy 718 in NaCl Solution
}

\author{
Jared S. Nutter
}

Nickel-based alloy 718 was originally developed for use in aircraft gas turbine engines, where there was a need for low cost, high temperature superalloys. Today, alloy 718 has evolved into a special grade (oilgrade) for use in the oil and gas industry for deep sea oil drilling where its good corrosion resistance and customization of mechanical properties via heat treatments are highly sought out. In recent decades, oil-grade Alloy 718 has been directly used in bottom-hole assembly components such as measurement while drilling tools and drill collars, where it applies a combination of good corrosion resistance, high fatigue/corrosion fatigue strength, and non-magnetism. However, as the modern oil and gas industry drilled into high pressure, high temperature, ultra-deep wells, the demand for increased strength and toughness is very critical for newly designed Alloy 718. Thus, a two-step aging treatment, which is used to maximize the yield strength of aerospace-grade Alloy 718 , has been adopted and modified for oilgrade alloy 718 . However, the effect of aging treatments on corrosion fatigue resistance of oil-grade alloy 718 has not been extensively investigated yet.

The aim of this study is to investigate the effect of three different aging treatments on corrosion fatigue crack growth (CFCG) of oil-grade Alloy 718 in $\mathrm{NaCl}$ solutions with various temperatures, concentrations, and waveforms.

The results show that there is no obvious effect of $3.5 \mathrm{wt}$.\% NaCl solution on the CFCG rates of oil-grade alloy 718 in all three different aged conditions. However, the CFCG rates of oil-grade alloy 718 in 21 wt.\% $\mathrm{NaCl}$ solution are increased as compared with the ones in air and in $3.5 \mathrm{wt} . \% \mathrm{NaCl}$ solution. Moreover, aging treatments lead to lower CFCG rates of oil-grade alloy 718 in all tested conditions. Fractographical examinations of the fractured surfaces showed that the fatigue cracks propagated in the transgranular mode for all conditions. 


\title{
CORROSION FATIGUE CRACK PROPAGATION OF OIL-GRADE ALLOY 718 IN NACL SOLUTION
}

\author{
Jared S. Nutter
}

\author{
Thesis submitted to the \\ Benjamin M. Statler College of Engineering and Mineral Resources \\ at West Virginia University \\ in partial fulfillment of the requirements for the degree of \\ Masters of Science in Mechanical Engineering \\ Department of Mechanical and Aerospace Engineering
}

APPROVAL OF THE EXAMINING COMMITTEE

Konstantinos Sierros, Ph.D.

Bruce Kang, Ph.D.

Date

Xingbo Liu, Ph.D., Chair 


\section{Dedication}

I would like to dedicate this thesis to my beloved grandmother, Edna Spencer, who always believed that I was capable of far more than I ever thought. Unfortunately she is no longer with us, but I hope that I will make her proud in my future career and life. 


\section{Acknowledgements}

Foremost, I would like to express my deepest gratitude to my advisor Xingbo Liu, Ph.D. for the continuous support of my Master's study and research, for his patience, motivation, enthusiasm, and immense knowledge. His guidance helped me in all the time of research and writing of this thesis. I could not have imagined having a better advisor and mentor for my Master's study.

This technical effort was performed in support of the National Energy Technology Laboratory's ongoing research in materials for ultra-deep drilling under the RES contract DE-FE000400. I would like to thank Jeffery Hawk, Ph.D. and the National Energy and Technology Laboratory (NETL) for providing the technical support and continued guidance over the duration of the project. Also, this project would not be possible without the help of Hendrik John, Ph.D., John Sevens, and Wei Chen, Ph.D. from Baker Hughes which generously provided the machined specimens, as well as, gave invaluable knowledge and insight over the course of the project. We acknowledge use of the WVU Shared Research Facilities.

Besides my advisor, I would like to thank the rest of my thesis committee: Konstantinos Sierros, Ph.D. and Bruce Kang, Ph.D., for their encouragement, insightful comments, and difficult questions.

I would also like to thank my project team member Ting Chen for her invaluable help on the project and expertise on topic of corrosion and material science.

Finally, I would like to thank my family for supporting me through my many years of college. I must acknowledge my brother, Justin Nutter, for always keeping the home life interesting while I was gone and never letting me forget where I come from. Of course I have to thank my niece and nephew, Jayden and Jacob Gessel, for their amazing help with my role playing and Lego building skills all through college, without them I don't know if I ever could have become an engineer. My sister and brother-in-law, Jessica and Jason Gessel, have been amazing in their support, and I cannot describe how much that has meant to me. Mostly, I would like to thank my parents, Debra and Gary Nutter, and grandmother, Edna Spencer, for their unconditional love and support through not only college but my entire life. They are the reason I work so hard and will continue to build my career. I must lastly thank my lord and savior Jesus Christ who ultimately gave me the strength and guidance to make all of this possible. 


\section{Table of Contents}

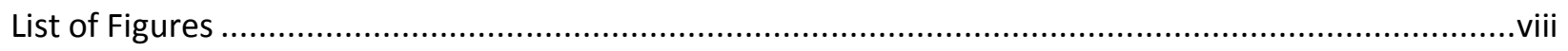

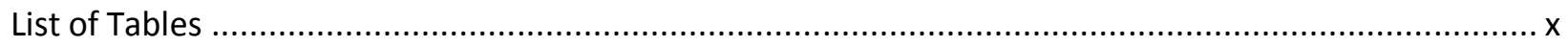

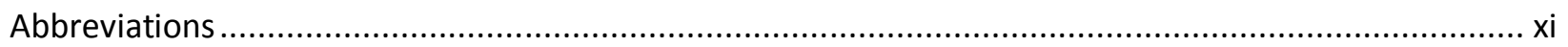

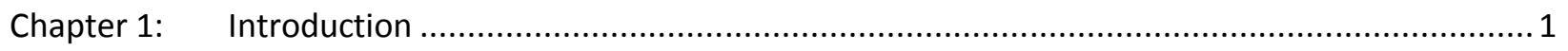

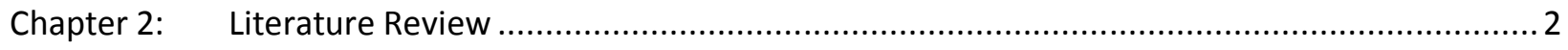

2.1 Chemical Composition \& Microstructure of Ni-based Superalloys....................................... 2

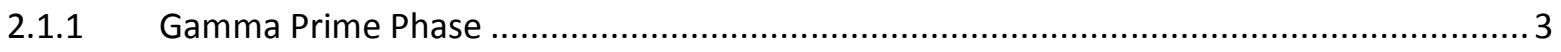

2.1.2 Gamma Double Prime Phase ......................................................................................... 4

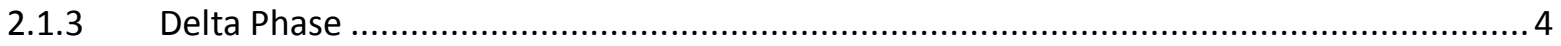

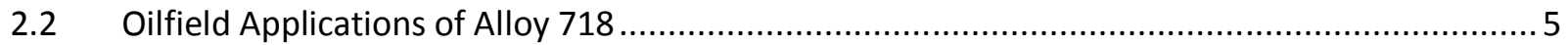

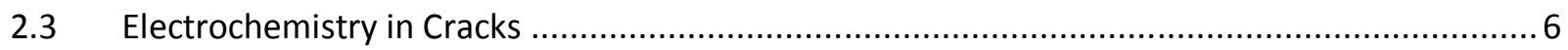

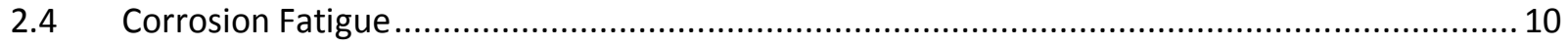

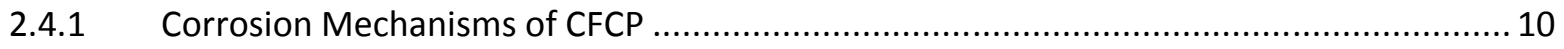

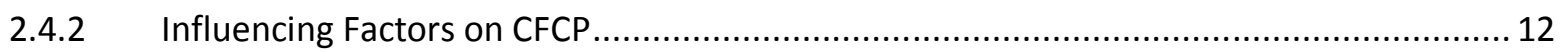

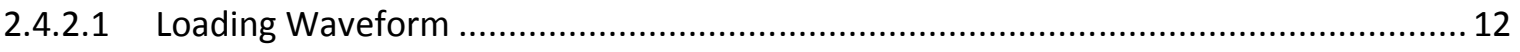

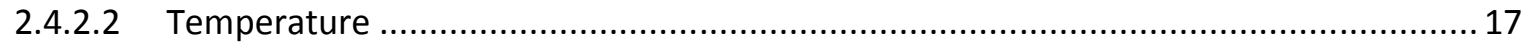

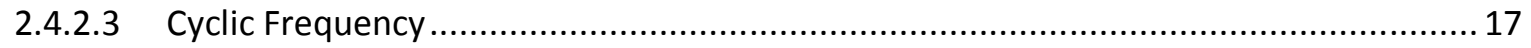

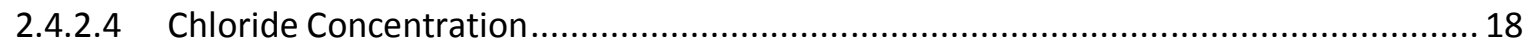

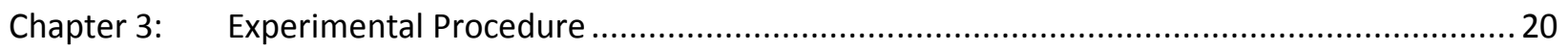

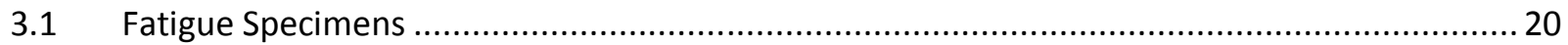

3.2 Corrosion Fatigue \& Electrochemical Testing ................................................................. 22

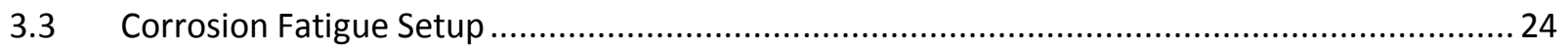

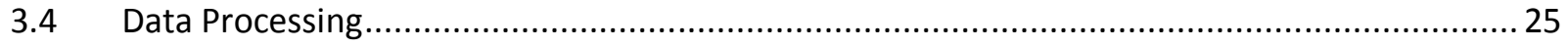

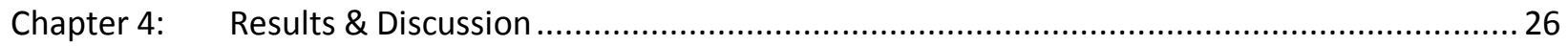

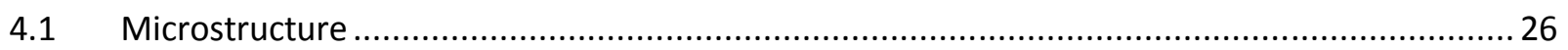

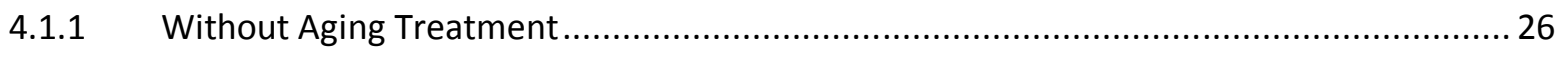

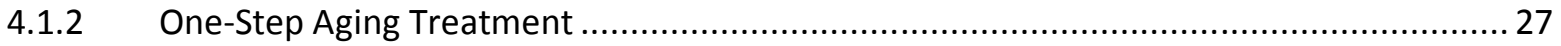

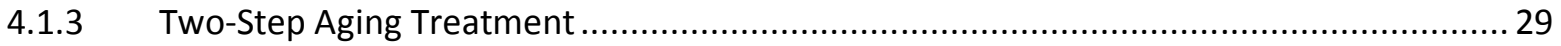




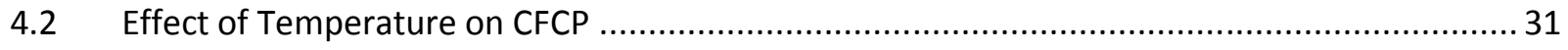

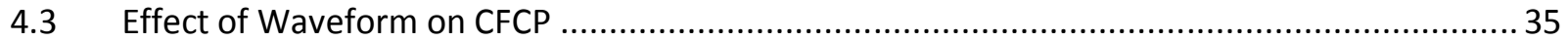

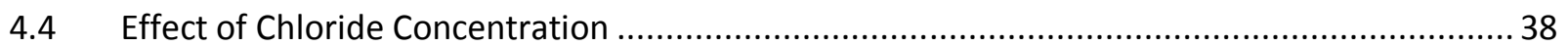

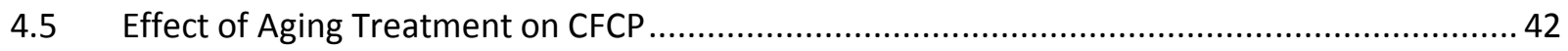

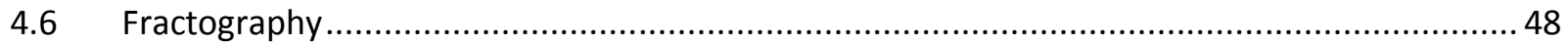

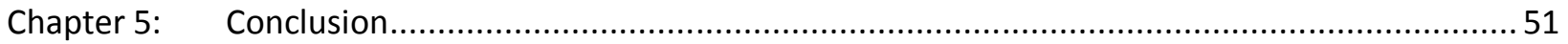

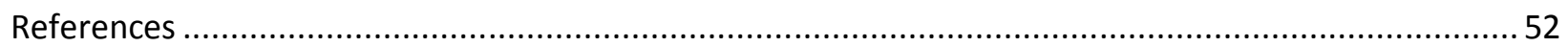

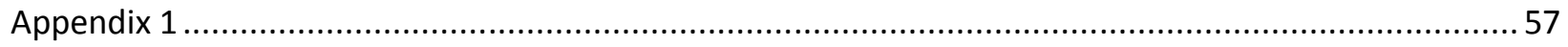

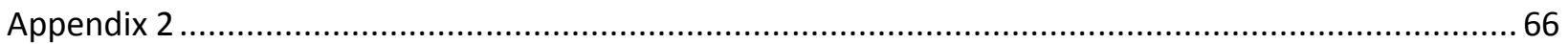




\section{List of Figures}

Figure 2.1 Categories of elements important to the constitution of the Ni-based superalloys, and their relative positions in the periodic table [14].

Figure 2.2 Gamma prime (a) ordered $\mathrm{L}_{2}$ and (b) disordered $\mathrm{Ni}_{3} \mathrm{Al}$ FCC phase. Gamma double prime (c)

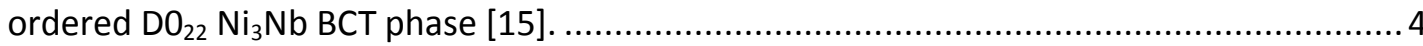

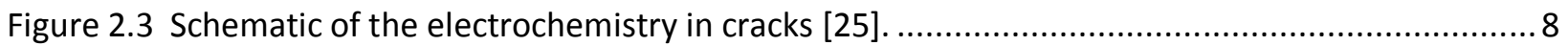

Figure 2.4 In-situ measurement of the crack potential and $\mathrm{Cl}^{-}$as a function of distance from the crack tip [22].

Figure 2.5 Simultaneous, real-time in-situ measurement of (a) crack length and (b) $\mathrm{pH}^{2}$ and $\mathrm{Cl}^{-}$during EAC test [22].

Figure 2.6 Effect of loading waveform on CFCP rate for iron in $3.5 \% \mathrm{NaCl}$ at free corrosion potential [32].

Figure 2.7 Effect of positive sawtooth and square loading waveforms on FCP rate for iron in air [32].... 13

Figure 2.8 Effect of hold-time for square waveform on CPCP rate for iron in $3.5 \% \mathrm{NaCl}$ at free corrosion potential [32]

Figure 2.9 The strain and transient current curves for iron in 3.5\% $\mathrm{NaCl}$ under (a) positive sawtooth, (b) square and (c) negative sawtooth loading waveforms [32]

Figure 2.10 The strain and transient current curves for iron in $3.5 \% \mathrm{NaCl}+1 \% \mathrm{NaNO}_{2}$ solution of (a) positive and (b) negative sawtooth waveforms [32].

Figure 2.11 The strain and transient current curves for iron in $3.5 \% \mathrm{NaCl}+1 \% \mathrm{NaNO}_{2}$ under (a) positive sawtooth, (b) square and (c) negative sawtooth loading waveforms [32].

Figure 2.12 (a) FCGR curves and (b) potentiodynamic polarization curves for UNS S45000-H900 in different environments [47].

Figure 3.1 CFCP single edge notched tensile specimen dimensions in millimeters.............................2 21

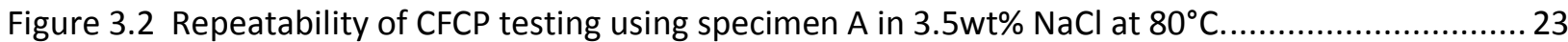

Figure 3.3 (a) uncovered sample, (b) covered sample with $5 \mathrm{~mm}$ exposed surface, and (c) wires connected for potential measurement.

Figure 3.4 (a) assembled corrosion fatigue test and (b) inner protective lining and insulation of container. 24

Figure 4.1 SEM image of Specimen A's microstructure at 1000x magnification. ................................. 26

Figure 4.2 (a) SEM of a nitride inclusion with (b) EDX of the nitride in Specimen A's microstructure...... 27

Figure 4.3 (a) SEM and (b) EDX of a cluster of carbide inclusions in Specimen A's microstructure.......... 27

Figure 4.4 SEM image of Specimen B's microstructure at 1000x magnification.................................. 28

Figure 4.5 SEM image of the grain boundaries of Specimen B at 5000x magnification....................... 28

Figure 4.6 Gamma prime and double prime precipitation of Specimen B at (a) 30,000x and (b) 50,000x

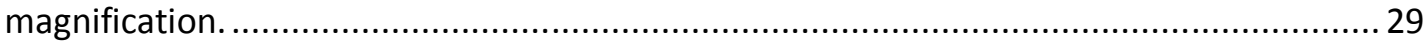

Figure 4.7 SEM image of Specimen C's microstructure at 1000x magnification................................... 30

Figure 4.8 SEM image of the grain boundaries of Specimen $C$ at 5000x magnification........................ 30 
Figure 4.9 Gamma prime and double prime precipitation of Specimen $C$ at (a) 30,000x and (b) 50,000x

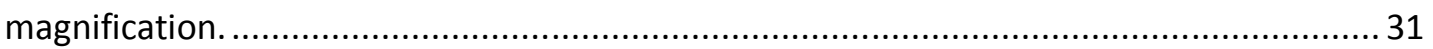

Figure 4.10 The effect of solution temperature on Specimen $\mathrm{A}$ in $3.5 \mathrm{wt} \% \mathrm{NaCl}$ solution..................... 32

Figure 4.11 The effect of solution temperature on Specimen $B$ in $3.5 \mathrm{wt} \% \mathrm{NaCl}$ solution. ................... 33

Figure 4.12 The effect of solution temperature on Specimen $\mathrm{C}$ in $3.5 \mathrm{wt} \% \mathrm{NaCl}$ solution. .................... 33

Figure 4.13 Potentiodynamic polarization curves for Specimen A in $3.5 \mathrm{wt} \% \mathrm{NaCl}$............................ 34

Figure 4.14 Potentiodynamic polarization curves for Specimen B in $3.5 \mathrm{wt} \% \mathrm{NaCl}$........................... 34

Figure 4.15 Potentiodynamic polarization curves for Specimen $\mathrm{C}$ in $3.5 \mathrm{wt} \% \mathrm{NaCl}$............................. 35

Figure 4.16 The effect of hold-time on CFCP for Specimen A in $3.5 \mathrm{wt} \% \mathrm{NaCl}$ solution at $80^{\circ} \mathrm{C}$.............36

Figure 4.17 The effect of hold-time on CFCP for Specimen B in $3.5 \mathrm{wt} \% \mathrm{NaCl}$ solution at $80^{\circ} \mathrm{C}$..............37

Figure 4.18 The effect of hold-time on CFCP for Specimen $\mathrm{C}$ in $3.5 \mathrm{wt} \% \mathrm{NaCl}$ solution at $80^{\circ} \mathrm{C}$.............. 37

Figure 4.19 The effect of chloride concentration on FCG rate for Specimen A.................................39

Figure 4.20 The effect of chloride concentration on FCG rate for Specimen B. ................................ 39

Figure 4.21 The effect of chloride concentration on FCG rate for Specimen C. ................................40

Figure 4.22 Potentiodynamic polarization curves of Specimen $\mathrm{A}$ in 3.5 and 21 wt. $\% \mathrm{NaCl}$ at $80^{\circ} \mathrm{C}$........ 40

Figure 4.23 Potentiodynamic polarization curves of Specimen B in 3.5 and $21 \mathrm{wt} . \% \mathrm{NaCl}$ at $80^{\circ} \mathrm{C}$........ 41

Figure 4.24 Potentiodynamic polarization curves of Specimen $\mathrm{C}$ in 3.5 and 21 wt. $\% \mathrm{NaCl}$ at $80^{\circ} \mathrm{C} \ldots \ldots . . .41$

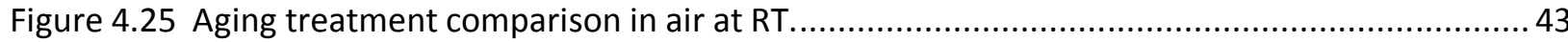

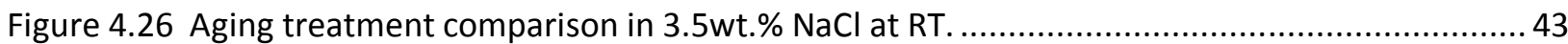

Figure 4.27 Potentiodynamic polarization curves for different aging treatments in $3.5 \mathrm{wt} \% \mathrm{NaCl}$ at RT.. 44

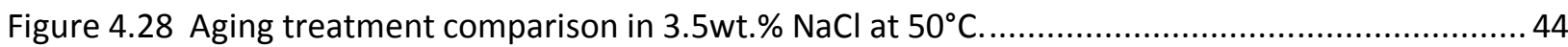

Figure 4.29 Potentiodynamic polarization curves for different aging treatments in $3.5 \mathrm{wt} \% \mathrm{NaCl}$ at $50^{\circ} \mathrm{C}$.

.45

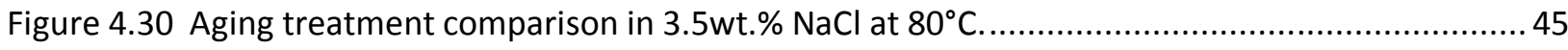

Figure 4.31 Potentiodynamic polarization curves for different aging treatments in $3.5 \mathrm{wt} \% \mathrm{NaCl}$ at $80^{\circ} \mathrm{C}$.

46

Figure 4.32 Aging treatment comparison under trapezoidal waveform in $3.5 \mathrm{wt} . \% \mathrm{NaCl}$ at $80^{\circ} \mathrm{C} \ldots \ldots \ldots . . . .46$

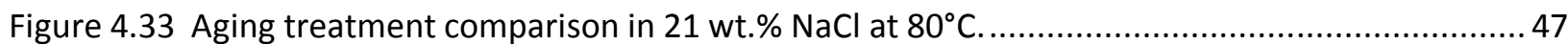

Figure 4.34 Potentiodynamic polarization curves of the different aging treatments in $21 \mathrm{wt} . \% \mathrm{NaCl}$ at $80^{\circ} \mathrm{C}$.

Figure 4.35 Fracture surface of Specimen A in $3.5 \mathrm{wt} . \% \mathrm{NaCl}$ at $80^{\circ} \mathrm{C}$ under (a) triangle waveform and (b)

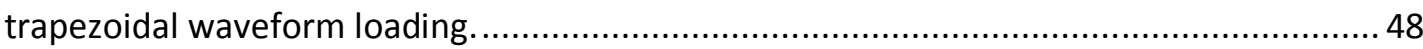

Figure 4.36 Fracture surface of Specimen B in $3.5 \mathrm{wt} . \% \mathrm{NaCl}$ at $80^{\circ} \mathrm{C}$ under (a) triangle waveform and (b)

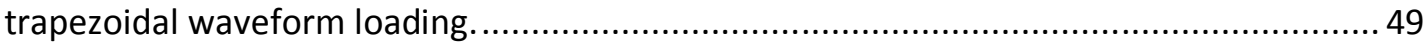

Figure 4.37 Fracture surface of Specimen $\mathrm{C}$ in $3.5 \mathrm{wt} . \% \mathrm{NaCl}$ at $80^{\circ} \mathrm{C}$ under (a) triangle waveform and (b) trapezoidal waveform loading.

Figure 4.38 SEM of striations on Specimen A fracture surface observed at $80^{\circ} \mathrm{C}$ in $3.5 \mathrm{wt} . \% \mathrm{NaCl}$ under triangle waveform loading at (a) 5,000x and (b) 50,000x magnification. 50

Figure 4.39 SEM of striations near an inclusion on Specimen A fracture surface observed at $80^{\circ} \mathrm{C}$ in 3.5 wt.\% $\mathrm{NaCl}$ under trapezoidal waveform loading at (a) 1,500x and (b) 10,000x magnification. 


\section{List of Tables}

Table 2.1 Comparison of aerospace and oilfield grade alloy $718[12,13,19]$..................................... 6

Table 2.2 Experimental results of the acidity at the crack tip in corrosive solution $[20-24,30] . \ldots \ldots \ldots \ldots . . .8$

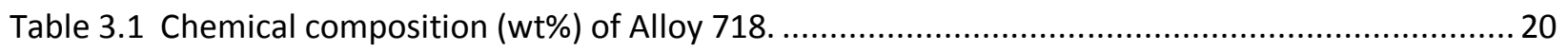

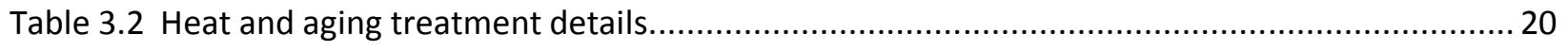

Table 3.3 Minimum mechanical properties at room temperature. ...................................................... 21 


\section{Abbreviations}

\begin{tabular}{|c|c|c|c|}
\hline$A D$ & Anodic Dissolution & HIC & Hydrogen-Induced Cracking \\
\hline$p$ & Applied Load & $a_{0}$ & Initial Crack Length \\
\hline BCT & Body-Centered Tetragonal & $u_{0}$ & Initial Potential Drop \\
\hline $\mathrm{CF}$ & Corrosion Fatigue & $\mathrm{R}$ & Load Ratio \\
\hline CFCP & $\begin{array}{l}\text { Corrosion Fatigue Crack } \\
\text { Propagation }\end{array}$ & LWD & Logging-While-Drilling \\
\hline & & MWD & Measurement-While-Drilling \\
\hline$E_{\text {corr }}$ & Corrosion Potential & $\mathrm{OCP}$ & Open-Circuit Potential \\
\hline$a$ & Crack Length & $E_{\text {pit }}$ & Pitting Potential \\
\hline$\frac{d a}{d N}$ & Crack Growth Rate & $u$ & Potential Drop \\
\hline$\delta$ & Delta-Phase & $\mathrm{E}_{\mathrm{rp}}$ & Repassivation Potential \\
\hline EDX & $\begin{array}{l}\text { Energy Dispersive X-ray } \\
\text { Spectroscopy }\end{array}$ & RT & Room Temperature \\
\hline EAC & Environmentally-Assisted Cracking & SCE & Saturated Calomel Electrode \\
\hline FCC & Face Centered Cubic & SEM & Scanning Electron Microscope \\
\hline FCG & Fatigue Crack Growth & $\mathrm{NaCl}$ & Sodium Chloride \\
\hline FCGR & Fatigue Crack Growth Rate & $t$ & Specimen Thickness \\
\hline$\gamma^{\prime \prime}$ & Gamma Double Prime Precipitates & $w$ & Specimen Width \\
\hline$\gamma$ & Gamma Matrix & SAD & Stress-Assisted Dissolution \\
\hline$\gamma^{\prime}$ & Gamma Prime Precipitates & SCC & Stress Corrosion Cracking \\
\hline GB & Grain Boundary & $K$ & Stress Intensity Factor \\
\hline$y$ & Half-Potential Probe Scan & $\Delta K$ & Stress Intensity Factor Range \\
\hline $\mathrm{HE}$ & Hydrogen Embrittlement & SSC & Sulfide Stress Cracking \\
\hline
\end{tabular}




\section{Chapter 1: Introduction}

For the past half century, the subject of corrosion fatigue crack propagation of metallic materials has attracted much attention from researchers throughout the world. This is due to the fact that corrosion fatigue is a big cause of many service failures in a wide variety of industries [1-4]. The oil and gas industry is particularly important with the exploration of deep wells in deep-water being the "new frontier" [5]. Deep wells generally have higher temperatures (up to $260^{\circ} \mathrm{C}$ ) and pressures (up to 172 MPa). There are two basic categories of wells, "sweet" and "sour", where sweet wells are mildly corrosive and sour wells are very corrosive. The material selection is especially important for sour wells, because they can contain hydrogen sulfide, carbon dioxide, chlorides, and free sulfur $[5,6]$. Deep wells generally require more high-performance, nickel-base alloys, which are stronger and more corrosion/corrosion fatigue resistant than comparable stainless steels.

Nickel-base Alloy 718 was originally developed for use in high temperature, aircraft gas turbine engines. It was first used in the oil and gas industry for fasteners, valve stems, shafts, and drill tools (applications that only involve brief exposure to corrosive conditions). By the 1980s, alloy 718 began to be used in critical well completion equipment such as hangers, packers, and subsurface safety valves [710]. Recently, the largest use of alloy 718 is for downhole tools such as subsurface safety valves, packers, flow control devices, and other tools $[5,8,11,12]$. Wellhead distribution equipment may also be made of high-strength, nickel-base alloys. These components reduce pressure through a complex system of valves and combine or distribute the oil and or gas flow. In the case of offshore wells, these devices sit on the ocean floor, exposing them to long term sea water environments. Alloy 718 has also been used in downhole measurement tools including devices such as logging-while-drilling (LWD) and measurement-while-drilling (MWD), where sophisticated electronic instruments are contained in a strong, nonmagnetic alloy tube [12].

It is well known that nickel-base alloy 718 can be age hardened to various strength levels by adjusting the heat treatment procedures. Oil-grade alloy 718 is solution annealed at a temperature of $1021^{\circ} \mathrm{C}$ to $1052^{\circ} \mathrm{C}$ for one to two and a half hours, followed by single-step aging treatment at $774^{\circ} \mathrm{C}$ to $802^{\circ} \mathrm{C}$ for six to eight hours [13]. This single-step aging treatment is described in API standard 6A718 specified for nickel-base alloy 718 , used in oil and gas drilling and production to increase stress corrosion cracking (SCC) and sulfide stress cracking (SSC) resistance. This is achieved by sacrificing mechanical properties such as yield strength and hardness $[9,12]$. Since the demand of strength and toughness increases in deep well drilling, a two-step aging treatment at $760^{\circ} \mathrm{C}$ and $650{ }^{\circ} \mathrm{C}$ has been adopted for oilgrade alloy 718 in recent years to maximize the mechanical properties. However, there has been no research into the corrosion fatigue properties of this new aging treatment or the standard aging treatment in low temperature aqueous $\mathrm{NaCl}$ environments. Thus, it is important to investigate whether aging treatment affects the corrosion and corrosion fatigue resistance of oil-grade alloy 718 since the mechanical properties have been improved. 
This study investigates the effects of heat treatment, solution temperature, cyclic waveform, and chloride concentration on corrosion fatigue crack propagation of oil-grade Alloy 718 in $\mathrm{NaCl}$ solution.

\section{Chapter 2: Literature Review}

\subsection{Chemical Composition \& Microstructure of Ni-based Superalloys}

The compositions of most common superalloys involve ten or more elements making superalloys some of the most complex materials engineered by man. Figure 2.1 shows important elements to the chemical makeup of $\mathrm{Ni}$-based superalloys, and their relative location in the periodic table.

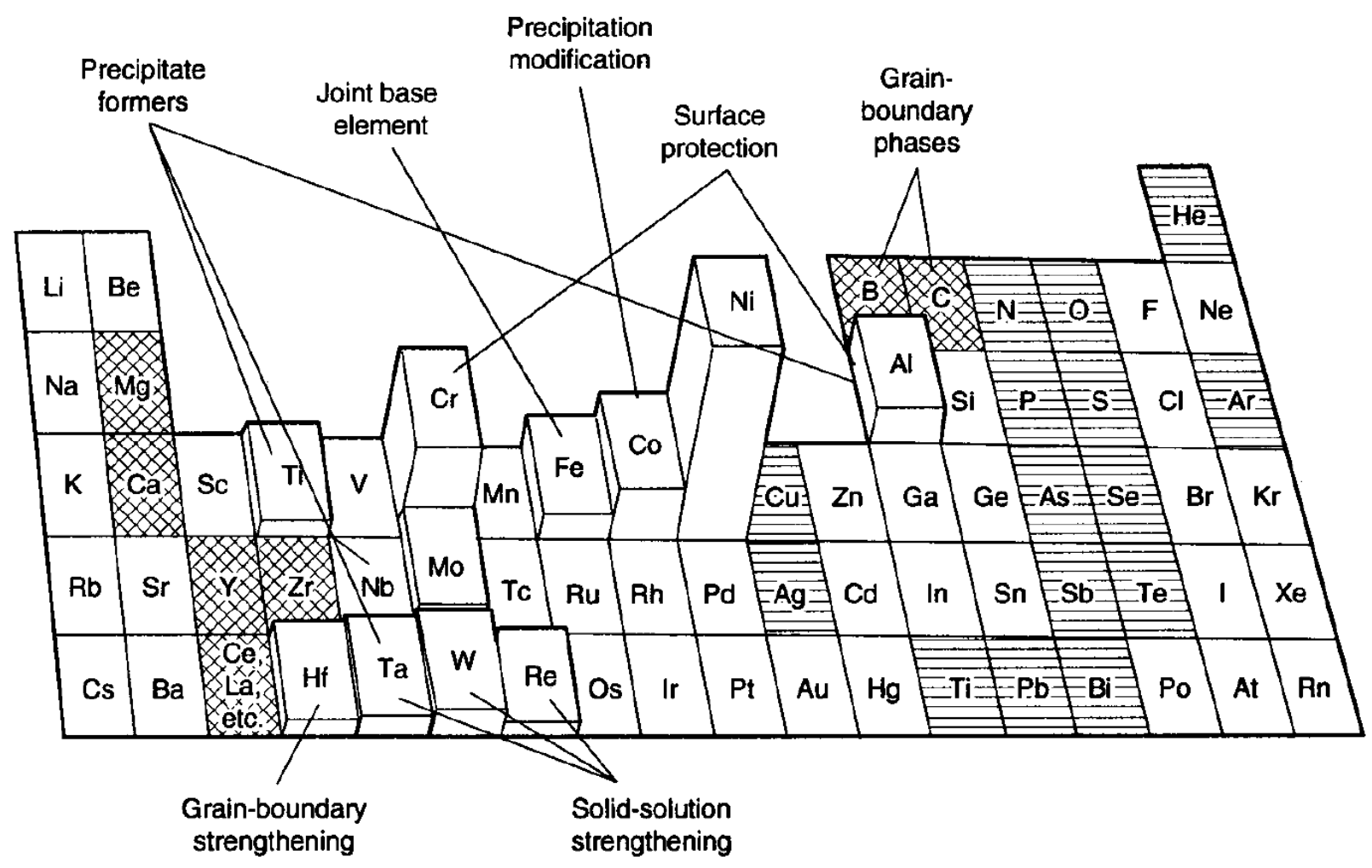

Figure 2.1 Categories of elements important to the constitution of the Ni-based superalloys, and their relative positions in the periodic table [14]. 
The first class of elements used to make up the austenitic gamma $(\gamma)$ matrix includes nickel, cobalt, iron, chromium, ruthenium, molybdenum, rhenium and tungsten. These elements have similar atomic radii to $\mathrm{Ni}$ and tend to partition to the $\gamma$-matrix stabilizing it [15]. The second class of elements (aluminum, titanium, niobium and tantalum) have greater atomic radii than the first class and assist in the formation of ordered phases such as the FCC gamma-prime $\left(\gamma^{\prime}\right)$ phase and BCC gamma double prime $\left(\gamma^{\prime \prime}\right)$. These phases precipitate in the $\gamma$-matrix and helps strengthen it by forming coherent bonds with the $\gamma$-matrix. A third class, made up of boron, carbon and zirconium, migrate to the grain boundaries to form carbides and borides because their atomic radii are very different than nickel's [15].

The microstructure of superalloys consists of different phases that do different things in the alloy. The main $\gamma$-matrix forms a continuous FCC structure in which other phases reside. Almost all of the elements used for corrosion resistance reside in this phase such as chromium, nickel, aluminum, titanium, molybdenum and copper. The $\gamma^{\prime}$ phase forms as a strengthening precipitate phase in the $\gamma^{-}$ matrix. In Ni-Fe based superalloys rich in niobium such as Alloy 718 , a second BCC precipitate phase forms along the grain boundary called gamma double prime phase ( $\left.{ }^{\prime \prime}\right)$. Carbides of the form $\mathrm{MC}$ are formed with carbon reacting with titanium, tantalum or hafnium along the grain boundaries. These can decompose to other species such as $\mathrm{M}_{23} \mathrm{C}_{6}$ and $\mathrm{M}_{6} \mathrm{C}$ residing in the $\mathrm{\gamma}$-matrix, and are rich in chromium, molybdenum and tungsten.

\subsubsection{Gamma Prime Phase}

The main strengthening component in superalloys without $\gamma^{\prime \prime}$ precipitate is the ordered $\mathrm{L}_{2} \mathrm{Ni}-\mathrm{Al}$ $\gamma^{\prime}$-phase. It precipitates in the continuous $\gamma$-matrix from mainly Aluminum, but may also include Titanium or Niobium. In the ordered $\mathrm{FCC} \mathrm{A}_{3} \mathrm{~B}$ compound shown in Figure 2.2(a), electronegative elements ( $\mathrm{Ni}, \mathrm{Co}, \mathrm{Fe}$ ) compose the " $\mathrm{A}$ " element, and more electropositive elements $(\mathrm{Al}, \mathrm{Ti}, \mathrm{Nb})$ compose the " $B$ " element $[7,14]$. In the ordered $L 1_{2}$ FCC structure, the A element is in the center of the faces and the " $\mathrm{B}$ " element is at the corners. Since the $\mathrm{Ni}$ atom is incompressible, this compound is favored in the $\mathrm{Ni}$ dominated $\mathrm{\gamma}$-matrix do to its small size change. More complex phases are avoided since they would require a larger size change. The shape of $\gamma^{\prime}$ is related to the matrix-lattice $\gamma / \gamma^{\prime}$ mismatch. The shape changes with increasing $\gamma / \gamma^{\prime}$ mismatch are spherical, globular, blocky and cuboidal. Spheres occur at 0$0.2 \%$ lattice mismatch, cubes at 0.5-1.0\% mismatch and plates appear above $1.25 \%$ mismatch [14]. Also, variations in Molybdenum content and in the Aluminum/Titanium ratio can change $\gamma^{\prime}$ morphology [14]. 


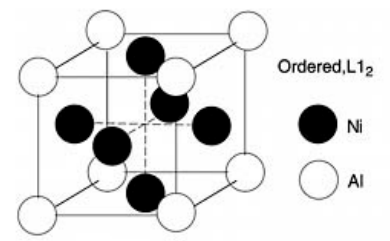

(a)

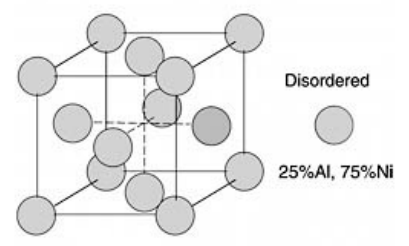

(b)

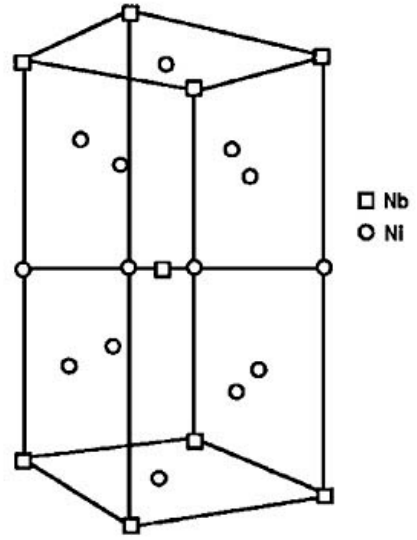

(c)

Figure 2.2 Gamma prime (a) ordered $\mathrm{L1}_{2}$ and (b) disordered $\mathrm{Ni}_{3} \mathrm{Al}$ FCC phase. Gamma double prime (c) ordered $\mathrm{DO}_{22} \mathrm{Ni}_{3} \mathrm{Nb}$ BCT phase [15].

\subsubsection{Gamma Double Prime Phase}

For Ni-Fe superalloys, such as Alloy 718, with sufficient niobium content, a second precipitate forms with a body-centered tetragonal ordered compound shown in Figure 2.2(c). Gamma double prime provides high strength at low-to-intermediate temperatures and is unstable above $650^{\circ} \mathrm{C}$. The precipitate is similar to $\gamma^{\prime}$ due to its $\mathrm{Ni}_{3} \mathrm{Nb}$ composition and thus is denoted gamma double prime ( $\left.\gamma^{\prime \prime}\right)$. It is an ordered compound with $\mathrm{DO}_{22}$ crystal structure with a disc-shaped morphology. The size of $\gamma^{\prime \prime}$ can have a thickness as small as $10 \mathrm{~nm}$ and diameter about $50 \mathrm{~nm}$ [15]. In alloys where $\gamma^{\prime}$ and $\gamma^{\prime \prime}$ are present, $\gamma^{\prime \prime}$ is the primary strengthening precipitate. Like $\gamma^{\prime}, \gamma^{\prime \prime}$ is coherent with the $\gamma$-matrix with coherency strains to several percent (of the order of 2.9\%) [14]. The high strength comes from coherency strains and the limited number of available slip systems which operate in $\gamma^{\prime \prime}$. The kinetics of formation, however, are sluggish as a consequence of the high coherency strains. In over aged conditions the niobium can migrate to form an incoherent phase called delta phase.

\subsubsection{Delta Phase}

The delta phase $(\delta)$ is a bi-product of niobium rich superalloys in overaged conditions. It is invariable incoherent with the $\gamma$-matrix and therefore does not directly add any strength to the superalloy. It forms in the range of $650-980^{\circ} \mathrm{C}$, and its characteristics of formation are strongly dependent on temperature $[7,15]$. At temperatures around $650-700^{\circ} \mathrm{C}, \delta$ nucleates at $\gamma$ grain boundary and grows at the expense of $\gamma^{\prime \prime}$. At $700-885^{\circ} \mathrm{C}$, both $\delta$ and $\gamma^{\prime \prime}$ precipitate together, beyond $885^{\circ} \mathrm{C} \gamma^{\prime \prime}$ is no longer stable. At $840-950^{\circ} \mathrm{C}$, the $\delta$ forms rapidly in the form of plates at times under 24 hours. The solvus temperature of $\delta$ is around $1000^{\circ} \mathrm{C}$. The $\delta$ phase distribution can be used to control and refine grain size to help optimize the tensile and fatigue properties. Evidence shows that hydrogen-cracking susceptibility of alloy 718 is directly related to the extent of $\delta$-phase coverage of the grain boundaries 
$[12,16]$. Hydrogen appears to play a role in promoting interface decohesion between $\delta$-phase and the matrix.

\subsection{Oilfield Applications of Alloy 718}

Originally, alloy 718 was developed for use in aircraft gas turbine engines; in fact, the patent makes no mention of aqueous corrosion capabilities. However, it was quickly recognized it would be useful in ambient temperature applications needing high strength, toughness, and moderate resistance to acids and salts. Around the same time, the oil and gas industry was moving into coastal and marine locations, deeper wells were being drilled with higher pressures and temperatures with more corrosive fluids creating the demand for a higher corrosive resistant alloy. Aero-grade alloy 718 was first used in the 1970s in the oil and gas industry for fasteners, valve stems, shafts, and drill tools (applications that only involve brief exposure to corrosive conditions). By the 1980s, alloy 718 began to be used in critical well completion equipment such as hangers, packers, and subsurface safety valves. Today, the largest use of alloy 718 is for downhole tools such as surface-controlled subsurface safety valves (which shut of flow at the top of the well), side-pocket mandrels (which inject inhibitors), packers and seal assemblies (which control and direct flow at the foot of the well into the collection pipe), hangers (which support the production tubing string at the well head), flow control devices, and other tools [5, 9-12]. Wellhead distribution equipment may also be made of high-strength nickel-base alloy. These components reduce pressure through a complex system of valves and combine or distribute the oil and or gas flow. Alloy 718 has also been used in downhole measurement tools including devices such as logging-while-drilling (LWD) and measurement-while-drilling (MWD), where sophisticated electronic instruments are contained in a strong, nonmagnetic alloy tube. Here, the need is for a nonmagnetic alloy with high strength, because magnetic surveying is used to measure the well orientation. At the same time, the material must resist corrosion in drilling mud that may be saturated with salts and acids used to dissolve the rock. Most other nonmagnetic materials available at the same strength rely on cold working to some extent and, therefore, not readily available in large diameters. Alloy 718 has also been used directly for drill string components, where it applies a favorable combination of high fatigue strength and high corrosion resistance with non-magnetism [12].

Initially, grades of alloy 718 such as AMS 5662 used for non-rotating aircraft turbine engine applications were applied in the oilfield. The microstructure of this grade contains a significant amount of $\delta$-phase to constrain grain growth, as well as a distribution of $\gamma / \gamma^{\prime}$ designed for maximum strength [12]. This created a very hard alloy that is susceptible to hydrogen embrittlement (HE), and several significant field component failures were associated with this rather than classical stress corrosion. Two important $[17,18]$ incidents were linked to hydrogen-induced fracture leading to the establishment of an oilfield specific chemistry, heat treatment, and microstructure of alloy 718 . In both cases, the undesirable combination of high level of applied hydrogen, and an unfavorable microstructure induced delayed fracture.

Oilfield heat treatments historically employed a high solution treatment temperature to improve fracture toughness. Fracture toughness is important for pressure containment because 
designers rely on "leak before burst" failure criteria [12]. The need to minimize $\delta$-phase dictated a solution treatment above the $\delta$-solvus at the expense of inherently coarser grain size. Oilfield and aerospace aging treatments also differ. The conventional aerospace heat treatment was designed to produce an optimum distribution of precipitates via a two-step aging treatment. The selection of the nominal $788^{\circ} \mathrm{C}$ single-step aging treatment now specified in API 6 A718 was to improve reliability of the treatment to simultaneously achieve maximum hardness of Rc 40 and minimum yield strength of $827 \mathrm{MPa}$ [12]. The composition of oilfield alloy 718 has evolved to support the microstructure requirements and also to enhance toughness. Niobium is restricted to $5.20 \%$ to minimize $\delta$, and carbon is limited to $0.045 \%$ to prevent formation of continuous grain boundary carbides during aging. Phosphorus is restricted to less than $0.010 \%$ to improve toughness. Table 2.1 displays some of the other differences between the two grades of alloy 718. As a result, the oilfield and aerospace alloys have become distinct within the broad definition of alloy 718 .

Table 2.1 Comparison of aerospace and oilfield grade alloy 718 [12, 13, 19].

\begin{tabular}{|lll|}
\hline Items & Aerospace AMS 5662 [19] & Oilfield Spec. API 6A718 [13] \\
\hline Solution Treatment & $941-1010^{\circ} \mathrm{C}$ & $1021-1052^{\circ} \mathrm{C}$ \\
\hline Grain Size (ASTM) & $4-5$ & $2-3$ \\
\hline Second Phase & $\begin{array}{l}\text { No Laves, delta banding per } \\
\text { Customer requirement }\end{array}$ & $\begin{array}{l}\text { No continuous GB network, } \\
\text { No acicular delta, no Laves }\end{array}$ \\
\hline Age Harden & $718^{\circ} \mathrm{C}+621^{\circ} \mathrm{C}$ & $774-802^{\circ} \mathrm{C}$ \\
\hline Carbon & $0.080 \%$ max. & $0.045 \%$ max. \\
\hline Phosphorus & $0.015 \%$ max. & $0.010 \%$ max. \\
\hline Copper & $0.30 \%$ max. & $0.23 \%$ max. \\
\hline Niobium & $5.50 \%$ max. & $5.20 \%$ max. \\
\hline Aluminum & $0.20 \%$ min. & $0.40 \%$ min. \\
\hline Titanium & $0.65 \%$ min. & $0.80 \%$ min. \\
\hline Yield Strength & $1034 \mathrm{MPa}$ min. & $827 \mathrm{MPa}$ min. \\
\hline Tensile Strength & $1276 \mathrm{MPa}$ min. & $1034 \mathrm{MPa}$ min. \\
\hline Elongation & $12 \%$ min. & $20 \% \min$ \\
\hline Red of area & $15 \%$ min. & $25-35 \%$ min. \\
\hline Hardness & Rc 36 min. & Rc 40 max. \\
\hline
\end{tabular}

\subsection{Electrochemistry in Cracks}

Once a crack has initiated in a corrosive environment, the growth rate is strongly influenced by the chemistry and electrochemistry in the crack, specifically at the crack tip. It is constantly changing due to growing crack walls, confined spaces and limited mass flow resulting in significant changes in chemistry from the bulk environment. The mass flow is controlled by diffusion, ion migration and fluid flow from cyclic fatigue loading. Fluid flow in a crack is most significant during cyclic loading where the fluid is forced in and out of the crack on each cycle. Also, the geometry of FCP samples expose the sides of the crack to the solution and allows for a less restrictive fluid flow through the crack. 
To understand the importance of mass transport, one must understand the chemistry at the crack tip and side walls. Anodic dissolution is the driving force behind the changing chemistry in the crack, illustrated in Figure 2.3. The strain from the rising load of the fatigue cycle fractures the passivation film, exposing the bare metal surface of the crack tip that is also under very high stress. Anodic dissolution takes place where metal cations $\left(\mathrm{M}^{\mathrm{n}+}\right)$ are dissolved from the crack tip surface, and chloride anions $\left(\mathrm{Cl}^{-}\right)$are attracted to the crack tip from the bulk solution to balance the charge. Hydrolysis takes place where the metal cations react with the water molecules to form $\mathrm{MOH}^{(\mathrm{n}-1)+}$ and hydrogen ions. This lowers the $\mathrm{pH}$ at the crack tip, shown in Table 2.2 for different metal alloys and environments. But, internal cathodic reactions in the crack, through reduction of $\mathrm{H}^{+}$ions and water, will counterbalance the decrease of $\mathrm{pH}$ at the crack tip to some extent. However, the process ultimately produces an aggressive, low $\mathrm{pH}$, electrolyte concentrated in metal cations and chloride anions near the crack tip [20-29]. The restricted mass flow maintains this environment, and an ohmic potential drop due to ion transport through the resistive crack medium creates the difference in electrochemistry between the crack and the bulk solution.

Cooper and Kelly [22] investigated the role of the crack environment in establishing environmentally-assisted cracking (EAC) in AA 7050 alloys via real-time in-situ measurements of the crack potential, $\mathrm{pH}$ and chloride concentration during stage II cracking in aqueous chromate-chloride solution under electrochemical control. They found that the electrode potential in the crack during EAC, shown in Figure 2.4, changed from the applied potential in the bulk solution. Figure 2.4 also shows the chloride concentration build up at the crack tip as a result of the accumulating metal cations from anodic dissolution. They said that the steep crack potential gradient, measured with the in-situ reference electrode, indicates ion movement within the crack; cations are driven out of the crack while anions are attracted to the tip. Also, the fact there is a net current within the crack indicates that the anodic reaction at the tip is not balanced by local cathodic reactions. Figure 2.5 shows this in real- time as the crack moves past the electrode around days 5-7, where there is an obvious drop in $\mathrm{pH}$ and peak in $\mathrm{Cl}^{-}$concentration at the crack tip and stability in the crack's wake.

The anodic process of hydrogen generation per electron is not very efficient because the of the incomplete hydrolysis process. So the kinetics of hydrogen ion and water reduction in the crack is likely to be much less than the kinetics of the anodic dissolution process but still has a strong influence of the $\mathrm{pH}$ of the crack [25]. Also, some of the hydrogen atoms generated will be absorbed into the metal and will localize just ahead of the tip in the plastic deformation zone due to the hydrostatic stress and the distribution of microstructural trap sites which can lead to hydrogen embrittlement. 


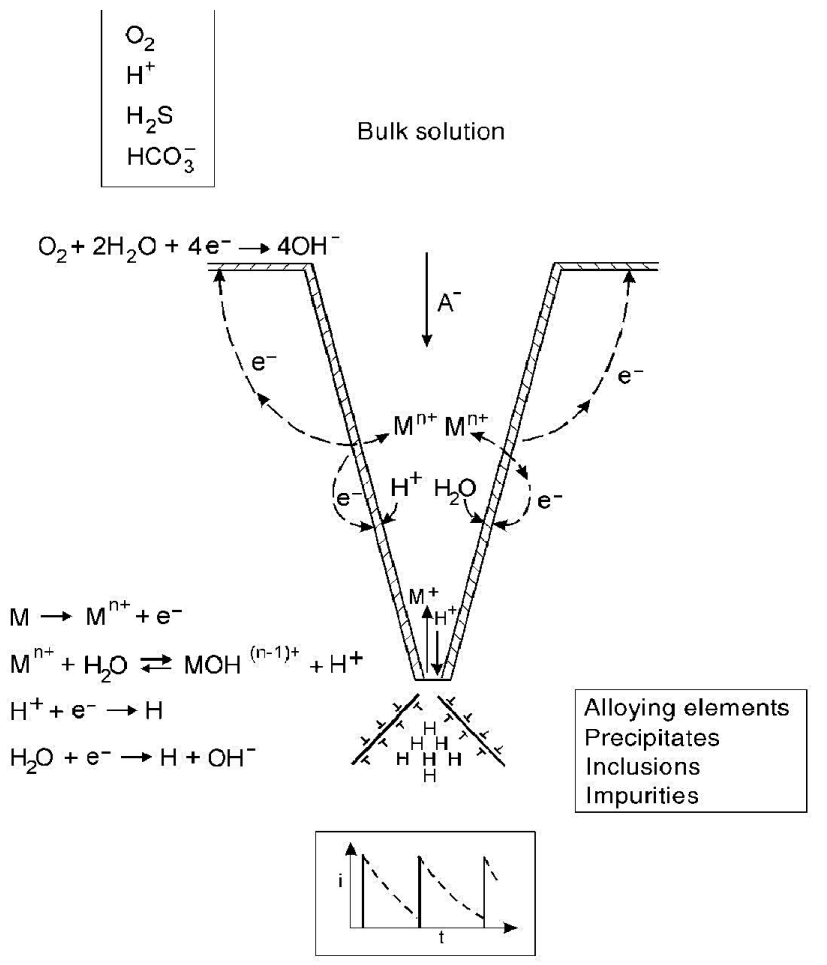

Figure 2.3 Schematic of the electrochemistry in cracks [25].

Table 2.2 Experimental results of the acidity at the crack tip in corrosive solution [20-24, 30].

\begin{tabular}{|c|c|c|c|}
\hline Material & Environment & $\mathrm{pH}_{\text {bulk }}$ & pH $\mathrm{H}_{\text {crack tip }}$ \\
\hline AISI 4340 steel & $3.5 \% \mathrm{NaCl}$ & 5.7 & $3.5-3.9$ \\
\hline 304 steel & Boiling $\mathrm{MgCl}_{2}$ & 4.5 & 1 \\
\hline 12Kh 18N10T steel & $3.0 \% \mathrm{NaCl}$ & 6.7 & $1.7-1.8$ \\
\hline 15KhNSMF steel & $3.0 \% \mathrm{NaCl}$ & 6.5 & 2.5 \\
\hline 45kHN2MF A steel & $3.0 \% \mathrm{NaCl}$ & -- & 3.5 \\
\hline $0.45 \mathrm{C}$ steel & $3.5 \% \mathrm{NaCl}$ & 6.5 & 3.8 \\
\hline $0.29 \mathrm{C}, 5.8 \mathrm{Ni}$ steel & $3.5 \% \mathrm{NaCl}$ & 6.0 & 3.7 \\
\hline $0.29 \mathrm{C}, 11.6 \mathrm{Cr}$ steel & $3.5 \% \mathrm{NaCl}$ & 6.0 & 3.7 \\
\hline $0.29 \mathrm{C}, 1.9 \mathrm{Mo}$ steel & $3.5 \% \mathrm{NaCl}$ & 6.0 & 3.7 \\
\hline $0.32 \mathrm{C}, 5.5 \mathrm{Mn}$ steel & $3.5 \% \mathrm{NaCl}$ & 6.0 & 3.7 \\
\hline 12Ni-5Cr-3Mo steel & $3 \% \mathrm{NaCl}$ & 7.0 & 3 \\
\hline 12Ni-5Cr-3Mo steel & $\begin{array}{l}3 \% \mathrm{NaCl}+ \\
\text { bal. } \mathrm{NaOH}\end{array}$ & 13.5 & 10 \\
\hline 7075T aluminum alloy & $3.5 \% \mathrm{NaCl}$ & 6.5 & 3.5 \\
\hline 7050 aluminum alloy & $\begin{array}{c}0.5 \mathrm{M} \mathrm{Na}_{2} \mathrm{CrO}_{4}+ \\
0.05 \mathrm{M} \mathrm{NaCl}\end{array}$ & 9.5 & 3.1 \\
\hline D16 aluminum alloy & $3.0 \% \mathrm{NaCl}$ & 6.5 & $2.1-2.2$ \\
\hline AT3 titanium alloy & $3.0 \% \mathrm{NaCl}$ & 6.5 & $0.7-0.8$ \\
\hline Ti8,Al1,Mo1,Y alloy & $3.5 \% \mathrm{NaCl}$ & 6.5 & 1.7 \\
\hline 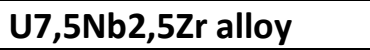 & $0.6 \% \mathrm{NaCl}$ & 9.5 & 1.2 \\
\hline
\end{tabular}




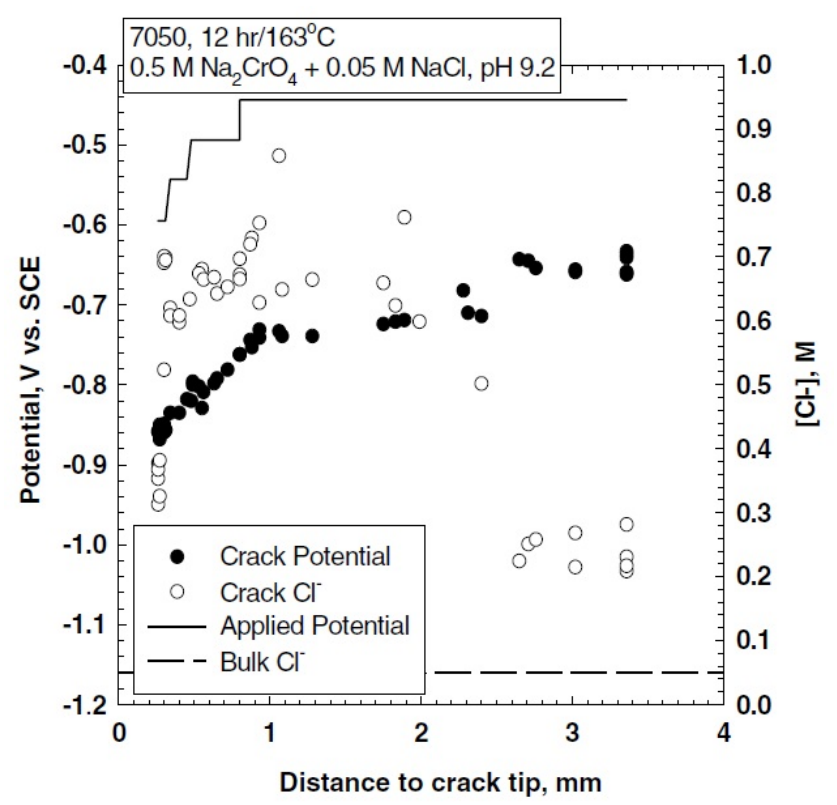

Figure 2.4 In-situ measurement of the crack potential and $\mathrm{Cl}^{-}$as a function of distance from the crack tip [22].
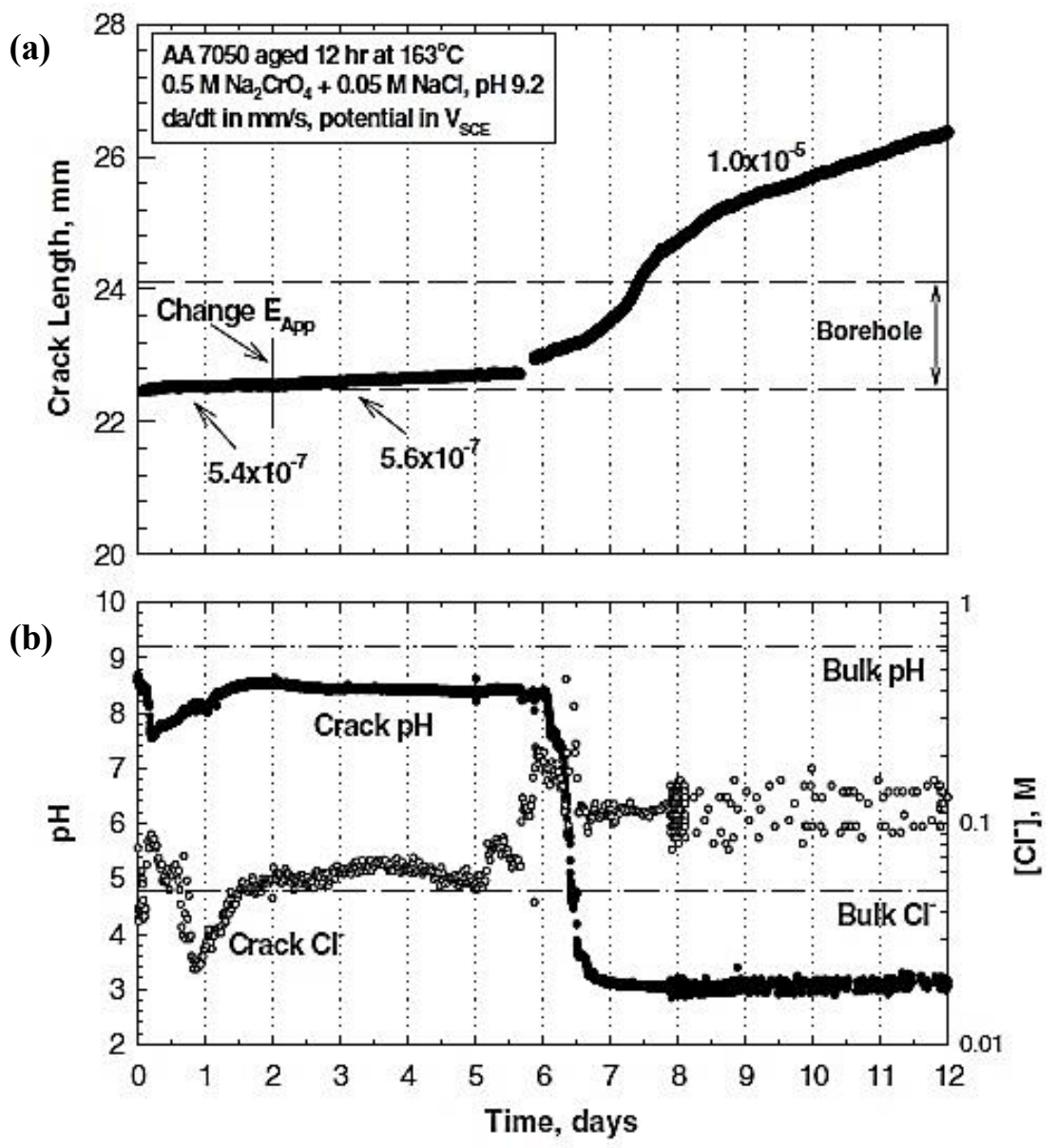

Figure 2.5 Simultaneous, real-time in-situ measurement of (a) crack length and (b) pH and $\mathrm{Cl}^{-}$during EAC test [22]. 


\subsection{Corrosion Fatigue}

Corrosion fatigue (CF) is a major cause of service failures in metal components, and there is still no effective method for preventing or predicting CF despite all the research over the last half century [2]. It is, however, generally accepted that the CF process of metals in aqueous solutions is controlled by localized corrosion or the presence of hydrogen at the crack tip. The intense plastic deformation of crack tip material and the high straining rate during CF cycling are both important influences on the corrosion process and hydrogen transport [4, 31-35]. CF damage accumulates with increasing load cycle count and in four stages: (1) cyclic plastic deformation, (2) micro-crack initiation, (3) small crack growth to linkup and coalescence, and (4) macro-crack propagation [36].

Experimental results indicate that chemical stress alone is not sufficient to create a cracked surface, but a mechanical stress is required to provide the necessary conditions to create a new fracture surface [37]. To facilitate crack nucleation, stress concentration by slip systems must occur [37]. The existence of multiple slip systems that help in homogenization of slip, such as in FCC materials like alloy 718 , enhance the resistance to CF. Crack nucleation or growth requires a threshold stress or stress intensity that varies with yield stress and plastic flow properties; a critical maximum chemical concentration suggestive of saturation effect; and a localized plasticity that is either required to establish in-situ stress concentrations as in smooth specimens, or required to provide a short transport distance for chemical species to ingress [37].

\subsubsection{Corrosion Mechanisms of CFCP}

There are two well-known corrosion mechanisms of corrosion fatigue crack propagation (CFCP) taking place at the crack tip: hydrogen-induced cracking (HIC) also known as hydrogen embrittlement and stress-assisted dissolution (SAD). In aqueous environments, anodic dissolution of metal at the crack tip and the entrance of hydrogen derived from the environment into the crack-tip plastic zone occur together during CFCP $[2,4,16,25,32,37,38]$. Depending on mechanical (cyclic frequency, stress level, mode of loading, stress ratio, waveform), metallurgical (chemical composition and microstructure of material, grain boundary composition, surface condition, specimen orientation) and environmental (composition and concentration of solution, $\mathrm{pH}$, potential, dissolved oxygen, temperature, flow rate) variables, one of these processes plays a dominant role in crack propagation [2, 34, 39]. Also, the intensity of anodic and/or cathodic reactions in the vicinity of the crack tip, the hydrogen-dependent properties of materials and the hydrogen content in the crack-tip zone determines the controlling CFCP mechanism as well $[2,34]$. It has been found that the mechanisms of CFCP are closely related to those used to explain stress corrosion cracking (SCC) [2]. In fact, SCC is a special case of CFCP with a load ration $(R)$ equal to one.

Hydrogen embrittlement involves the local breakdown of the passive film at the crack-tip surface provided by the FCG, producing a bare (film-free) metal surface during the opening part of each stress or fatigue cycle [2]. This promotes the entry of hydrogen into the metal that is transported under the driving force of the stress gradient to the region of highest dilation ahead of the crack where some 
form of hydrogen embrittlement could take place, presumably, by a reduction in the cohesive strength of the lattice. The relative effect of HIC to CFCP increases with increasing load ratio R. There is also a general trend toward increasing susceptibility of materials to HIC with increasing strength. Alloy 718 and other high strength nickel based alloys have been shown to be highly susceptible to both gaseous and cathodic hydrogen-induced cracking at room temperature [16]. Fournier et al. [16] investigated room temperature cathodic hydrogen embrittlement in alloy 718 by slow strain rate tensile tests conducted on specimens charged either prior to or during deformation. He showed that there was a correlation between hydrogen embrittlement and hydrogen segregation to dislocations and hydrogen transport by dislocations. Also, Fournier emphasized the principal difference between hydrogen embrittlement and SCC. Hydrogen embrittlement involves both hydrogen induced crack initiation and hydrogen assisted crack growth. Whereas in SCC, anodic dissolution takes place to nucleate a critical surface defect, and hydrogen assisted cracking is expected to be the controlling mechanism.

Sheng et al. [38] investigated the anodic dissolution process of a crack tip in 2024-T351 aluminum alloy by means of scanning Kelvin probe. Sheng says that under SAD controlled CFCP, applied stress causes the electron energy of the crack tip to raise high enough for electrons to escape from the metal when immersed in $\mathrm{NaCl}$ solution, enhancing the electrochemical activity at the crack tip within the stress field. The region at the crack tip can be seen as an anode with respect to the surrounding matrix. After immersion in the solution, anodic dissolution occurs at the crack tip and generates corrosion products in the crack. This could produce critical defects, promoting a localized plasticity, and provide a fast entry for hydrogen into the material leading to potential embrittlement.

Generally, anodic polarization increases metal dissolution and decreases hydrogen generation, whereas cathodic polarization decreases metal dissolution and increases hydrogen generation [2-4, 16, $25,32,37,38,40-43]$. This characteristic of the electrochemistry of CFCP allows for a controlledpotential technique to be utilized for the purpose of distinguishing between HIC and SAD as the dominate mechanism of CFCP by studying the effect of applied potential on the crack growth rate. If an applied cathodic current increases crack growth rate and an anodic current decreases it, the dominant crack growth mechanism would be HIC. The mechanism is considered SAD if crack growth rate is decreased with the application of cathodic current and increased with the application of anodic current. 


\subsubsection{Influencing Factors on CFCP}

There are a variety of influencing factors on CFCP such as loading waveform, temperature cyclic frequency, strain rate, R-ratio, and chloride concentration. Below is a brief review of a few of the important factors.

\subsubsection{Loading Waveform}

Loading waveform influences the straining mode for crack tip material resulting in different CFCP rates. Wang, $L i$, Wang, and Ke [32] investigated the influence of loading waveform on CFCP rate for iron in $3.5 \% \mathrm{NaCl}$ and $3.5 \% \mathrm{NaCl}+1 \% \mathrm{NaNO}_{2}$ solutions at different applied potentials. Figure 2.6 displays the da/dN vs. $\Delta \mathrm{K}$ results for four different loading waveforms that were tested for iron in $3.5 \%$ $\mathrm{NaCl}$ at free corrosion potential at a frequency ( $f$ ) of $0.1 \mathrm{~Hz}$ and load ration ( $R$ ) equal to 0 . From the results, it is clear that all the tests were greater than air and the largest is the positive sawtooth waveform. The results, shown in Figure 2.7, for square and positive sawtooth waveform loadings on $\mathrm{CFCP}$ in air at $1 \mathrm{~Hz}$ and $\mathrm{R}=0$ shows no difference, indicating the change in loading waveform only effects corrosion solutions.

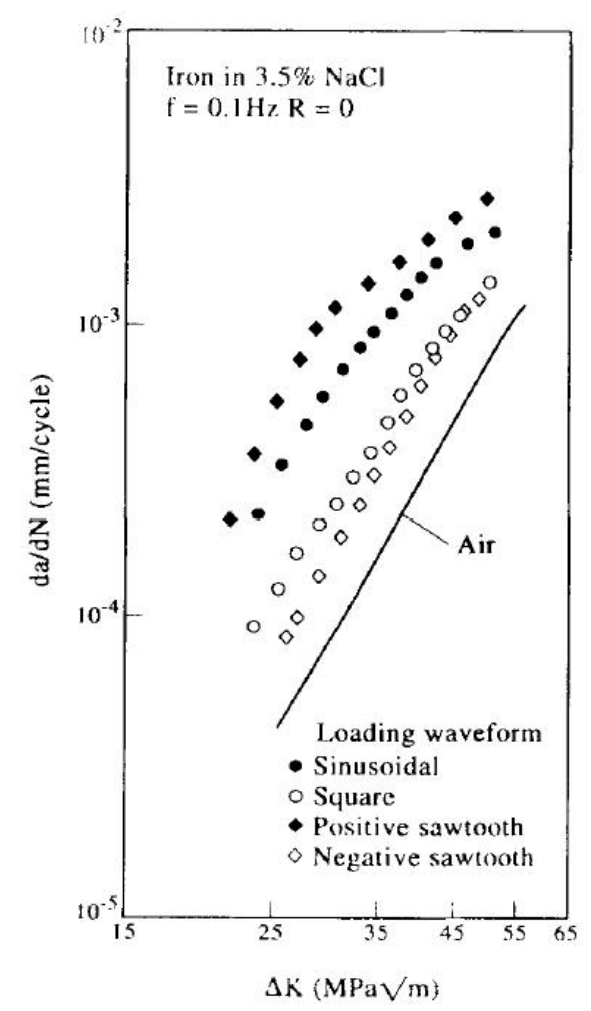

Figure 2.6 Effect of loading waveform on CFCP rate for iron in $3.5 \% \mathrm{NaCl}$ at free corrosion potential [32]. 


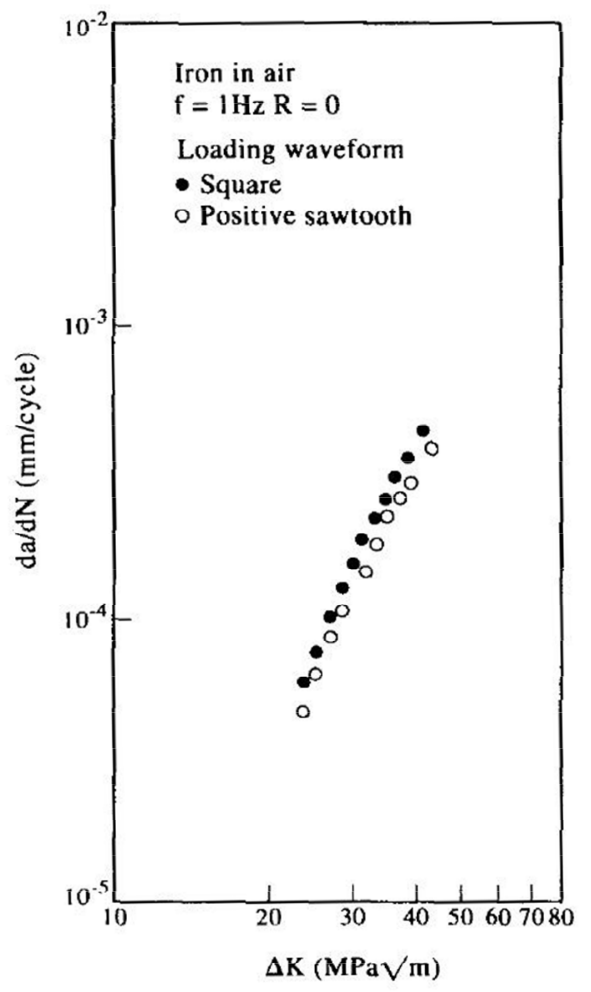

Figure 2.7 Effect of positive sawtooth and square loading waveforms on FCP rate for iron in air [32].

The effect of square waveform hold-time is shown in Figure 2.8 for hold-times of 0.1 and 0.9 seconds in $3.5 \% \mathrm{NaCl}$ at free corrosion potential. The difference between the two hold-times is small which indicates that the influence of the waveform mainly came from the continuous deformation of the crack-tip [32, 44, 45]. Saxena, Liaw, and Landes [46] had the opposite experience when they investigated the influence of waveform and long hold-time on the CFCP behavior of $18 \mathrm{Mn}-5 \mathrm{Cr}$ austenitic steel in a hydrogen environment. They found that increasing the hold-times at $80^{\circ} \mathrm{C}$, which were much longer than Wang et al.'s hold-times, increased the crack growth rate. This was most likely due to SCC due to the fact that the hold-times ranged from 50 s to 500 s. 


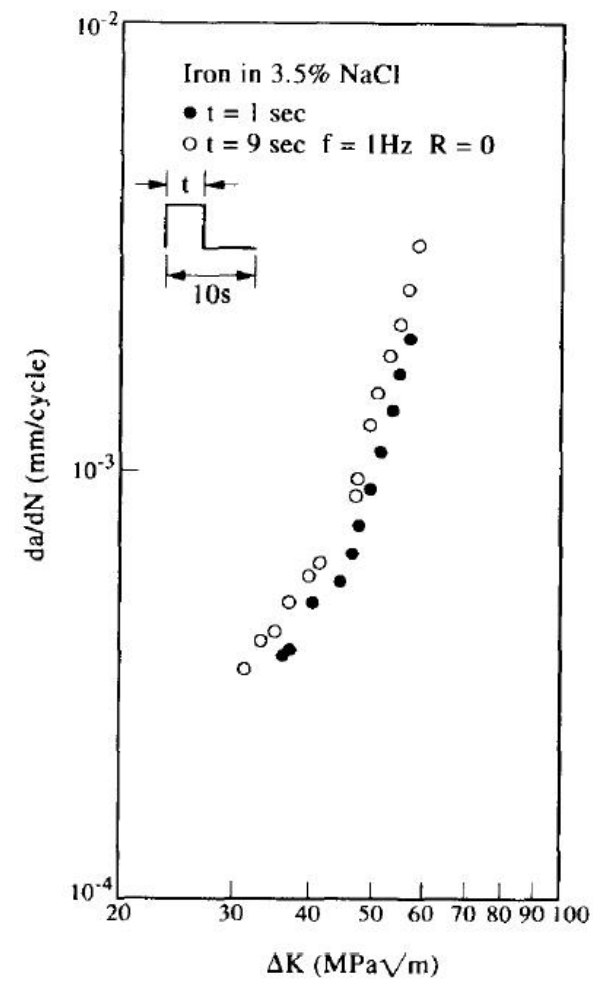

Figure 2.8 Effect of hold-time for square waveform on CPCP rate for iron in $3.5 \% \mathrm{NaCl}$ at free corrosion potential [32].

To gain a better understanding of the effect of loading waveform on da/dN in CF controlled by anodic dissolution, Wang et al. used smooth specimens as straining electrodes in an acidic solution (to simulate the crack tip environment) and measured the dissolution current response at an applied potential corresponding to OCP with different straining waveforms. Figure 2.9 shows the variation of transient current and strain under the different loading waveforms. For the positive sawtooth in Figure 2.9(a), the transient current increased with the increasing load reaching the maximum current at the maximum strain, then dropped with the release of load. Wang et al. says the unloading gives a rapid plastic deformation in the opposite direction which results in a current peak overlapped on the original tensile current. For the square and negative sawtooth waveforms in Figure 2.9(b) and (c), there is an initial peak from the rapid increase in load, but overall, no change from the positive sawtooth waveform. Wang et al. concludes that the faradaic amount of dissolution for one cycle is almost the same under all loading waveforms. It is generally accepted that continuous deformation during loading is related to a greater dissolution current, meaning the positive sawtooth waveform should have had the largest amount of faradaic current. He speculates that rapid loading could result in a geometric blunting of the crack-tip, giving rise to a large dissolving area. 
(a)

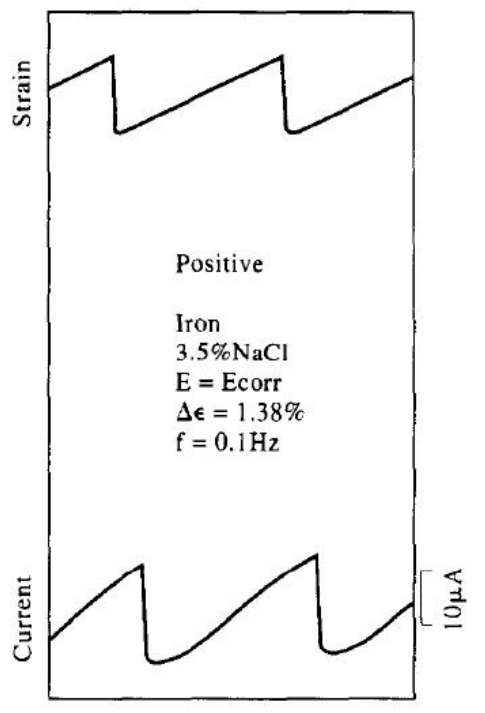

(b)

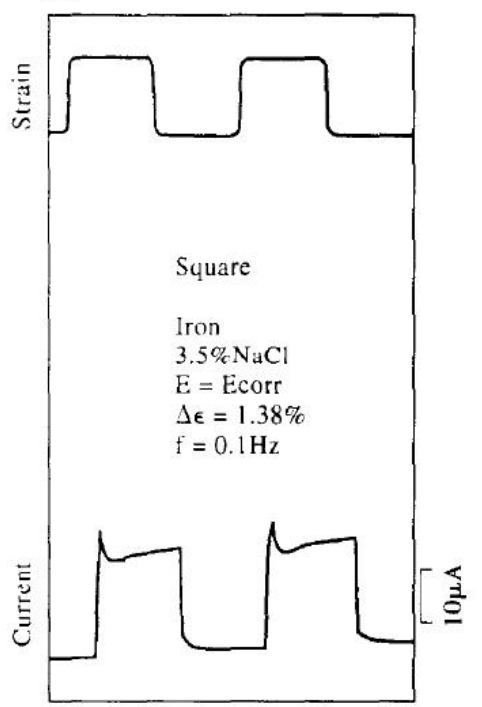

(c)

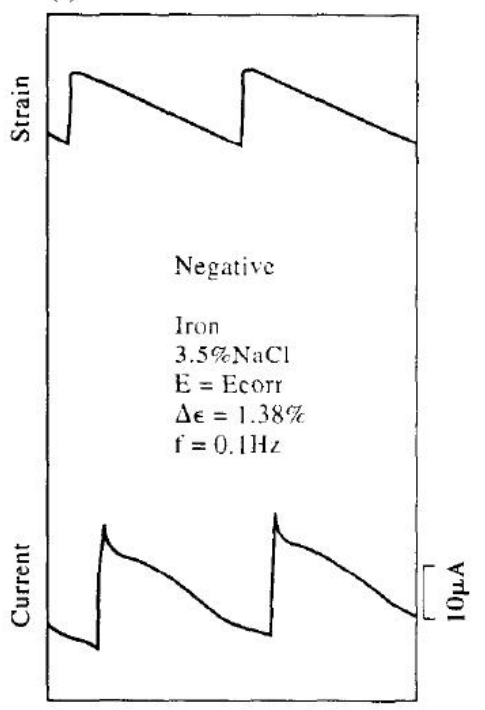

Figure 2.9 The strain and transient current curves for iron in $3.5 \% \mathrm{NaCl}$ under (a) positive sawtooth, (b) square and (c) negative sawtooth loading waveforms [32].

Wang et al. then introduced a passivating agent $\left(3.5 \% \mathrm{NaCl}+1 \% \mathrm{NaNO}_{2}\right)$ into the solution to form a passivation layer on the iron allowing for the comparison between active and passive systems. The strain and transient current curves for iron in $3.5 \% \mathrm{NaCl}+1 \% \mathrm{NaNO}_{2}$ solution can be seen in Figure 2.10 with an applied strain of $1.38 \%$ and frequency of $0.1 \mathrm{~Hz}$. The faradaic current for the positive sawtooth in Figure 2.10(a) shows the current increase with the applied load but at a more aggressive slope. As the passivation layer ruptures from the increasing strain amplitude, it forms a new layer accounting for the increased current similar to the trend in Figure 2.9(a). In Figure 2.10(b), the faradaic current is much different than Figure 2.10(a). There is only an initial peak in the current from the rapid loading and exposure of new surface but there is no trail off as in Figure 2.9(c). This is due to the repassivation of the new surface as the strain is unloaded. Wang found that in the condition of a passive system, the dissolved quantity is largest for the positive sawtooth loading waveform and the repassivation of new surface for the square and negative sawtooth waveforms result in reduction of dissolution rate. 
(a)

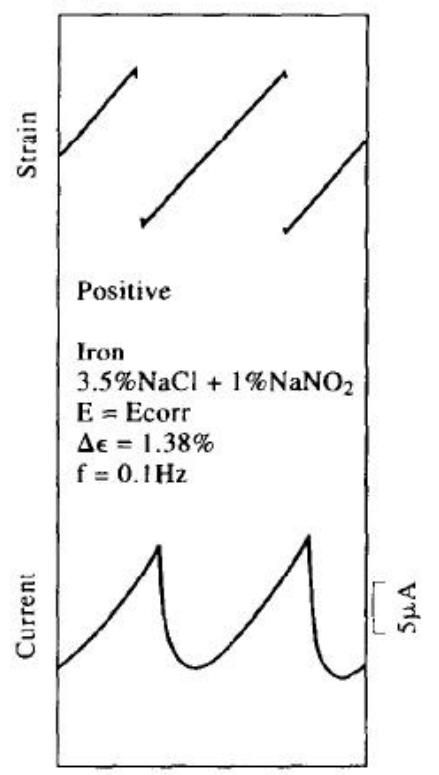

(b)

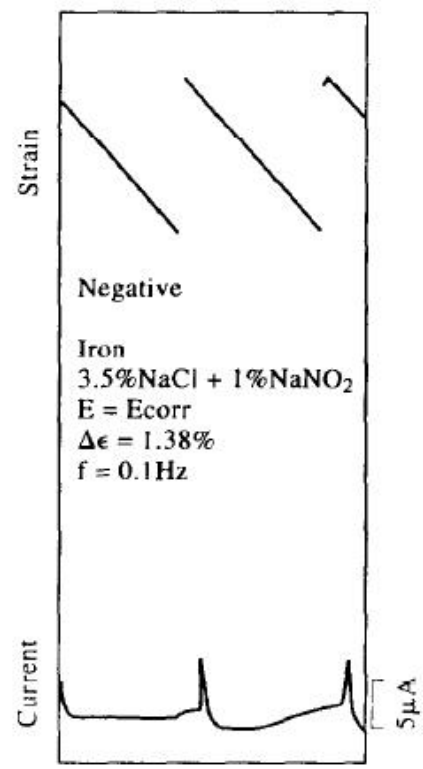

Figure 2.10 The strain and transient current curves for iron in $3.5 \% \mathrm{NaCl}+1 \% \mathrm{NaNO}_{2}$ solution of (a) positive and (b) negative sawtooth waveforms [32].

The transient current is different under the passive system for different strain rates and strain amplitudes. The evolution of the strain current under different loading waveforms is shown in Figure 2.11 for tests at the free corrosion potential with strain amplitude of $0.24 \%$ and loading frequency of 0.1 $\mathrm{Hz}$. For the positive waveform in Figure 2.11(a), the result was different from Figure 2.10(a), the current was almost completely unaffected by the rising strain amplitude until the maximum is reached at which the current spikes and drops to the original value. For square and negative sawtooth waveforms in Figure 2.11(b) and (c), the results indicated a decreasing current after loading. Wang says that at very low strain rates the straining mode can have no effect on $\mathrm{da} / \mathrm{dN}$ due to the rapid repassivation of new surface at the crack tip. In the condition of a passive system, the effect of straining mode depends on the straining rate and repassivating rate at the same time. If repassivation is possible, the da/dN by AD will decrease compared to an active system. 
(a)

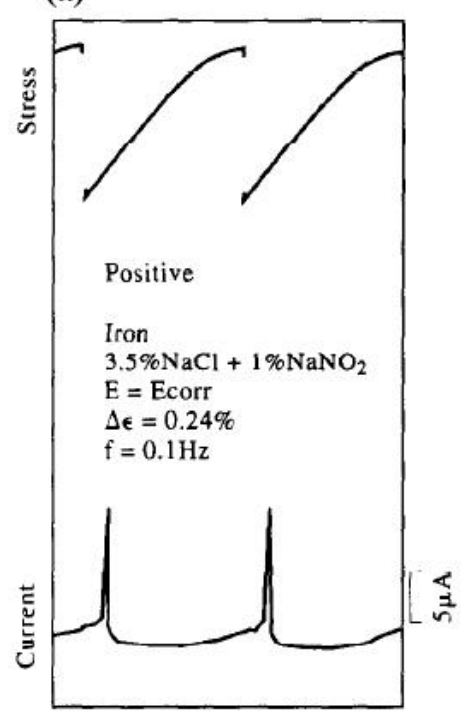

(b)

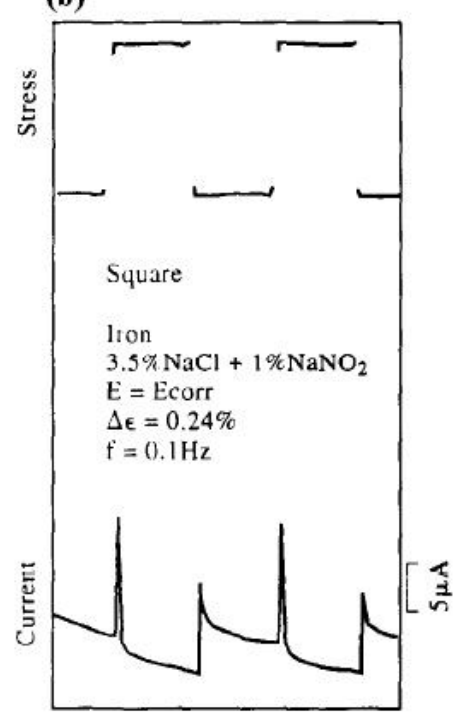

(c)

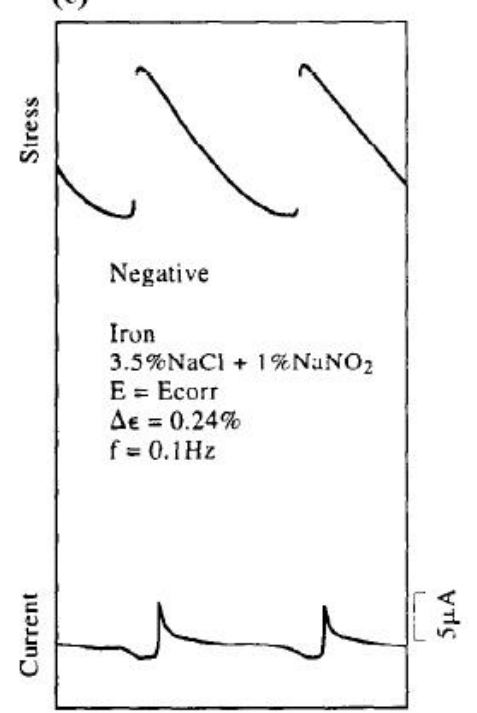

Figure 2.11 The strain and transient current curves for iron in $3.5 \% \mathrm{NaCl}+1 \% \mathrm{NaNO}_{2}$ under (a) positive sawtooth, (b) square and (c) negative sawtooth loading waveforms [32].

\subsubsection{Temperature}

The effect of temperature can have a rather large or small effect on corrosion fatigue depending on the controlling corrosion mechanisms of the material. Since corrosion is an activation controlled chemical reaction, the rate is generally increased with increasing temperature [47-49]. The increased corrosion rate results from an increase in activation energy for chemical and electrochemical reactions. By increasing the corrosion rate, the CFCP rate is increased due to the increased ionic activity inside the crack and at the crack tip [47, 50,51]. Higher temperature can also promote a higher reduction rate and greater amount of hydrogen generation and absorption at the crack tip [52].

\subsubsection{Cyclic Frequency}

There are many adverse effects of frequency to CFCP such as convective mixing of electrolyte, differences in crack tip strain rates and different degrees of crack tip blunting. Generally, reduced frequency has a negative effect (i.e. increased growth rate) on crack growth rate in corrosive environments $[1,42,46,51,53,54]$. Because corrosion is a time dependent process, decreasing the frequency increases the exposure time of the bare metal crack surface at the tip to the corrosive solution by continuously rupturing the passivation film in a passive system as the crack opens. These effects have been observed and are well documented [43, 51-53, 55].

Ho and $Y_{o}$ [56] observed no effect of frequency on crack growth rate for Alloy 600 in $\mathrm{NaCl}$ solution at room temperature. They said that the general trend of decreased frequency increases the rate of crack growth may be altered for cases in which increased frequency increases the rate of environmental cracking because of enhanced mass transport by convective mixing, enhanced crack-tip 
strain and surface reaction rates, and reduced crack-tip blunting by dissolution. Menan et al. [57-59], Piascik et al. [60] and Warner et al. [61] observed negative frequency dependence, i.e. an increase in growth rate with increasing frequency. Menan explained that this was due to passivation of the crack tip. His argument was that a long rise time would provide sufficient time for the passivation film to form which would protect the metal surface from the aggressive species. While at a short rise time, there is not enough time for the passivation film to form thus exposing the crack tip metal surface to the corrosive solution increasing crack growth [57]. Therefore, the cyclic frequency is an important influencing factor to corrosion fatigue and is dependent on a number of variables that change for each material, environment and temperature.

\subsubsection{Chloride Concentration}

The presence of chloride ions in the solution not only aids in the breakdown of the passivation film by, but the ions also slow the transport of hydrogen ions toward the electrode [52]. Increased $\mathrm{Cl}^{-}$ concentration also reduces the pitting potential $\left(E_{\text {pit }}\right)[62]$, which is the potential that breaks down the passivation film. If the $\mathrm{Cl}^{-}$concentration reduces the pitting potential below the passivation potential $\left(E_{\mathrm{rp}}\right)$, it will completely suppress the passive state altogether allowing for accelerated anodic dissolution. The chloride ions do not affect the solution of hydrogen atoms into the specimen, but rather decelerate the hydrogen ion reduction rate at cathodic regions $[52,63]$. Therefore, increasing the chloride concentration will generally increase crack growth rate $[52,54,61]$.

Lin, Fan, and Tsai [47] investigated the corrosion fatigue properties of a precipitation-hardening martensitic stainless steel, Custom 450 (UNS S45000-H900), under different corrosion environments at $20 \mathrm{~Hz}$. Figure 2.12 shows the crack growth rates and potentiodynamic polarization curves for the martensitic stainless steel in the different environments. They observed the elimination of the passivation range and the significant increase in corrosion rate because the higher concentration of $\mathrm{Cl}^{-}$ broke down a larger amount of the passivation film on each cycle. From the potentiodynamic polarization curves in Figure 2.12(b), it is clear that the increased $\mathrm{Cl}^{-}$concentration lowered the OCP $\left(E_{\text {corr }}\right)$ and more importantly the $E_{\text {pit }}$. This indicates that the passivation film has been weakened and the reformation process slowed, making it much more difficult to reform on each cycle and allowing for an increase in dissolution rate. Despite the increased corrosion characteristics of the metal, $\mathrm{Cl}^{-}$ concentration had little effect on CFCP shown Figure 2.12(a). This was likely due to the high testing frequency rather than the differences in crack tip chemistry from the bulk solution as the authors suggested. Even at such a high frequency (with typical frequencies of CFCP testing being in the range of 0.01 to $1 \mathrm{~Hz}$ ) there was still a small difference in crack growth rate at low $\Delta \mathrm{K}$ (blow $14 \mathrm{MPaVm}$ ) and high $\Delta \mathrm{K}$ (above $40 \mathrm{MPaVm}$ ). 

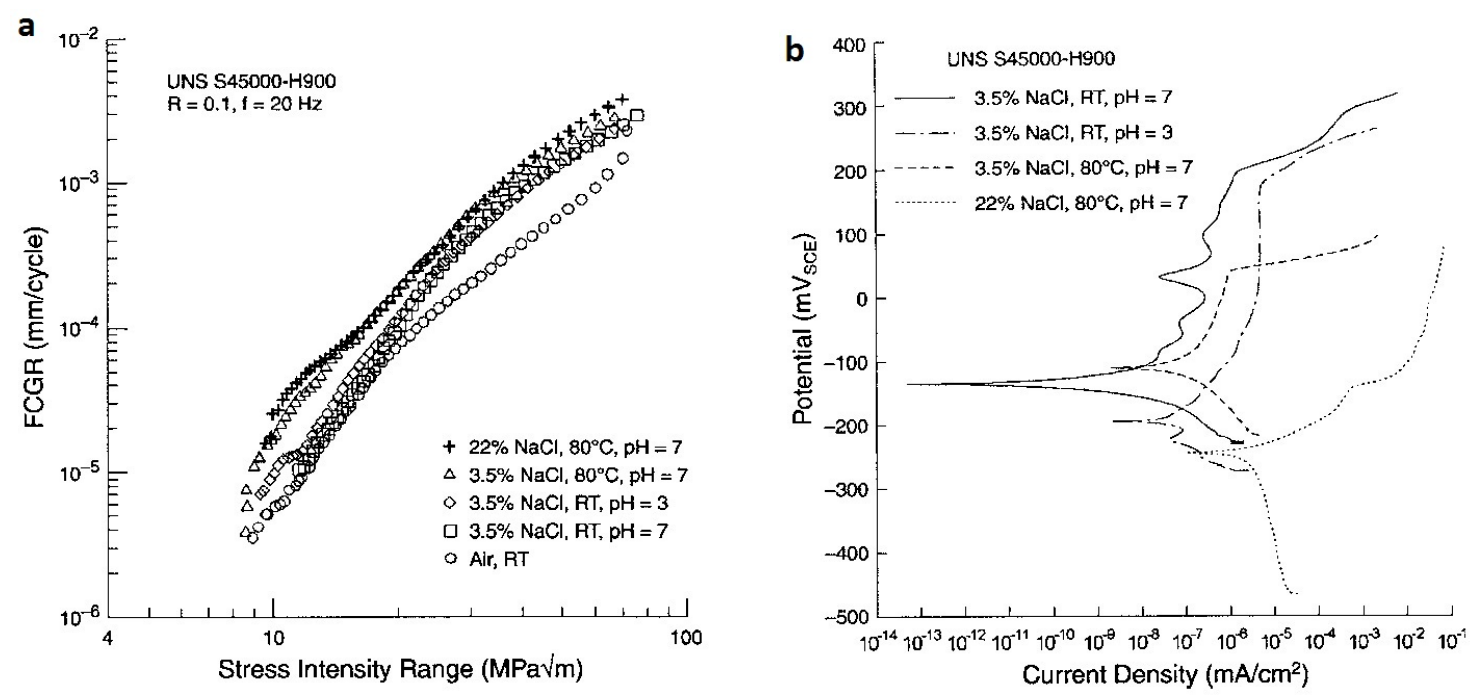

Figure 2.12 (a) FCGR curves and (b) potentiodynamic polarization curves for UNS S45000H900 in different environments [47]. 


\section{Chapter 3: Experimental Procedure}

\subsection{Fatigue Specimens}

Corrosion fatigue crack propagation (CFCP) test were performed with oil-grade Alloy 718 single edge notched tensile specimens with the chemical composition listed in Table 3.1. The specimens were machined to the dimensions shown in Figure 3.1, and polished to a 600-grit finish. Three different aging treatments, single step, double step, and unaged, were investigated with the name and details listed in Table 3.2, and the mechanical properties listed in Table 3.3.

Table 3.1 Chemical composition (wt\%) of Alloy 718.

\begin{tabular}{|c|c|cccc|c|c|c|c|cc|ccc|c|c|}
\hline $\mathrm{Ni}$ & $\mathrm{Cr}$ & $\mathrm{Fe}$ & $\mathrm{Mo}$ & $\mathrm{Nb}$ & $\mathrm{Al}$ & $\mathrm{Ti}$ & $\mathrm{Mn}$ & $\mathrm{Si}$ & $\mathrm{C}$ & $\mathrm{Co}$ & $\mathrm{Cu}$ & $\mathrm{Ta}$ & $\mathrm{P}$ & $\mathrm{S}$ & $\mathrm{B}$ & $\mathrm{Pb}$ \\
\hline 52.66 & 18.34 & 19.18 & 3.00 & 4.96 & 0.49 & 0.95 & 0.05 & 0.06 & 0.03 & 0.04 & 0.04 & 0.01 & 0.006 & 0.001 & 0.003 & 0.0002 \\
\hline
\end{tabular}

Table 3.2 Heat and aging treatment details.

\begin{tabular}{|lc|ll|}
\hline Specimen & Soln. Annealing & Aging Treatment & \multicolumn{1}{c|}{ Details } \\
\hline A & $1026^{\circ} \mathrm{C}, 1.5 \mathrm{hrs} / \mathrm{WQ}$ & No Aging & $\mathrm{N} / \mathrm{A}$ \\
\hline B & $1026^{\circ} \mathrm{C}, 1.5 \mathrm{hrs} / \mathrm{WQ}$ & One-Step & $780^{\circ} \mathrm{C}, 8 \mathrm{hrs}$. \\
\hline C & $1026^{\circ} \mathrm{C}, 1.5 \mathrm{hrs} / \mathrm{WQ}$ & Two-Step & $780^{\circ} \mathrm{C}, 4.5 \mathrm{hrs} .+650^{\circ} \mathrm{C}, 5 \mathrm{hrs}$. \\
\hline
\end{tabular}




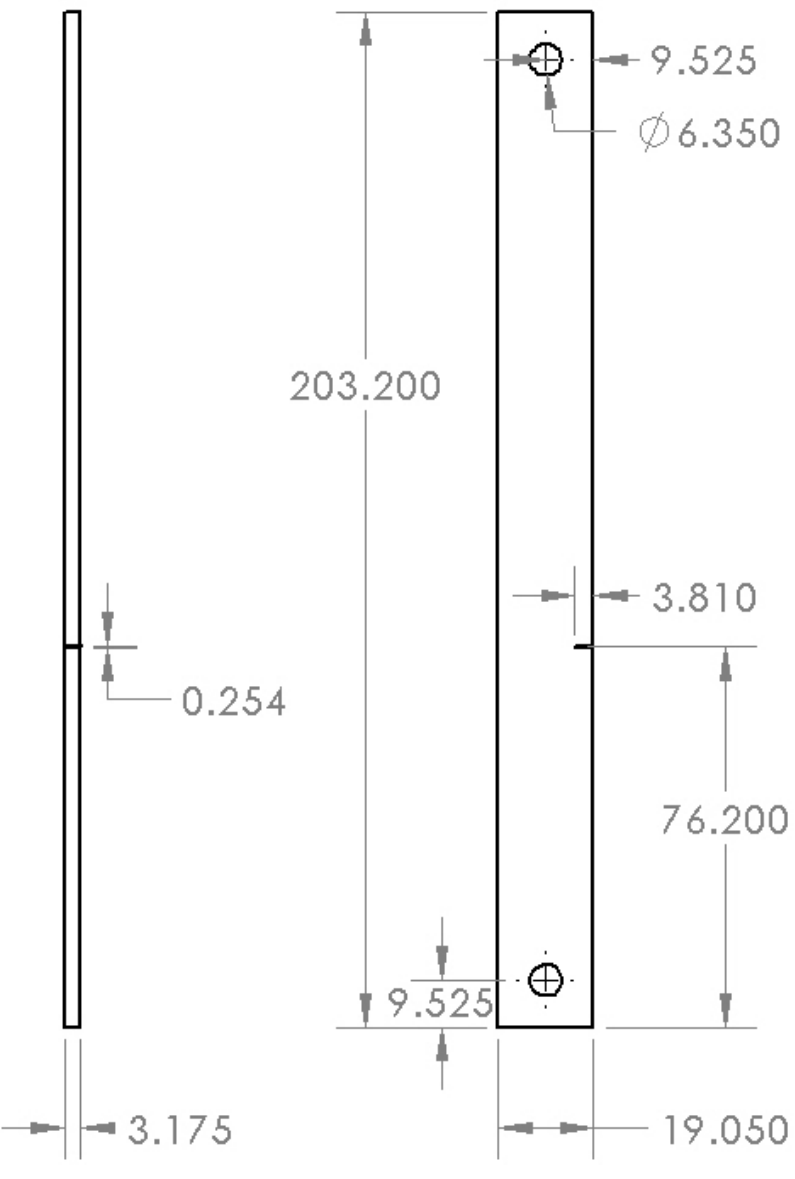

Figure 3.1 CFCP single edge notched tensile specimen dimensions in millimeters.

Table 3.3 Minimum mechanical properties at room temperature.

\begin{tabular}{|cc|cc|}
\hline $\begin{array}{c}\text { Property } \\
\begin{array}{c}\text { Yield Strength } \\
\text { (0.2\% Offset) }\end{array}\end{array}$ & Nicrofer $^{\oplus 5219} \mathbf{~ N b - A l l o y ~ 7 1 8 *}$ & Specimen B & Specimen C \\
\hline Tensile Strength & $520 \mathrm{MPa}$ & $965 \mathrm{MPa}$ & $1100 \mathrm{MPa}$ \\
\hline Elongation after Fracture & $965 \mathrm{MPa}$ & $1151 \mathrm{MPa}$ & $1250 \mathrm{MPa}$ \\
\hline Reduction of Area & --- & $20 \%$ & $18 \%$ \\
\hline Hardness & $30 \%$ & $30 \%$ & $30 \%$ \\
\hline
\end{tabular}

* Solution annealed at $1065^{\circ} \mathrm{C}$ without aging similar to Specimen $\mathrm{A}$ [64]. 


\subsection{Corrosion Fatigue \& Electrochemical Testing}

Fatigue tests were carried out to around $10 \mathrm{~mm}$ using a servo-hydraulic fatigue test stand manufactured by MTS. Specimens were pre-cracked in air to about $4.5 \mathrm{~mm}$ using a triangle waveform loading cycle at a frequency of $10 \mathrm{~Hz}$ prior to crack propagation testing. Two different fatigue waveforms were used, trapezoidal and triangular. The triangle waveform consisted of constant loading at a frequency of $1 \mathrm{~Hz}$ in $3.5 \mathrm{wt} . \% \mathrm{NaCl}$ at $\mathrm{RT}, 50^{\circ} \mathrm{C}$, and $80^{\circ} \mathrm{C}$. The trapezoidal waveform involved a 0.5 second linear ramp up to maximum load, 29 second hold at maximum load and 0.5 second linear ramp down to minimum load hold-time waveform in $3.5 \mathrm{wt} . \% \mathrm{NaCl}$ at $80^{\circ} \mathrm{C}$. Hold-time was only tested at $80^{\circ} \mathrm{C}$ solution temperature because the corrosion container was limited to ambient pressures, and the lower temperatures would only lesson the effect of the solution. Both cycles, as well as the pre-crack cycle, used the same constant loading of a minimum of $890 \mathrm{~N}$ and a maximum of $8896 \mathrm{~N}$ resulting in a load ratio ( $R=$ minimum load/maximum load) of 0.1 . The actual applied loads by the hydraulics were $1333 \mathrm{~N}$ minimum and $8452 \mathrm{~N}$ with $\mathrm{R}=0.15$. Direct current potential drop method was utilized to monitor the crack length with an applied constant current of 10.0 A. The voltage was measured and recorded by a strain gage input channel connected to the MTS controller with a resolution of one microvolt. Data points were recorded based on time since the cycles were also time dependent. Trapezoidal waveform potentials were recorded every 0.5 second, $1 \mathrm{~Hz}$ triangle wave potentials were recorded every 0.5 second and pre-crack data was recorded every 1 second. The repeatability of the testing is shown in Figure 3.2. For CFCP tests, $3.5 \mathrm{wt} \% \mathrm{NaCl}(0.36 \mathrm{M} \mathrm{NaCl})$ with a $\mathrm{pH}$ of 6.15 and $21 \mathrm{wt} \% \mathrm{NaCl}(2.4 \mathrm{M} \mathrm{NaCl})$ aqueous solutions were used. The specimens were protected with a corrosion resistant tape with a $5 \mathrm{~mm}$ exposed area for crack growth shown in Figure 3.3.

Electrochemical polarization characteristics were obtained for samples with an exposed area of $1 \mathrm{~cm}^{2}$ (after epoxy mounting) in a $1.5 \mathrm{~L}$ glass cell with the different $\mathrm{NaCl}$ solutions and temperatures. A three-electrode cell setup was used consisting of the specimen as the working electrode, a pair of graphite counter electrodes, and a saturated calomel electrode (SCE) serving as the reference electrode. Electrochemical measurements were recorded using a Solartron SI 1287 electrochemical interface with a scan rate of $0.5 \mathrm{mV} / \mathrm{s}$. Each test was conducted at least three times then averaged. 


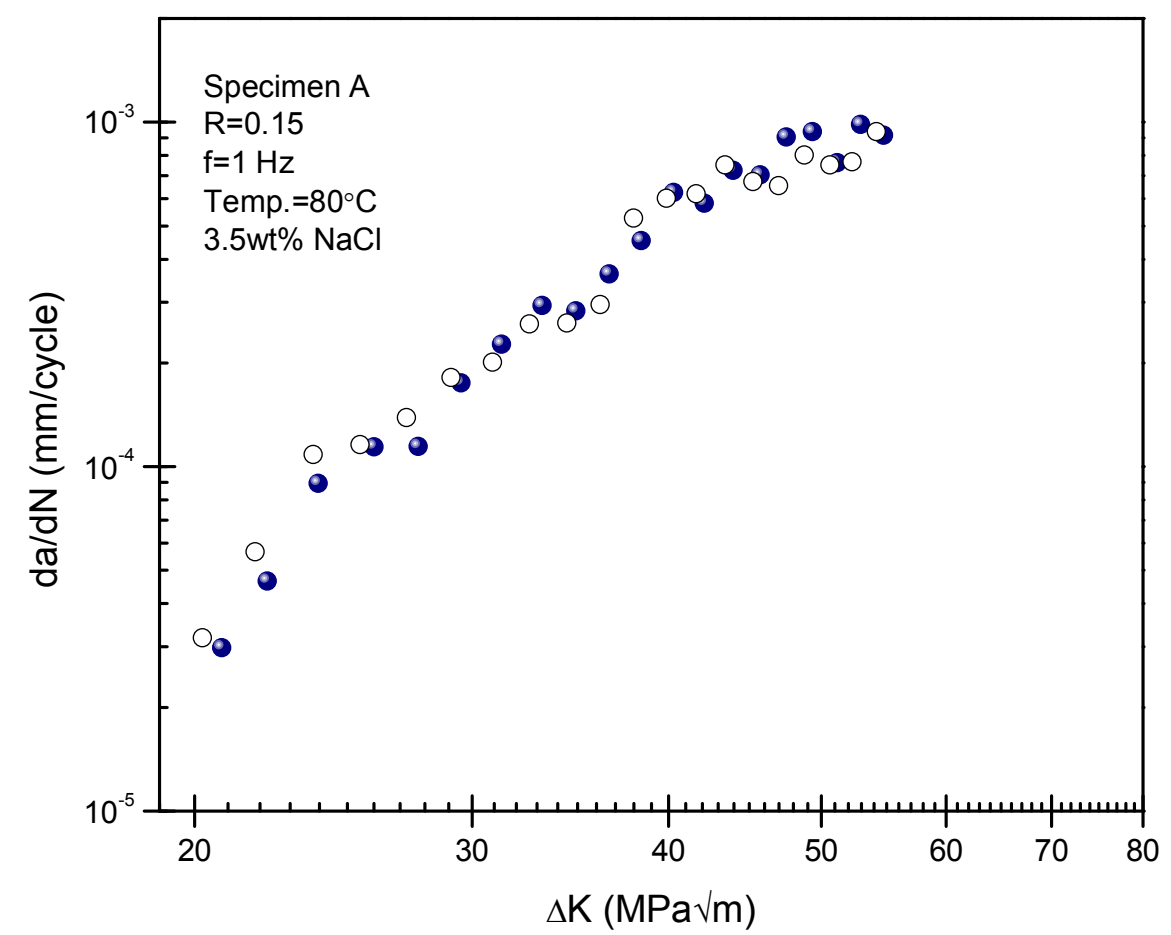

Figure 3.2 Repeatability of CFCP testing using specimen $\mathrm{A}$ in $3.5 \mathrm{wt} \% \mathrm{NaCl}$ at $80^{\circ} \mathrm{C}$.
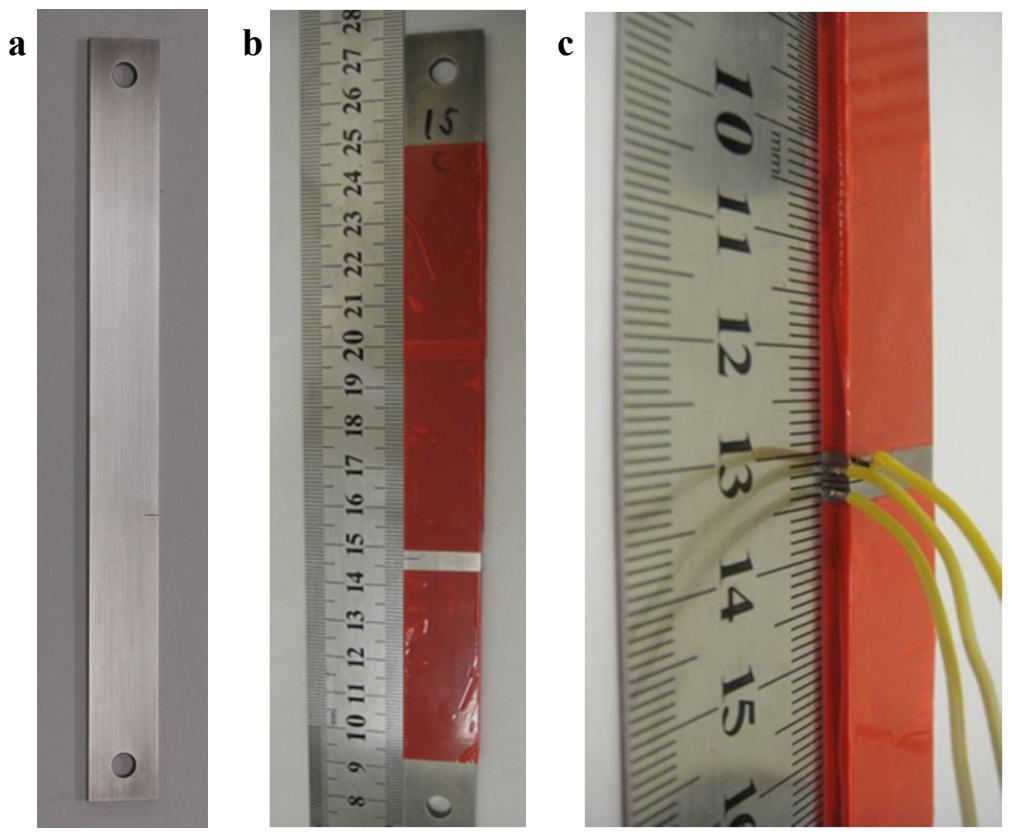

Figure 3.3 (a) uncovered sample, (b) covered sample with $5 \mathrm{~mm}$ exposed surface, and (c) wires connected for potential measurement. 


\subsection{Corrosion Fatigue Setup}

A custom container, shown in Figure 3.4, was designed to submerge the specimen crack in the corrosive solution during fatigue testing. Aluminum 5052 was selected for the building material due to its good resistance to corrosion and low weight. Weight was considered because the container was mounted freely to the specimen so it could move with the cycle movement without impeding on the specimen's freedom of movement along the loading axes. The specimen passed through the middle of the container using rubber corks on the top and bottom sealed by two different kinds of silicon sealant. The sealant, not submerged in solution on the top, was bathroom silicon that was easier to work with, and the bottom sealant was an automotive gasket sealant that was corrosion resistant. It was heated to the desired temperature using a single resistant heating rope controlled by an auto tuned programmable temperature controller. The temperature was monitored near the crack tip with a T-type thermocouple implementing an Inconel sheath material to protect it from the corrosive environment. Wires were passed in and out of the container through holes in the acrylic lid sealed by the bathroom silicon to monitor the potential drop of the crack growth.
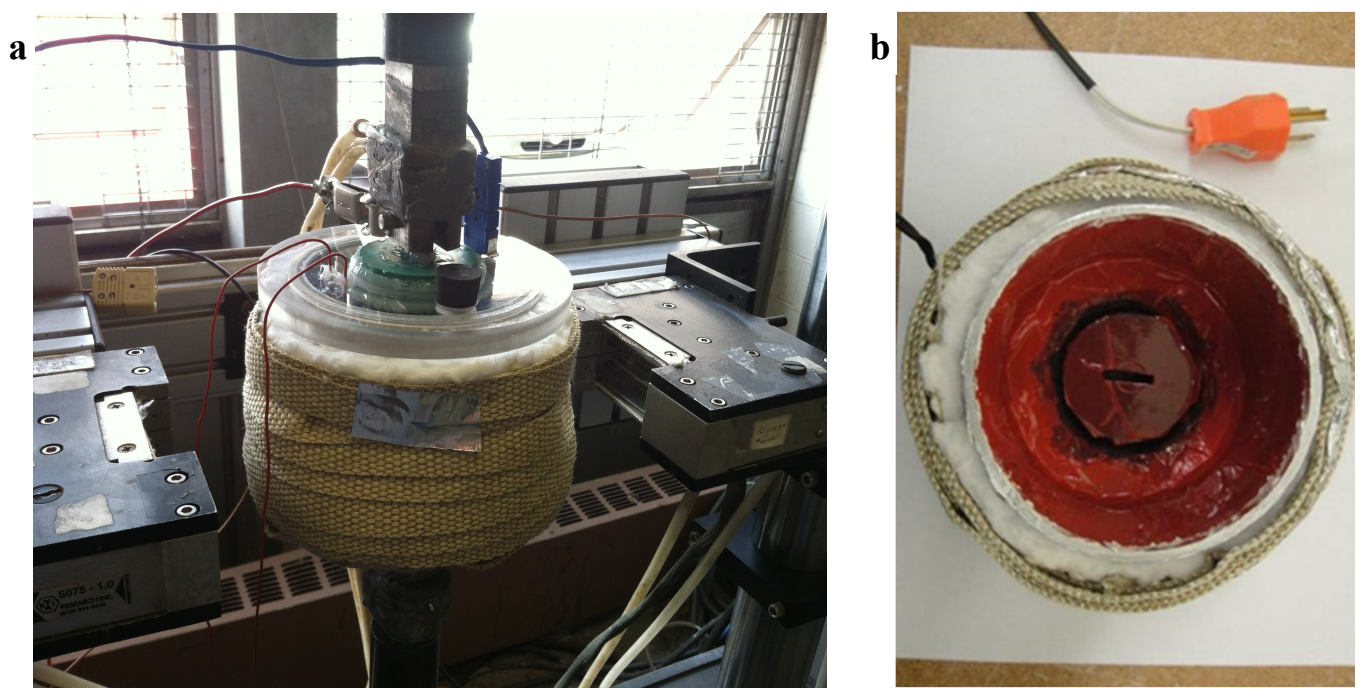

Figure 3.4 (a) assembled corrosion fatigue test and (b) inner protective lining and insulation of container. 


\subsection{Data Processing}

A MATLAB program, listed in Appendix 1, was written to remove the noise and calculate the change in crack length and stress intensity factor difference from the voltage data. The noise was removed by defining the raw voltage as an array and running it through a loop that defined a new max voltage array with a progressing maximum creating voltage steps. This method is based on the assumption that the crack cannot reduce its' length and therefore the voltage can only grow in magnitude, making all voltage below the current maximum irrelevant for crack growth. Using the new maximum voltage array, the crack length was calculated with Equation 3.1 below $[65,66]$.

$$
a=\frac{y}{\phi} \cos ^{-1}\left[\frac{\cosh (\phi)}{\cosh \left\{\frac{u}{u_{0}} \cosh ^{-1}\left(\frac{\cosh (\phi)}{\cos \left(\phi a_{0} y^{-1}\right)}\right)\right\}}\right]
$$

where $a_{0}$ is the initial crack length, $w$ is the specimen width, $y$ is the half potential probe span, $u_{0}$ is the initial measure potential drop, and $u$ is the current measure potential drop. The stress intensity factor for this specimen geometry was calculated with Equation 3.2 [65-68].

$$
\begin{gathered}
K=\frac{p}{t \sqrt{w}} \frac{\sqrt{2 \tan \theta}}{\cos \theta}\left[0.752+2.02\left(\frac{a}{w}\right)+0.371(1-\sin \theta)^{3}\right] \\
\text { where, } \theta=\frac{\pi a}{2 w}
\end{gathered}
$$

where $t$ is the specimen thickness and $p$ is the applied load. The final data points for plotting crack growth rates was produced by averaging $d a / d N$ based on $\Delta K$, which was necessary due to the large amount of zero crack growth the voltage steps created. The averaging loop uses a function written by Dr. Murtaza Khan [69] to locate the calculated range values in the complete $\Delta K$ array. This function is listed in Appendix 2. 


\section{Chapter 4: Results \& Discussion}

\subsection{Microstructure}

\subsubsection{Without Aging Treatment}

The scanning electron microscopy (SEM) image of Specimen A without aging treatment is shown in Figure 4.1 at $1000 x$ magnification. There are sparse amounts of inclusions spread throughout the grains and grain boundaries including nitrides, carbides and globular delta phases. Figure 4.2(a) displays a magnified image of the nitride inclusion found in Figure 4.1, and the EDX, shown in Figure 4.2(b), confirms that it is Ti enriched nitride. Also, Figure 4.3(a) shows a magnified image of the cluster of inclusions in Figure 4.1 and the EDX in Figure 4.3(b) reveals them to be niobium enriched carbides.

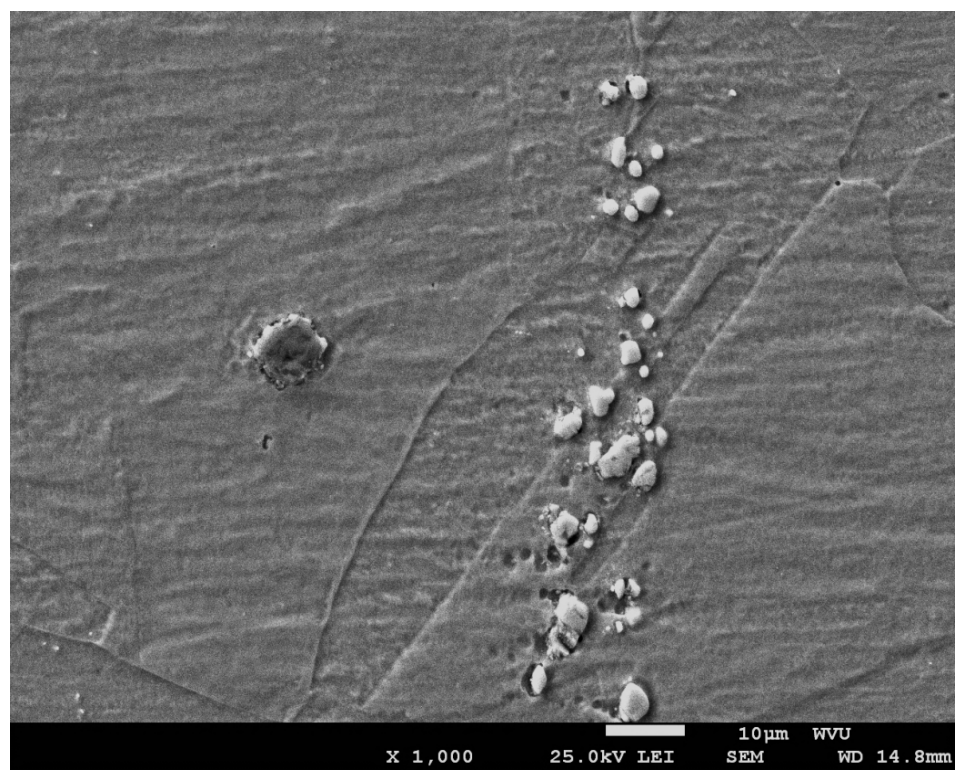

Figure 4.1 SEM image of Specimen A's microstructure at 1000x magnification. 
a
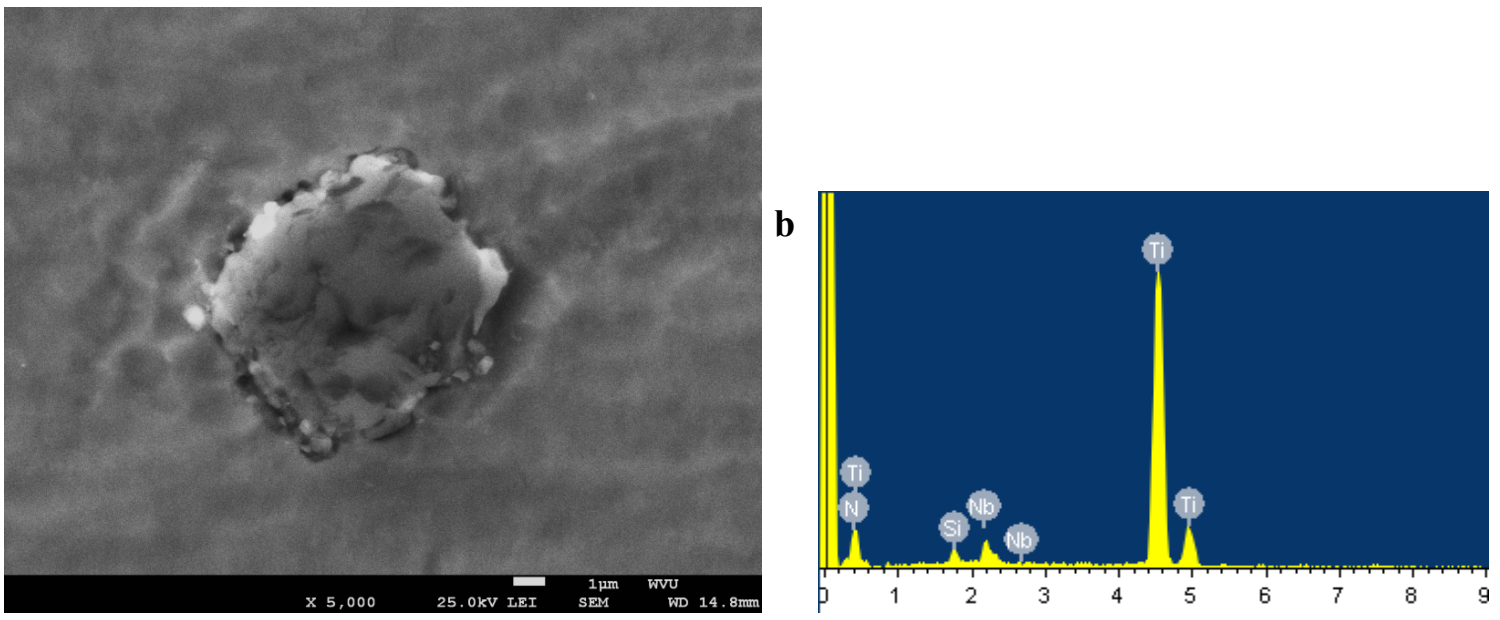

Figure 4.2 (a) SEM of a nitride inclusion with (b) EDX of the nitride in Specimen A's microstructure.

$\mathbf{a}$

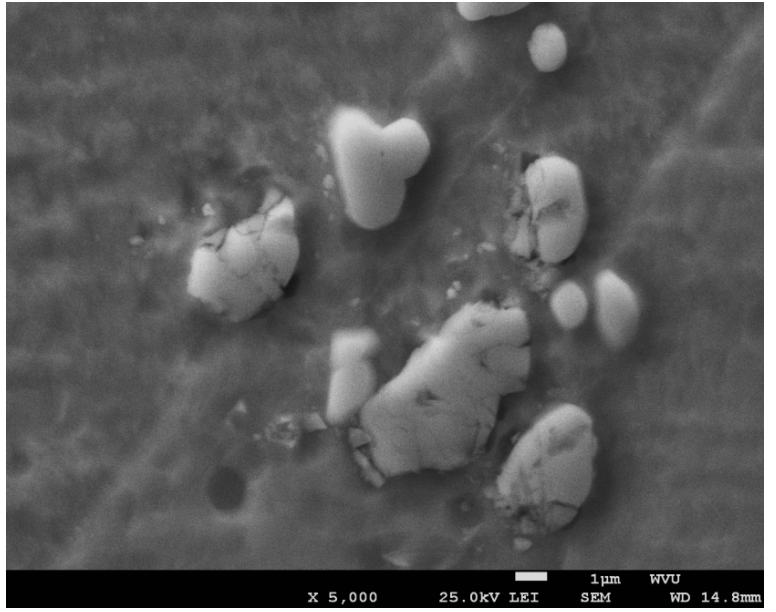

b

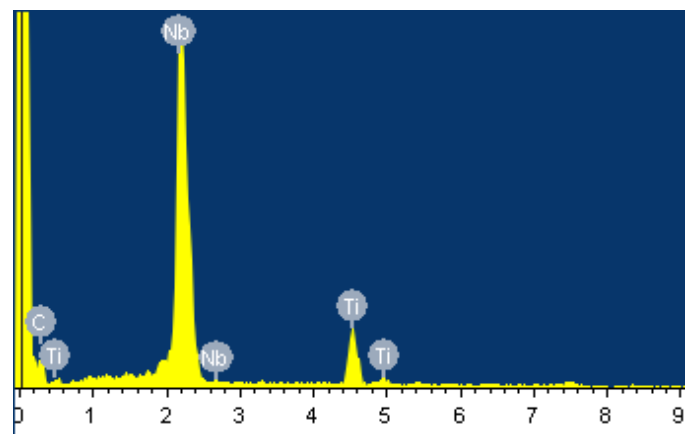

Figure 4.3 (a) SEM and (b) EDX of a cluster of carbide inclusions in Specimen A's microstructure.

\subsubsection{One-Step Aging Treatment}

Figure 4.4 shows the SEM image of Specimen B's microstructure at 1000x magnification. The average grain size is ASTM 3. Figure 4.5 shows the grain boundaries of Specimen B where there are some discontinuous delta phases. There are also some inclusions spread throughout the microstructure. In Figure 4.6(a) gamma prime and double prime precipitation are shown as well as discontinuous platelet shaped delta phase formed along the grain boundary. The average size, shown in Figure 4.6(b), of $\gamma^{\prime}$ is $20-30 \mathrm{~nm}$ in diameter and $\gamma^{\prime \prime}$ is 5-15 nm in the c dimension and 30-150 nm in diameter. 


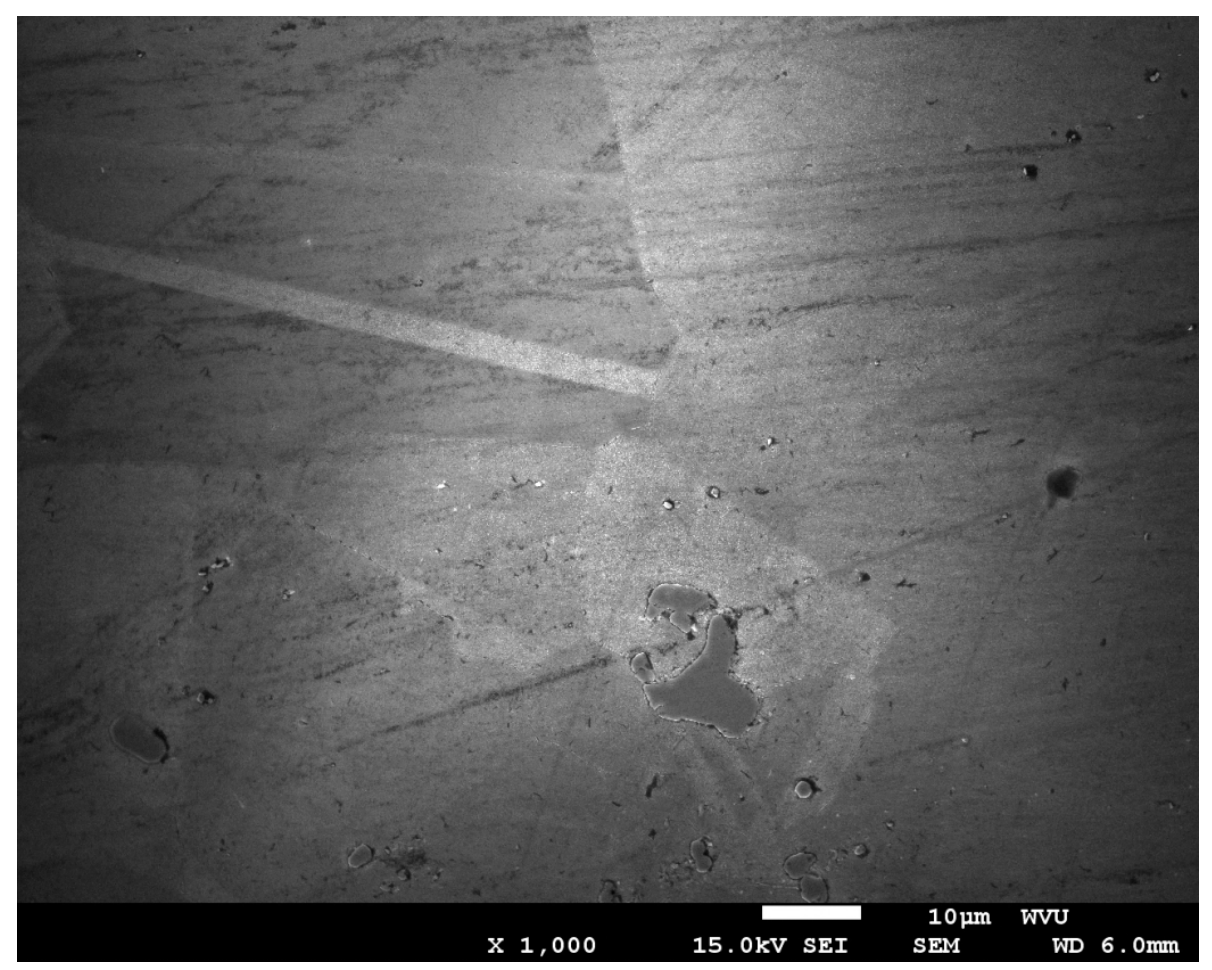

Figure 4.4 SEM image of Specimen B's microstructure at 1000x magnification.

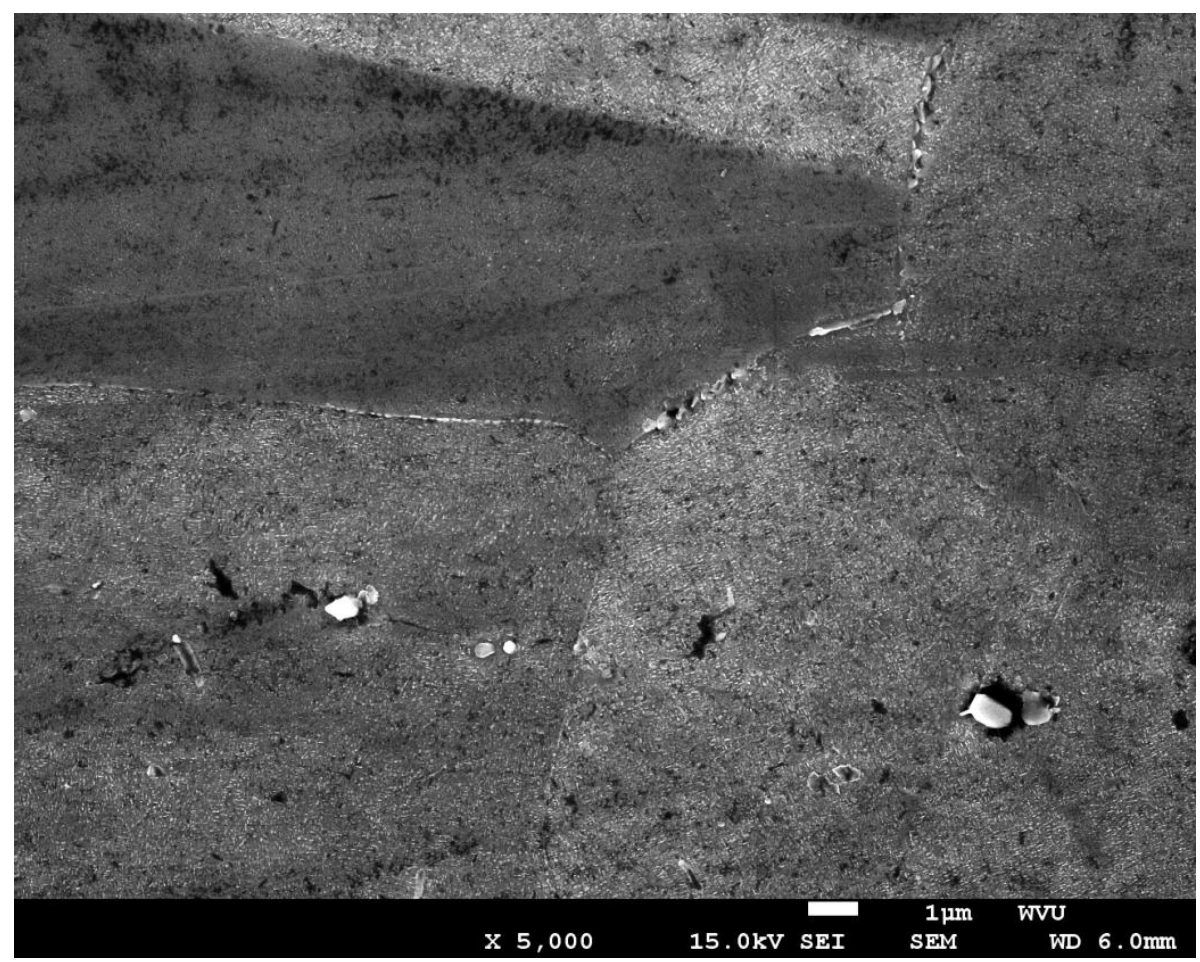

Figure 4.5 SEM image of the grain boundaries of Specimen B at 5000x magnification. 

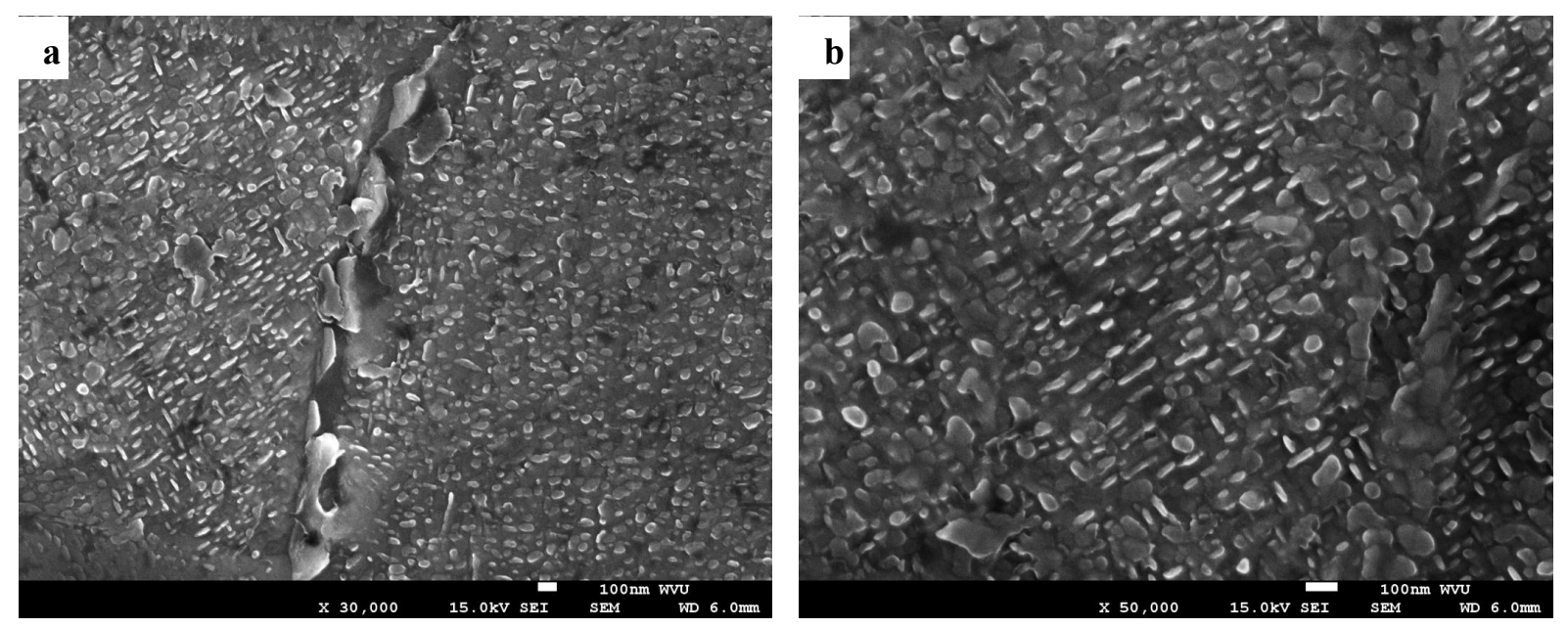

Figure 4.6 Gamma prime and double prime precipitation of Specimen B at (a) 30,000x and (b) 50,000x magnification.

\subsubsection{Two-Step Aging Treatment}

Figure 4.7 shows the SEM image of Specimen C's microstructure at $1000 x$ magnification. The average grain size is ASTM 3. Figure 4.8 shows the grain boundaries of Specimen $\mathrm{C}$ where there are some discontinuous delta phases. There are also some inclusions spread throughout the microstructure. In Figure 4.9 (a) gamma prime and double prime precipitation are shown as well as discontinuous platelet shaped delta phase formed along the grain boundary. The average size, shown in Figure 4.9(b), of $\gamma^{\prime}$ is 2-10 nm in diameter and $\gamma^{\prime \prime}$ is 2-12 $\mathrm{nm}$ in the c dimension and 5-35 $\mathrm{nm}$ in diameter. Note the precipitates are much smaller than the single-step aging treatment for Specimen B. 


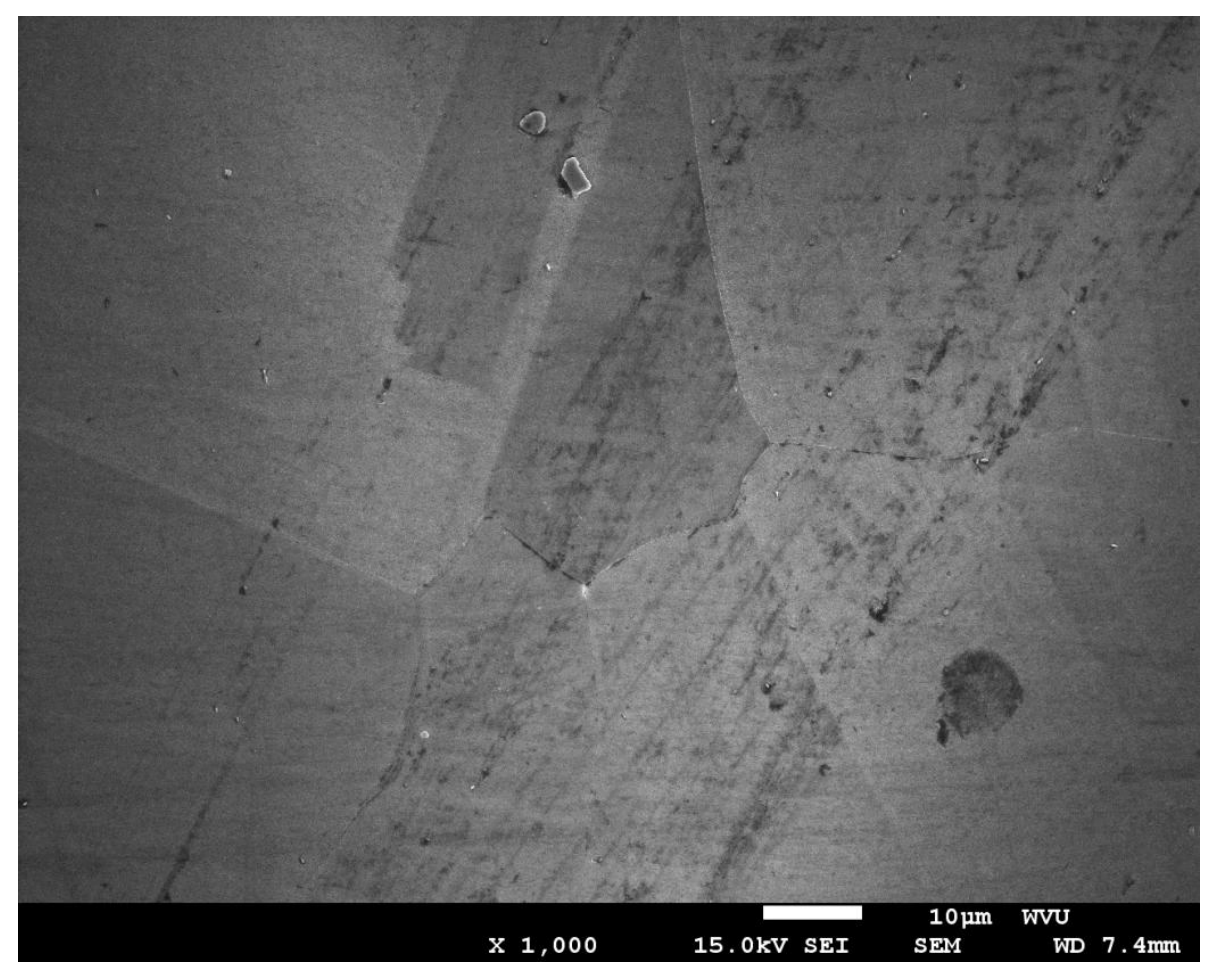

Figure 4.7 SEM image of Specimen C's microstructure at 1000x magnification.

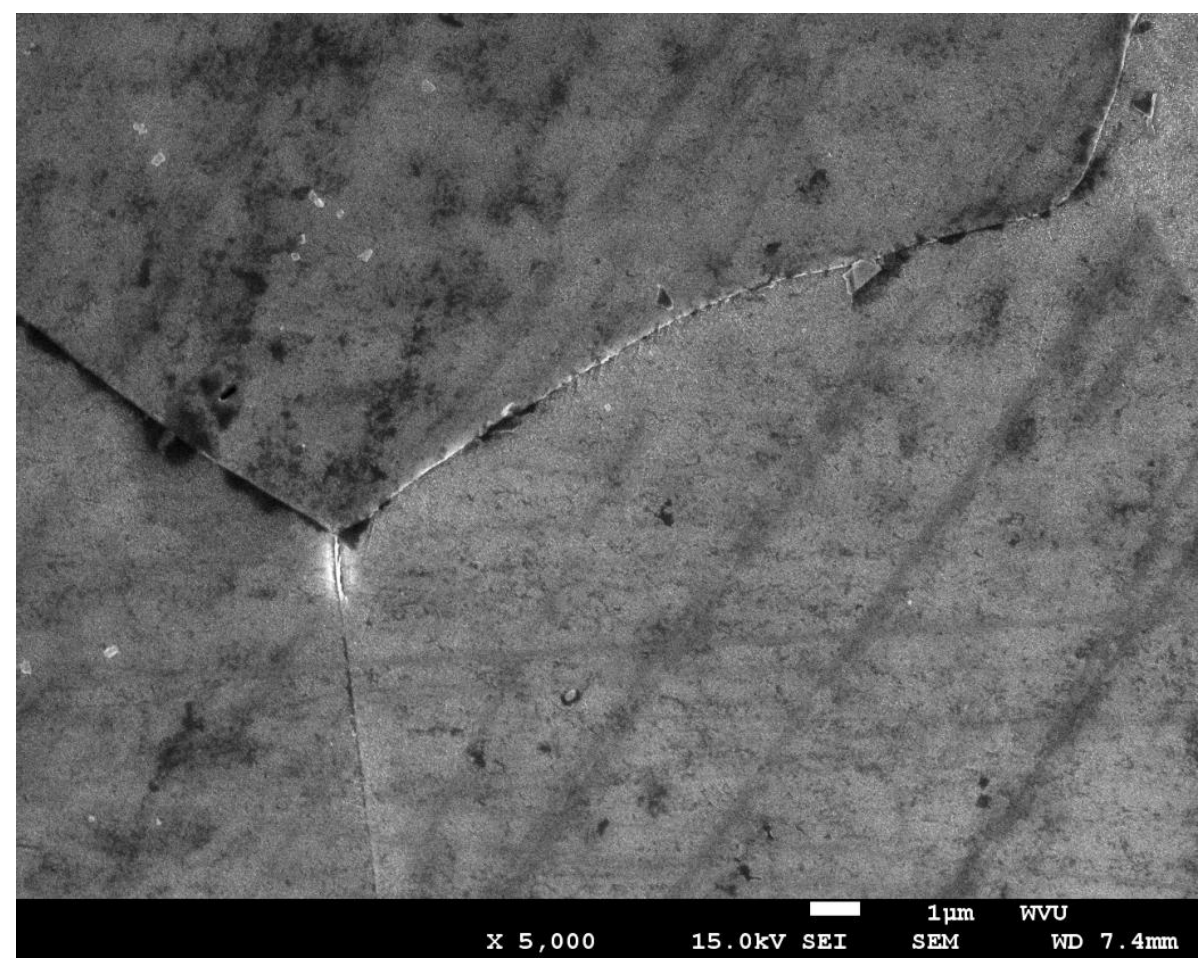

Figure 4.8 SEM image of the grain boundaries of Specimen $C$ at 5000x magnification. 

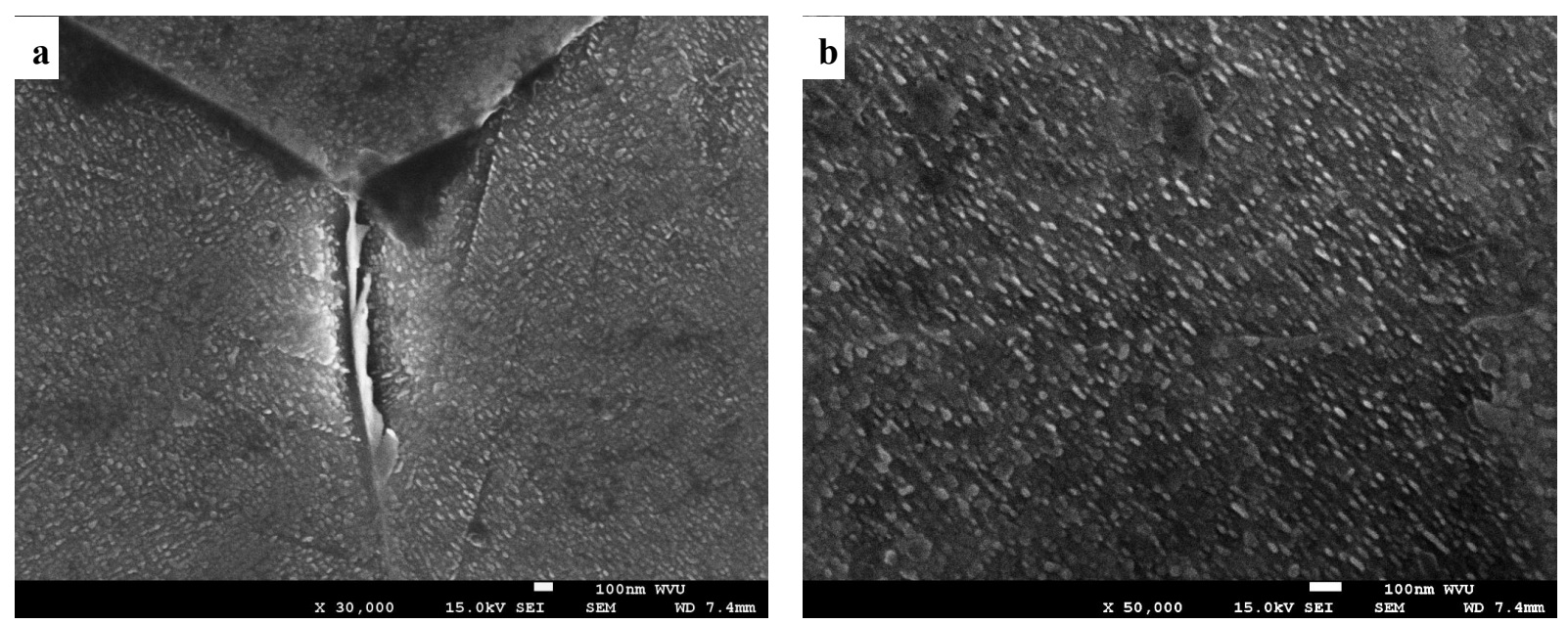

Figure 4.9 Gamma prime and double prime precipitation of Specimen $C$ at (a) 30,000x and (b) 50,000x magnification.

\subsection{Effect of Temperature on CFCP}

The FCG rate $(\mathrm{R}=0.15, f=1 \mathrm{~Hz})$ of Specimens $\mathrm{A}, \mathrm{B}$, and $\mathrm{C}$ in $3.5 \mathrm{wt} . \% \mathrm{NaCl}$ at room temperature, $50^{\circ} \mathrm{C}$, and $80^{\circ} \mathrm{C}$ compared with air at RT are shown in Figure 4.10, Figure 4.11, and Figure 4.12 respectively. It is clear from Figure 4.10 that the crack growth rate of Specimen A shows little to no effect of solution temperature on crack growth rate. Although the CFCP rate in $\mathrm{NaCl}$ at $\mathrm{RT}$ is higher than air at low $\Delta \mathrm{K}$ (below $23 \mathrm{MPaVm}$ ), the growth rate of $\mathrm{NaCl}$ at $80^{\circ} \mathrm{C}$ is the same as air which indicates that all the points for Specimen $A$ lie within the same error band and should be considered the same. The crack growth rate of Specimen B in Figure 4.11 shows a very small increase (1.1 to 1.2 times) in solution at any temperature below a $\triangle \mathrm{K}$ of $40 \mathrm{MPaVm}$. However, the potential error for crack length measurement exceeds the change in CFCP rate, rendering these results to be the same in terms of solution temperature effect. Figure 4.12 shows a 1.1 to 1.4 times increase of crack growth rate for Specimen $\mathrm{C}$ for all tested temperatures $\left(80^{\circ} \mathrm{C}\right.$ being the most significant) below a $\Delta \mathrm{K}$ of $40 \mathrm{MPaVm}$ and above a $\Delta \mathrm{K}$ of $50 \mathrm{MPaVm}$. These changes are very small, however, and are most likely due to noise in the crack growth measurement.

The potentiodynamic polarization curves in $3.5 \mathrm{wt} . \% \mathrm{NaCl}$ solution at $\mathrm{RT}, 50^{\circ} \mathrm{C}$, and $80^{\circ} \mathrm{C}$ for Specimens A, B, and C are shown in Figure 4.13, Figure 4.14, and Figure 4.15 respectively. The same general trends are shown for all three specimens. There is a substantial drop in the pitting potential $\left(\mathrm{E}_{\text {pit }}\right)$ from $\mathrm{RT}$ to $50^{\circ} \mathrm{C}$ and a negligible drop between $50^{\circ} \mathrm{C}$ and $80^{\circ} \mathrm{C}$ indicating the pitting temperature is around $50^{\circ} \mathrm{C}$ for all three specimens. The lack of change in crack growth rates indicate that in $3.5 \mathrm{wt} . \%$ $\mathrm{NaCl}$ solution at any temperature between $\mathrm{RT}$ and $80^{\circ} \mathrm{C}$, the fatigue crack growth is mechanically controlled rather than corrosion controlled for all specimens.

As indicated by the polarization curves, when the temperature is increased the ionic activity is also increased, however, there is not enough of an increase in AD or suppression of repassivation at the crack tip to increase the CFCP rate from that of air. The passivation film reformation during cyclic 
deformation (when the protective film is fractured and bare metal at the crack tip is exposed to the corrosive solution) is likely to fast to allow a significant amount of dissolution at the exposed crack tip surface before reformation of the protective film. Also, there are not enough chloride anions at the crack tip to slow the repassivation or weaken the newly formed film (to aid in breakdown) to effect crack growth. These results are not surprising because this alloy is designed to endure much more aggressive environments $[9,10,12]$.

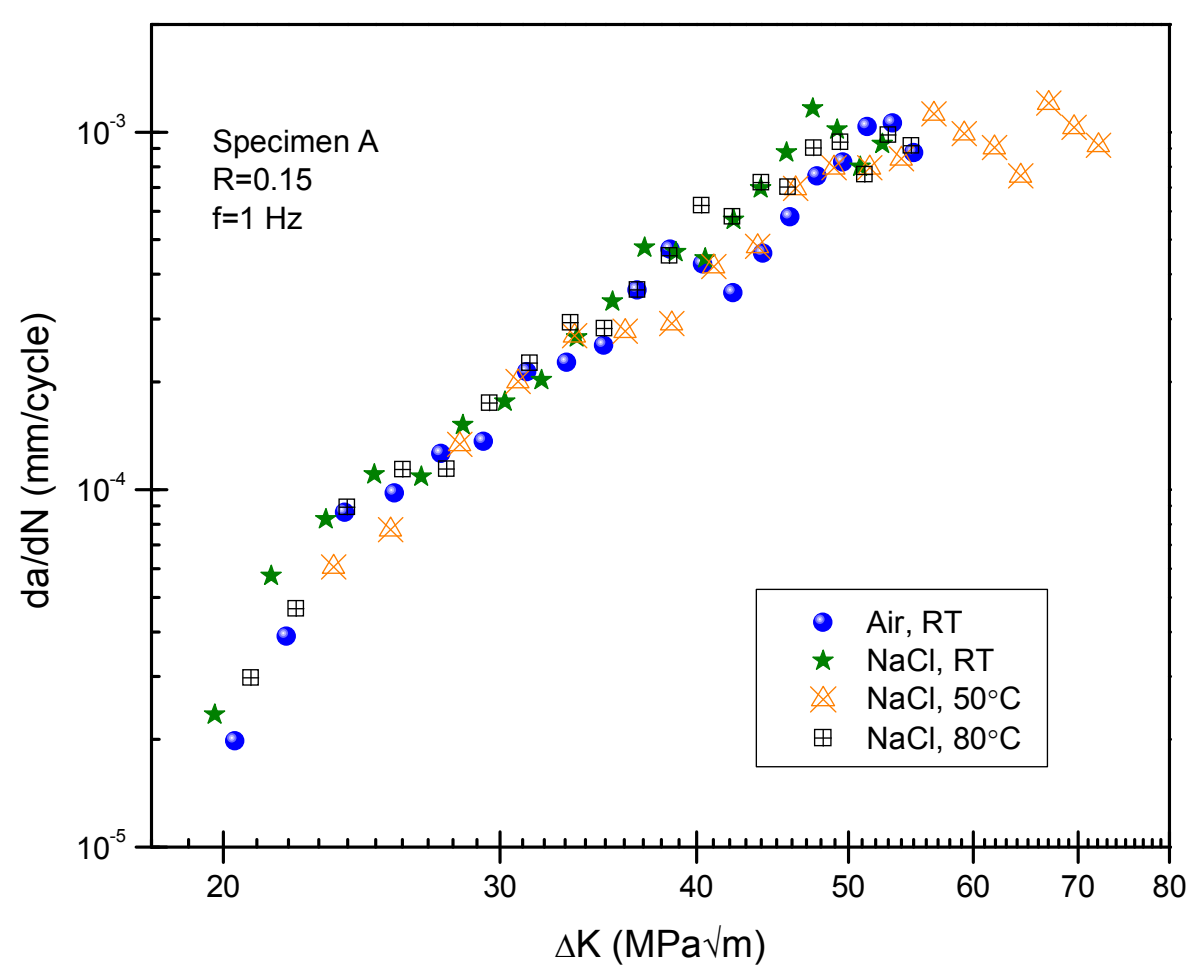

Figure 4.10 The effect of solution temperature on Specimen $\mathrm{A}$ in $3.5 \mathrm{wt} \% \mathrm{NaCl}$ solution. 


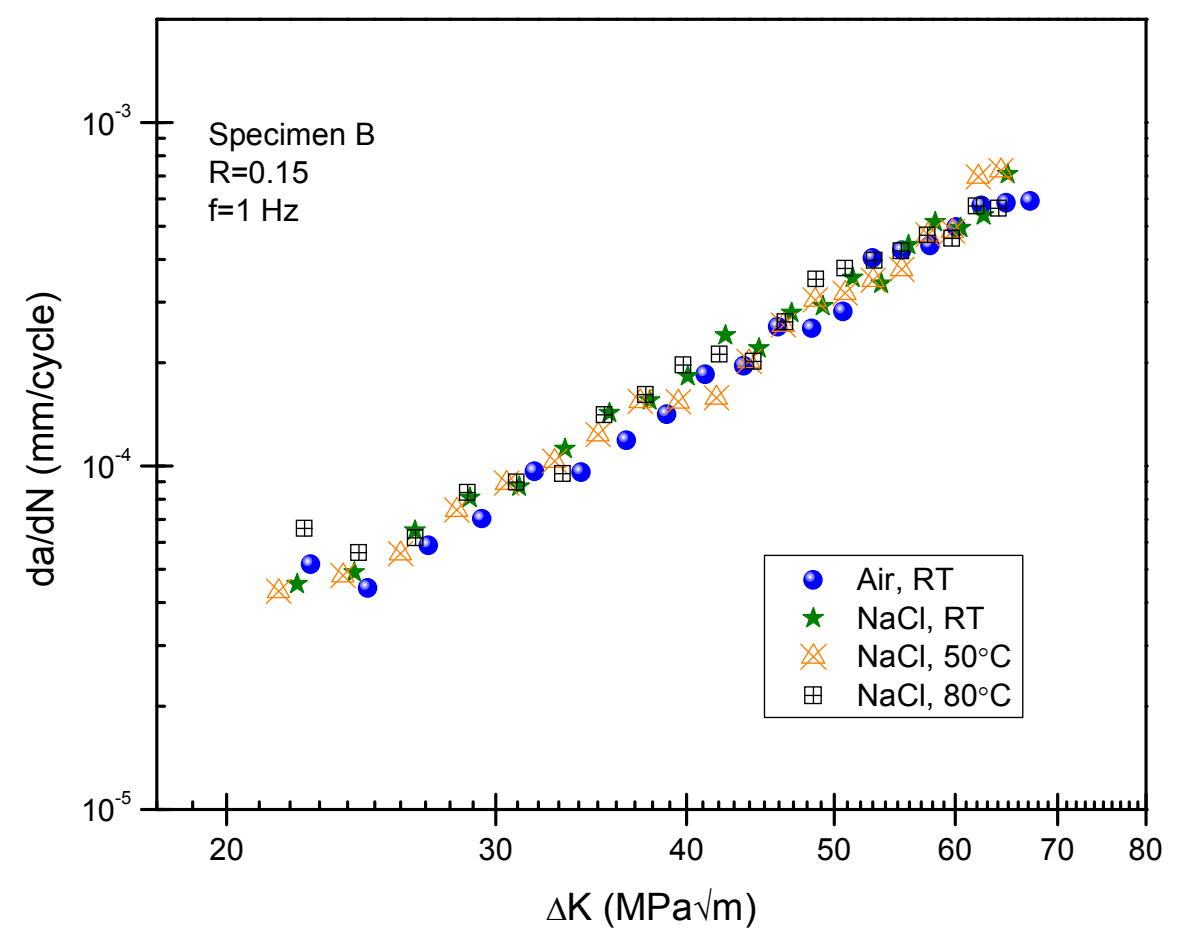

Figure 4.11 The effect of solution temperature on Specimen B in $3.5 \mathrm{wt} \% \mathrm{NaCl}$ solution.

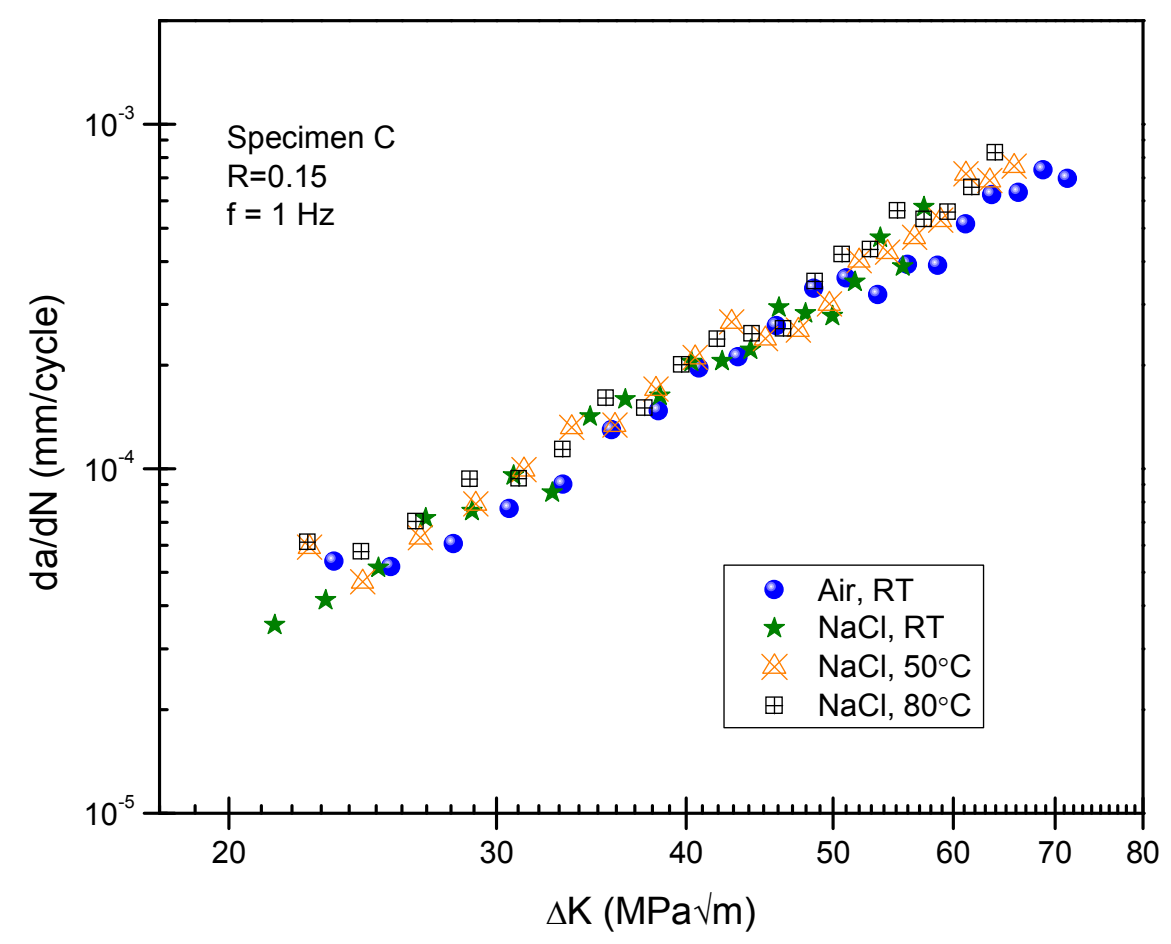

Figure 4.12 The effect of solution temperature on Specimen $\mathrm{C}$ in $3.5 \mathrm{wt} \% \mathrm{NaCl}$ solution. 


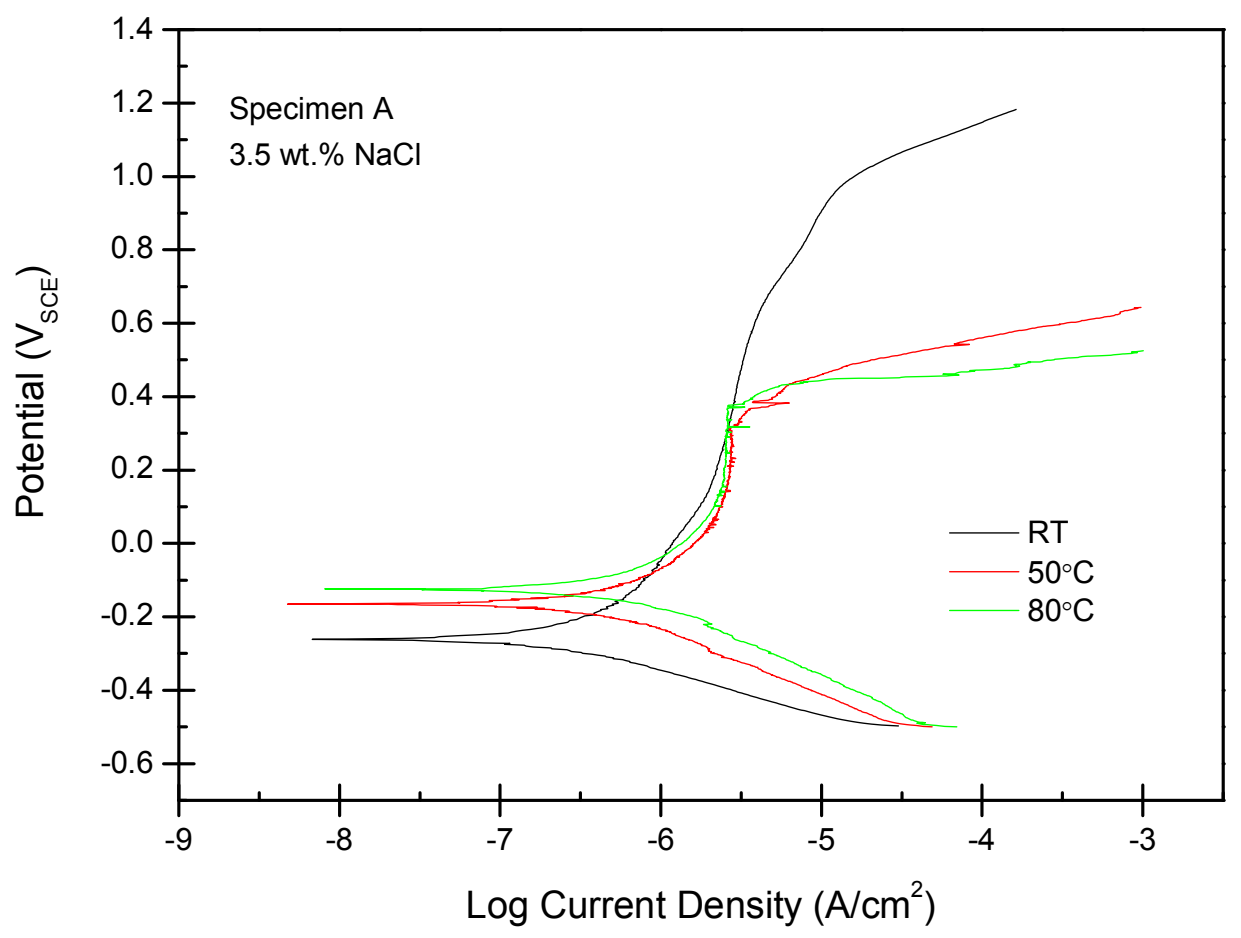

Figure 4.13 Potentiodynamic polarization curves for Specimen A in 3.5wt\% $\mathrm{NaCl}$.

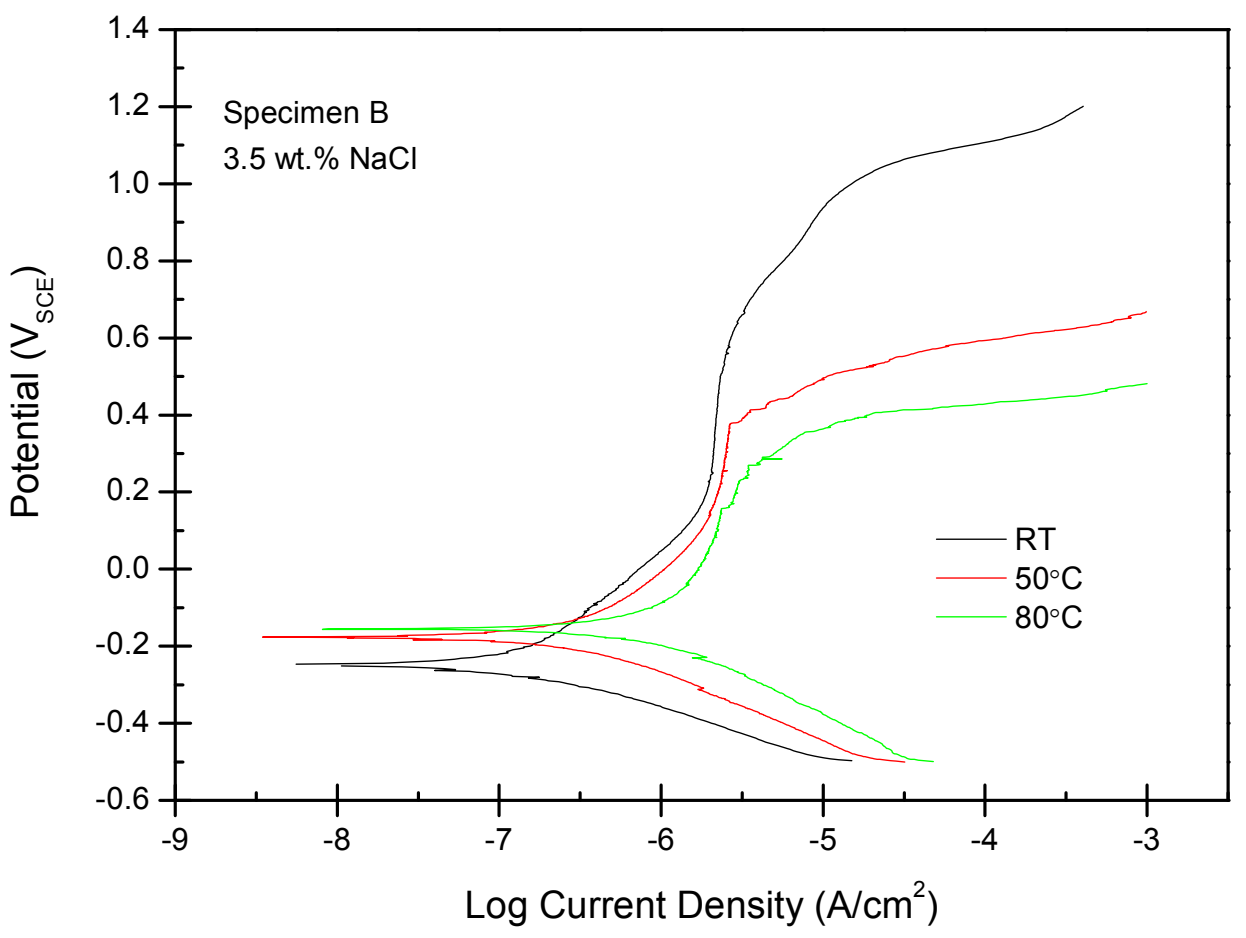

Figure 4.14 Potentiodynamic polarization curves for Specimen B in 3.5wt\% $\mathrm{NaCl}$. 


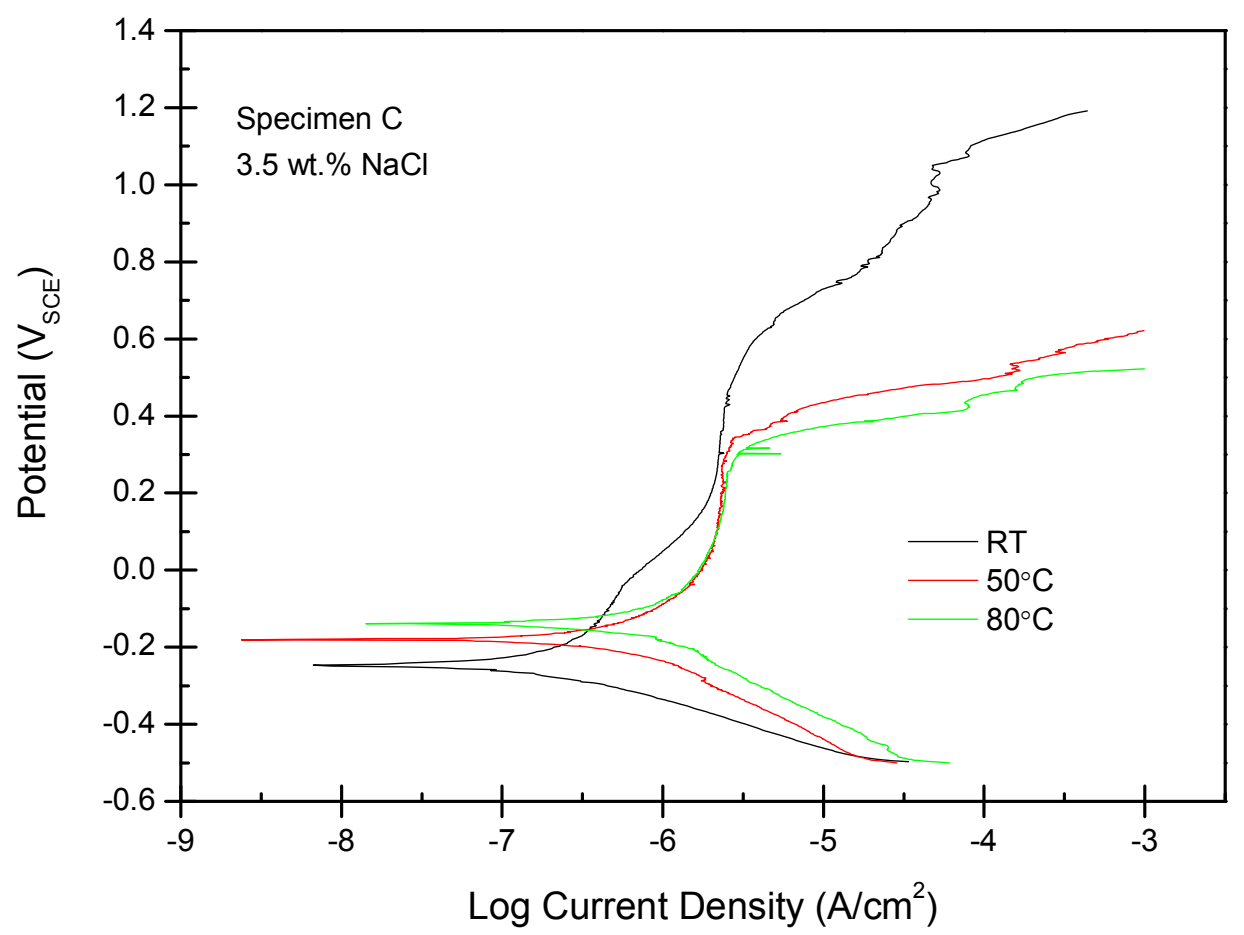

Figure 4.15 Potentiodynamic polarization curves for Specimen $\mathrm{C}$ in $3.5 \mathrm{wt} \% \mathrm{NaCl}$.

\subsection{Effect of Waveform on CFCP}

To investigate the effect of waveform (specifically triangular and trapezoidal waveforms) on crack growth rate, as stated in $\S 3.2$, a trapezoidal waveform was used with a 29 second hold-time and 0.5 second linear loading and unloading in $80^{\circ} \mathrm{C}$ solution temperature. The FCG rates $(R=0.15)$ of Specimens $\mathrm{A}, \mathrm{B}$, and $\mathrm{C}$ under trapezoidal and triangular waveforms in air at $\mathrm{RT}$ and $3.5 \mathrm{wt} . \% \mathrm{NaCl}$ at $80^{\circ} \mathrm{C}$ are shown in Figure 4.16, Figure 4.17, and Figure 4.18 respectively. The FCG rates in $\mathrm{NaCl}$ solution are almost equal to the rate in air for the entire $\Delta \mathrm{K}$ range. Even at the end of Region 1 of the da/dN vs. $\Delta \mathrm{K}$ for Specimen $A$ in Figure 4.16, there is no effect of hold-time at maximum loading. The first two points in both Figure 4.17 and Figure 4.18 suggests a difference at first glance, but these first points are unreliable due to a verity of reasons involving the damage zone ahead of the crack from the pre-cracking process and additional corrosion from the extended exposure time to the corrosive solution during test setup.

Wang, Li, Wang, and Ke [32] investigated the influence of loading waveform on CFCP rate for iron in $3.5 \% \mathrm{NaCl}$ and $3.5 \% \mathrm{NaCl}+1 \% \mathrm{NaNO}_{2}$ solutions at different applied potentials. The effect of square waveform hold-time is shown in Figure 2.8 for hold-times of 0.1 and 0.9 seconds in $3.5 \% \mathrm{NaCl}$ at free corrosion potential. The difference between the two hold-times is small which indicates that the influence of the waveform mainly came from the continuous deformation of the crack-tip with no effect from the hold-time. It has already been shown in the previous section (\$4.2)that crack growth rate is unaffected by the corrosive medium at $80^{\circ} \mathrm{C}$, so it is not surprising that there is also no effect of waveform on CFCP rate. These results would seem to agree with the observations of Wang et al., where 
the effect of the corrosive solution takes place on the rise and fall of the applied load, and the hold-time at maximum load is not important for crack growth rate in CF. But, since there is no change in crack growth rate compared with air, this conclusion cannot be drawn from these results because there was no effect of the corrosive solution on crack growth rate.

It is unlikely, however, that the hold-time from a trapezoidal waveform would increase the CFCP rate, because Alloy 718 is not susceptible to stress corrosion cracking under the current testing conditions $[9,10]$. Onyewuenyi $[10]$ tested the SCC properties for $U$ bend specimens of Alloy 718 with various standard aerospace heat treatments in $25 \% \mathrm{NaCl}$ at $204^{\circ} \mathrm{C}$ for six day. He found only one of three heat treatments failed under much harsher conditions than the current testing conditions.

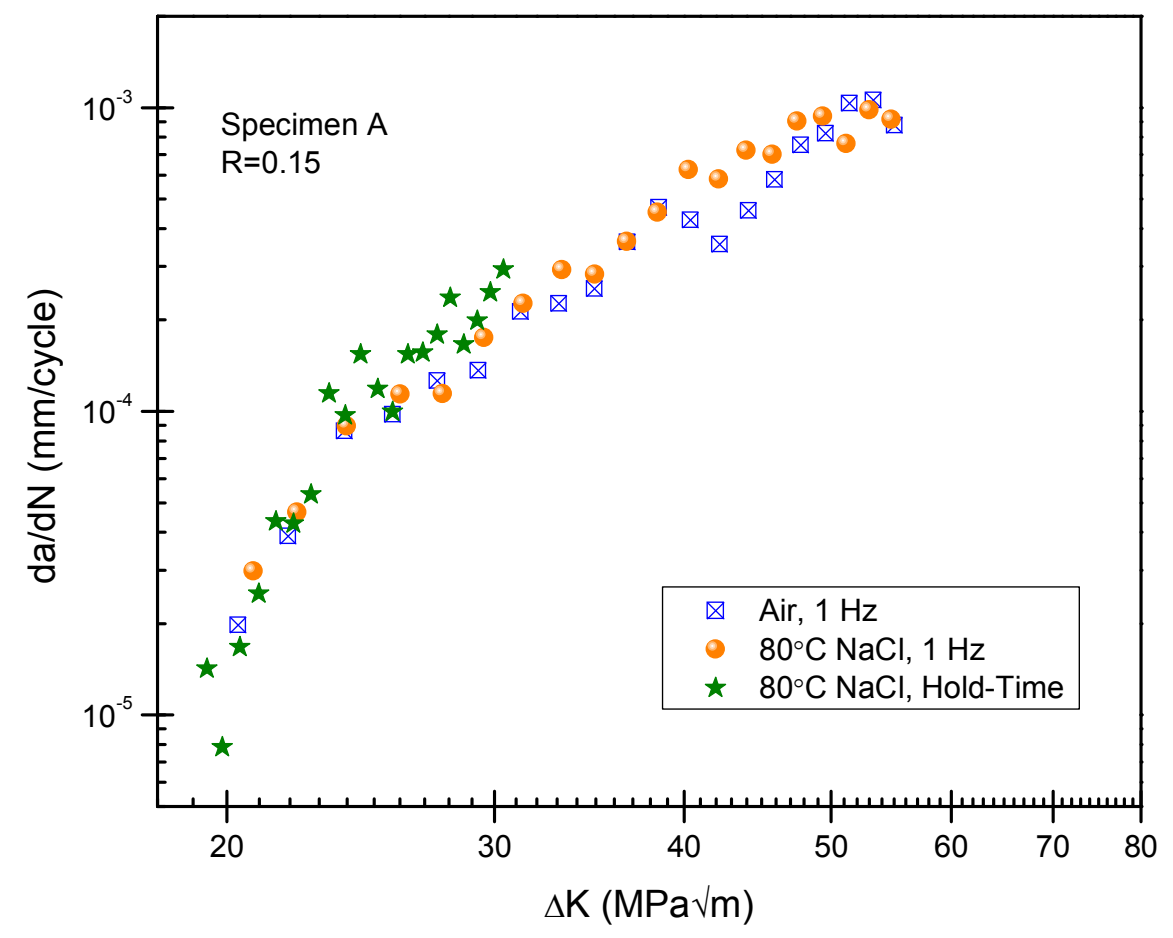

Figure 4.16 The effect of hold-time on CFCP for Specimen A in $3.5 \mathrm{wt} \% \mathrm{NaCl}$ solution at $80^{\circ} \mathrm{C}$. 


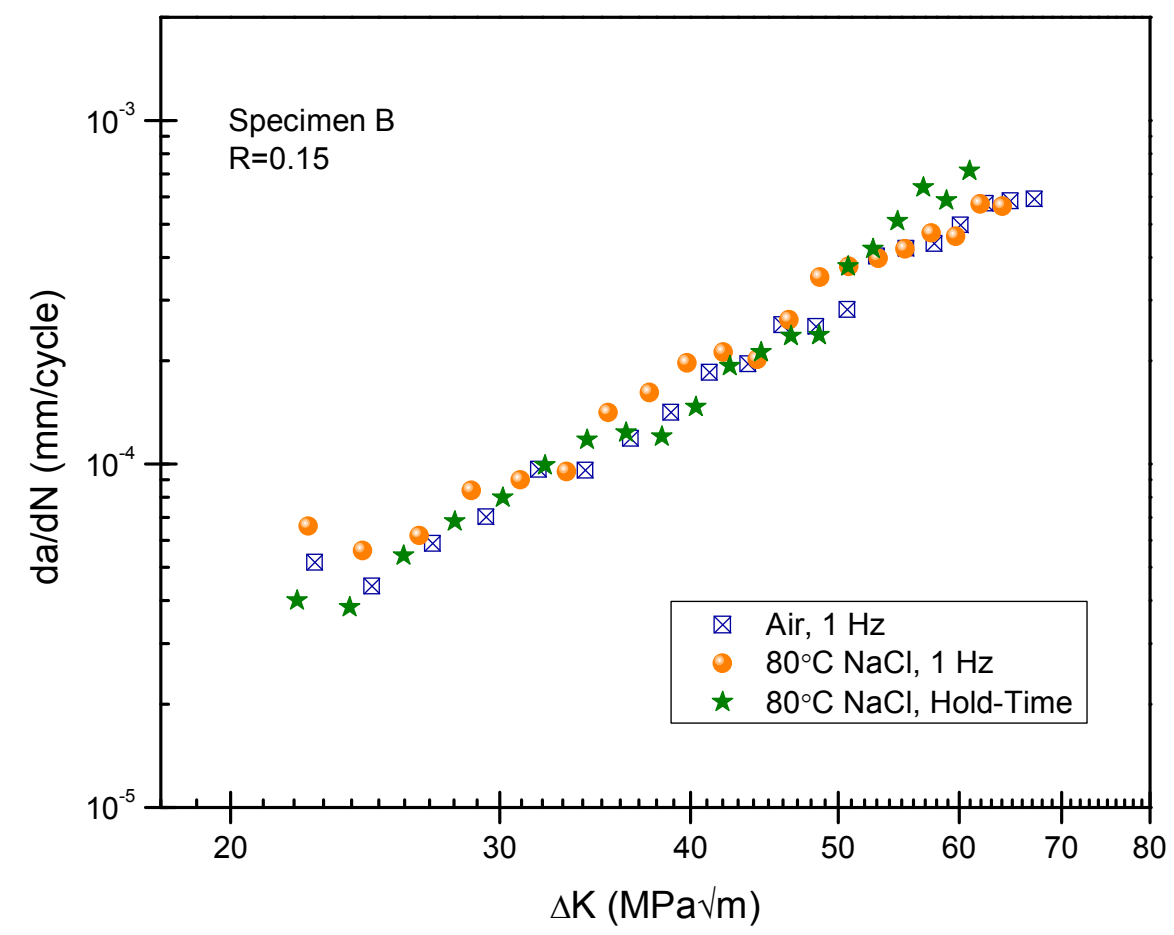

Figure 4.17 The effect of hold-time on CFCP for Specimen B in $3.5 \mathrm{wt} \% \mathrm{NaCl}$ solution at $80^{\circ} \mathrm{C}$.

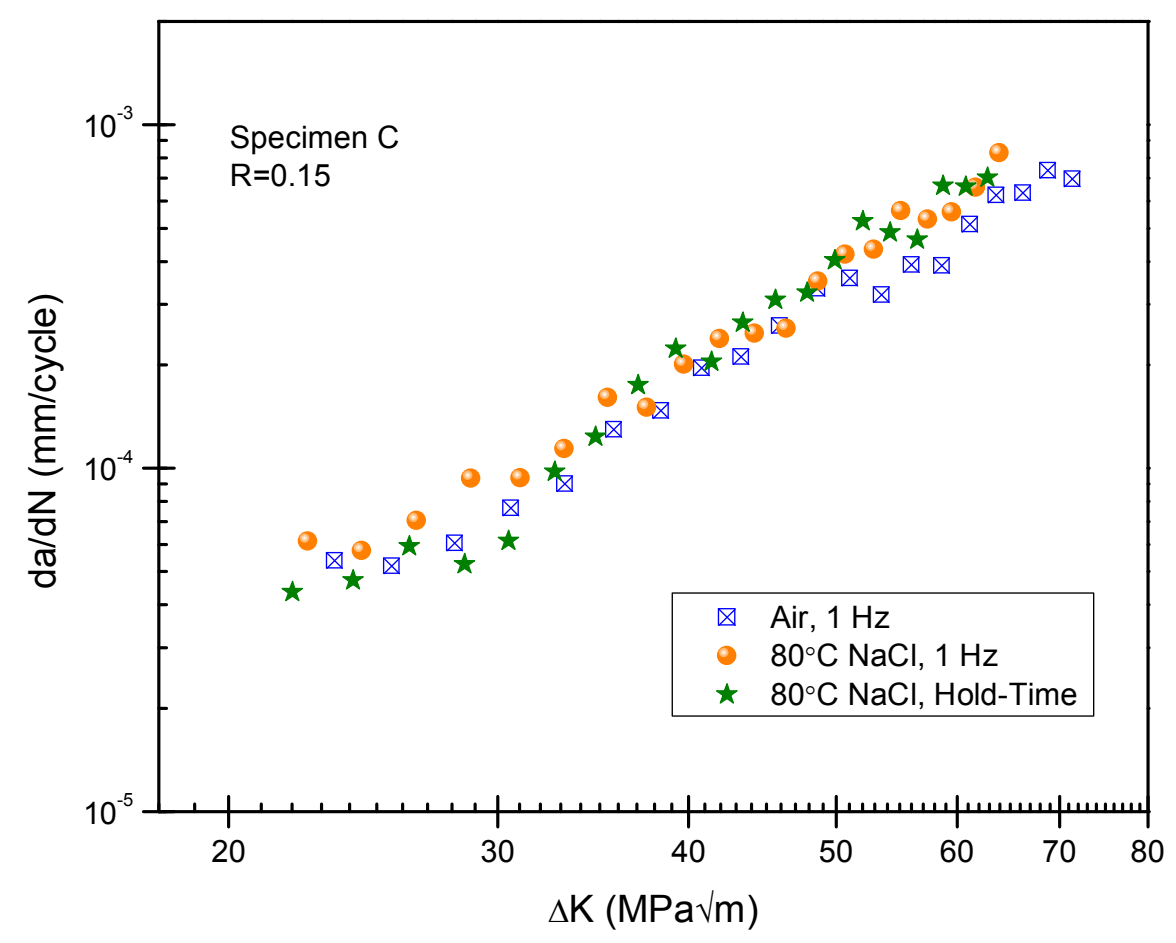

Figure 4.18 The effect of hold-time on CFCP for Specimen C in $3.5 \mathrm{wt} \% \mathrm{NaCl}$ solution at $80^{\circ} \mathrm{C}$. 


\subsection{Effect of Chloride Concentration}

The FCG rates $(\mathrm{R}=0.15, f=1 \mathrm{~Hz})$ of Specimens $\mathrm{A}, \mathrm{B}$, and $\mathrm{C}$ in air at $\mathrm{RT}$ and $\mathrm{NaCl}$ solutions (3.5 wt.\% and 21 wt.\%) at $80^{\circ} \mathrm{C}$ are shown in Figure 4.19, Figure 4.20, and Figure 4.21 respectively. From Figure 4.19, the increased concentration is shown to have about a 1.5 to 2.5 times increase in CFCP rate of Specimen $\mathrm{A}$ below the $\Delta \mathrm{K}$ value of $31 \mathrm{MPaVm}$. Above $31 \mathrm{MPaVm}$, the crack growth rate is the same as 3.5 wt.\% and air indicating that the mode of crack growth becomes mechanically driven rather than corrosion driven. From the potentiodynamic polarization curve, shown in Figure 4.22, there is a large drop in the pitting potential $\left(E_{\text {pit }}\right)$ from $+0.365 \mathrm{mV}$ to $+0.135 \mathrm{mV}$ as the $\mathrm{Cl}^{-}$concentration is increased indicating the passivation film is much more unstable in the $21 \mathrm{wt} . \% \mathrm{NaCl}$ solution at $80^{\circ} \mathrm{C}$. Figure 4.21 shows the crack growth rate for Specimen $\mathrm{C}$ is increased about 1.5 to 2 times through the entire length of data. Like Specimen A, the pitting potential, shown in Figure 4.24, is dramatically decreased from $+0.268 \mathrm{mV}$ to $-0.140 \mathrm{mV}$ when the chloride concentration is increased. For Specimen B, in Figure 4.20, the increase is around 1.5 to 2 times more than air below the $\Delta \mathrm{K}$ value of $46 \mathrm{MPaVm}$, but the increase is much closer to the $3.5 \mathrm{wt} . \% \mathrm{NaCl}$ test than the other specimens. Since $3.5 \mathrm{wt} . \% \mathrm{NaCl}$ test cannot be distinguished from air (as stated in §4.2), the effect of increasing the chloride concentration on the CFCP rate is the same as for Specimen $A$ and $C$ at low $\Delta K$ values. The polarization curve for Specimen $B$ in Figure 4.23 also shows $E_{\text {pit }}$ lower than at 3.5 wt.\% concentration (from $+0.175 \mathrm{mV}$ to $-0.140 \mathrm{mV}$ ), which is a lesser amount than the other two specimens. The crack growth rate increases in $21 \mathrm{wt} . \% \mathrm{NaCl}$ for all of the specimens are very small, however, compared with $3.5 \mathrm{wt} . \% \mathrm{NaCl}$, and are more pronounced in the lower $\Delta K$ regions where the effects of stress and strain on the crack tip are less dominate.

It's been proven that the presence of chloride ions in the solution results in a localized acidification of the crack tip, leading to a higher dissolution rate and increased crack growth rate $[22,56$, 70]. The chloride anions also slow the oxide formation reaction, allowing for more time for the crack tip surface cations to dissolve in the active region [70]. MacDoughall [70] investigated the effect of $\mathrm{Cl}^{-}$ion on the passivation of nickel in $\mathrm{pH} 2.8 \mathrm{Na}_{2} \mathrm{SO}_{4}$ in an attempt to determine its role in initiating pitting on nickel substrates. He found that the role of $\mathrm{Cl}^{-}$is to disrupt oxide repassivation at local breakdown sites, leading to more extensive $\mathrm{Ni}^{2+}$ dissolution in the local areas. This increases to the local solution acidity through hydrolysis and more rapid film breakdown through chemical dissolution. In the crack, this process is amplified due to the confined space of the crack tip and ion migration to the crack tip as a result of the increased acidity. At higher values of $\Delta \mathrm{K}$, mechanical effects become increasingly more dominant [56], which explains the reduced effect at $31 \mathrm{MPaVm}$ for Specimen A. The effect of chloride concentration is not always seen as in the case of Specimen B. Ho and $Y u$ [56] investigated the fatigue crack growth behavior of mill annealed Alloy 600 in $\mathrm{NaCl}$ solution at $25^{\circ} \mathrm{C}$ under different solution concentrations. Ho et al. did not observe any increase in CFCP rate for increased chloride concentration, because the controlling factor was shown to be the mechanical contribution rather than the corrosiveness of the alloy. The chloride ions don't always slow the repassivation process enough for a significant amount of dissolution to occur between cycles to affect the crack growth rate. MacDoughall described it as battle between absorption of $\mathrm{Cl}^{-}$ion and the oxygen-containing species responsible for passive film formation, with the extent of $\mathrm{Cl}^{-}$absorption increasing with its bulk concentration. 


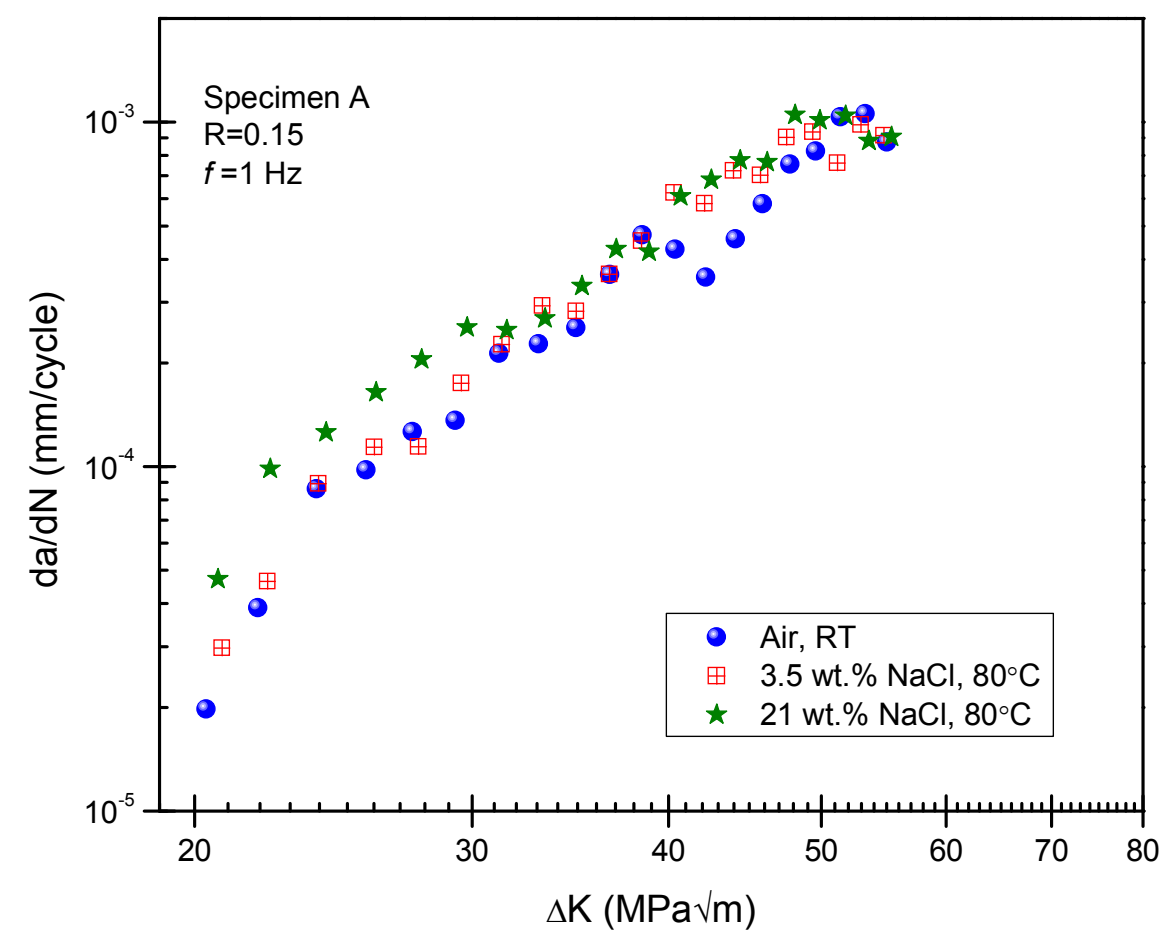

Figure 4.19 The effect of chloride concentration on FCG rate for Specimen A.

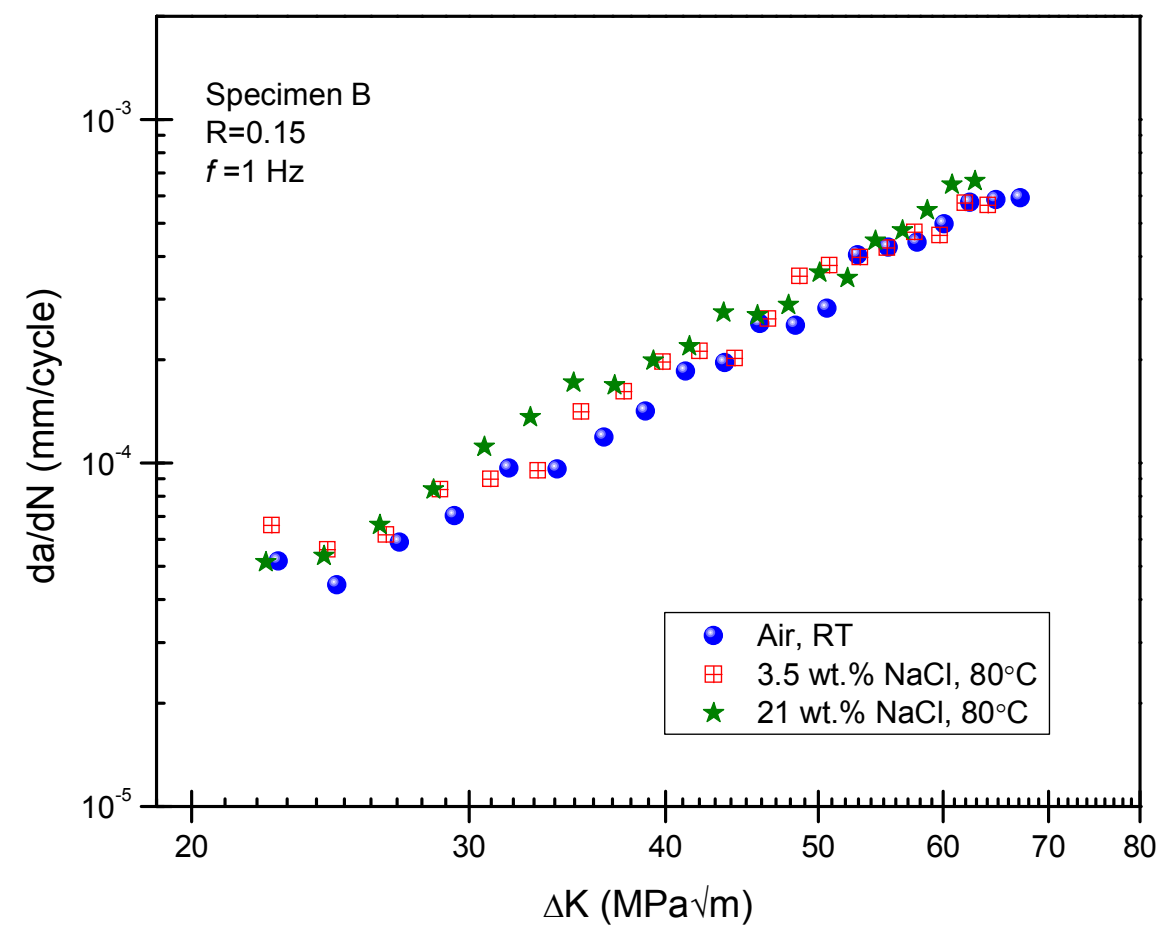

Figure 4.20 The effect of chloride concentration on FCG rate for Specimen B. 


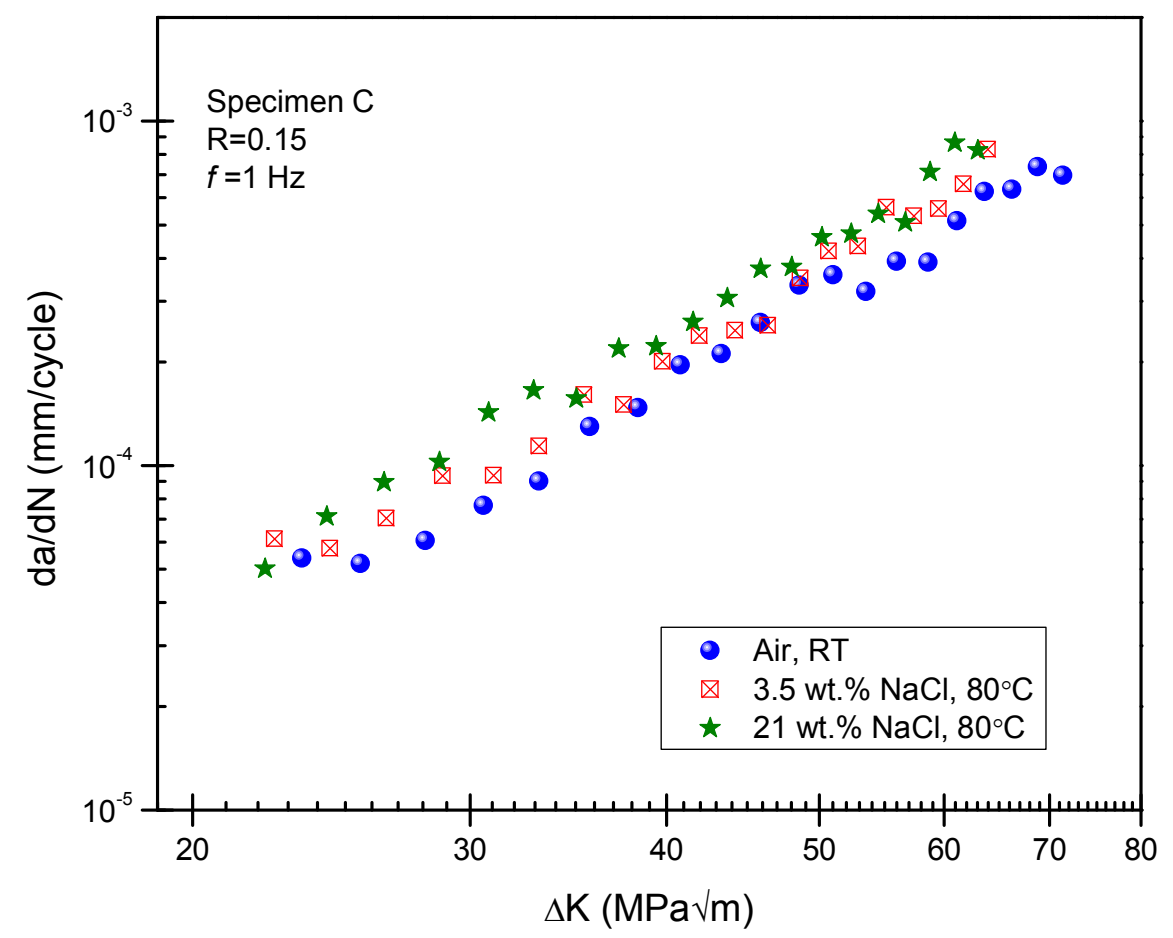

Figure 4.21 The effect of chloride concentration on FCG rate for Specimen C.

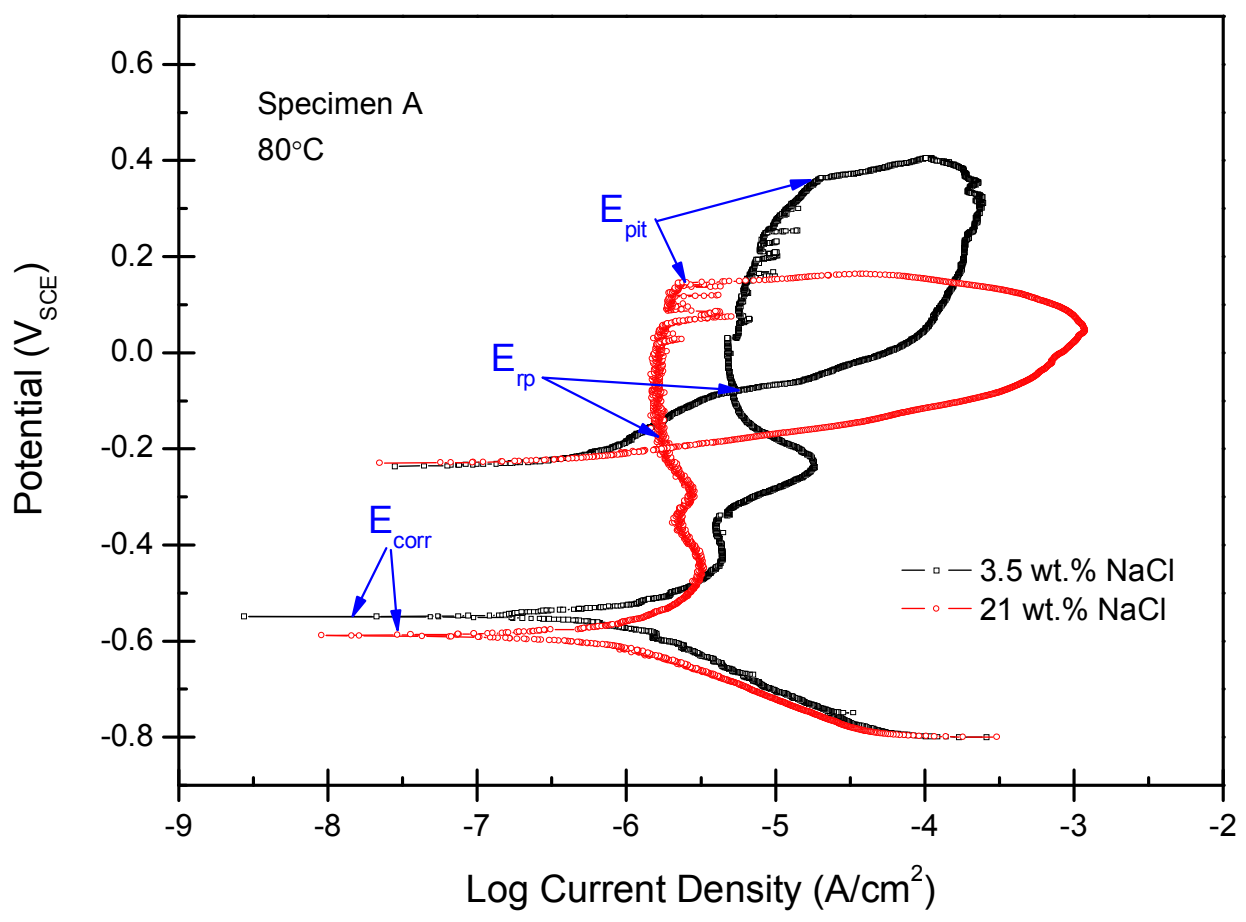

Figure 4.22 Potentiodynamic polarization curves of Specimen A in 3.5 and 21 wt.\% $\mathrm{NaCl}$ at $80^{\circ} \mathrm{C}$. 


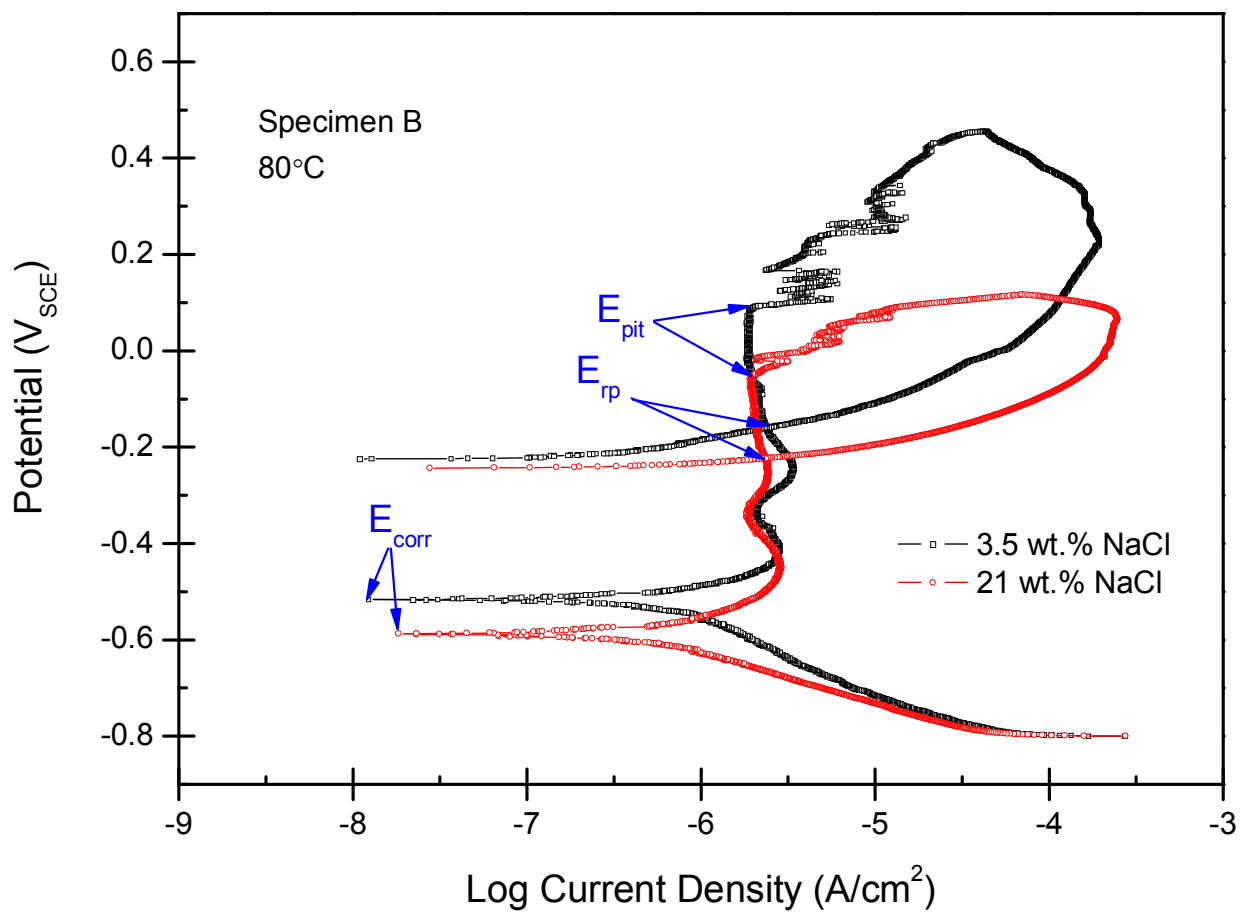

Figure 4.23 Potentiodynamic polarization curves of Specimen B in 3.5 and 21 wt.\% $\mathrm{NaCl}$ at $80^{\circ} \mathrm{C}$.

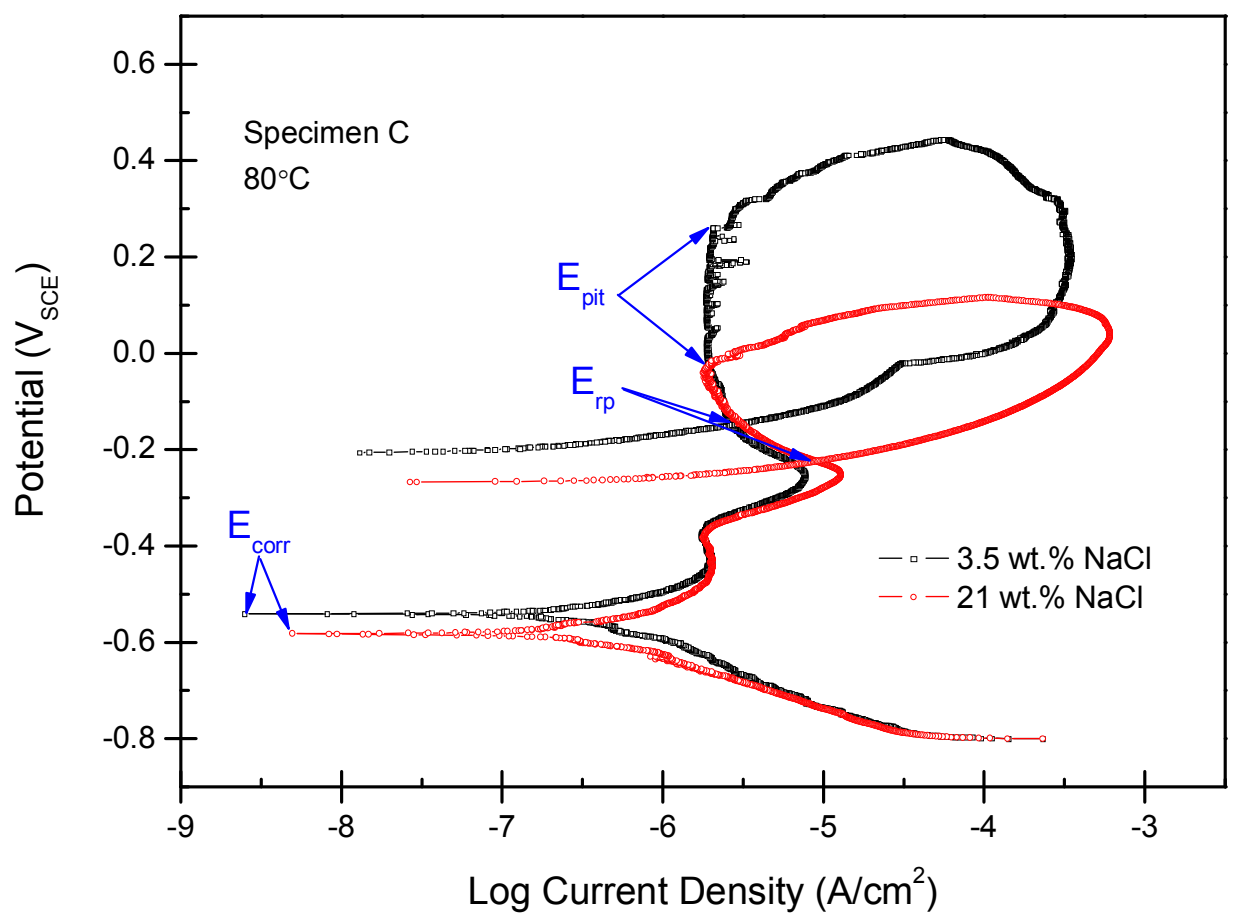

Figure 4.24 Potentiodynamic polarization curves of Specimen C in 3.5 and 21 wt.\% $\mathrm{NaCl}$ at $80^{\circ} \mathrm{C}$. 


\subsection{Effect of Aging Treatment on CFCP}

The FCG rates $(\mathrm{R}=0.15, f=1 \mathrm{~Hz})$ for Specimens $\mathrm{A}, \mathrm{B}$, and $\mathrm{C}$ in air at $\mathrm{RT}$ are shown in Figure 4.25. It is clear that Specimen A has a much higher, 2.25 to 3.3 times higher, crack growth rate in air than the two aged samples which are equal. As mentioned in $\S 4.2$ and $\S 4.3$, temperature and hold-time have no noticeable effect on CFCP rate for all three aging treatments. Therefore, it is not unreasonable to assume that this fact carries over when the aging treatments are compared to one another under the same environmental and fatigue loading conditions. Figure 4.26 shows the CFCP rates $(\mathrm{R}=0.15, f=1$ $\mathrm{Hz}$ ) for all of the specimens in $3.5 \mathrm{wt} . \% \mathrm{NaCl}$ at RT. As predicted, there is no change from that of Figure 4.25 in air, which is not surprising when the potentiodynamic polarization curves for each specimen under the same conditions are compared in Figure 4.27. From this figure, it is clear that there is no difference in the corrosion properties between the different aging treatments in $3.5 \mathrm{wt} . \% \mathrm{NaCl}$ at RT. This trend is the same for $50^{\circ} \mathrm{C}$ and $80^{\circ} \mathrm{C}$ with the CFCP rates and potentiodynamic polarization curves shown in Figure 4.28 to Figure 4.31. The hold-time crack growth rates, shown in Figure 4.32, were no exception to the pattern of no difference from the FCG rate results in air either.

In fact, the only testing condition that had any effect on crack growth rate or corrosion was the increase in $\mathrm{NaCl}$ concentration from 3.5 to 21 wt.\%. The comparison of CFCP rates $(\mathrm{R}=0.15, f=1 \mathrm{~Hz})$ for Specimens $\mathrm{A}, \mathrm{B}$, and $\mathrm{C}$ in $21 \mathrm{wt} . \% \mathrm{NaCl}$ at $80^{\circ} \mathrm{C}$ are shown in Figure 4.33. As stated in the previous section ( $\$ 4.4)$, there is a noticeable increase in all of the specimens from crack growth rates in air and 3.5 wt.\% NaCl at an equal temperature. However, Figure 4.33 shows a larger increase in growth rate for Specimens A and C compared with Specimen B. This indicates that Specimen B may be more corrosion resistant than both Specimen A and C. The potentiodynamic polarization curves, shown in Figure 4.34, is too close to distinguish between the two aged samples indicating that there is likely no difference in the corrosion performance. As a result of this, there is no difference in the CF performance for any environment tested as discussed in the other sections. 


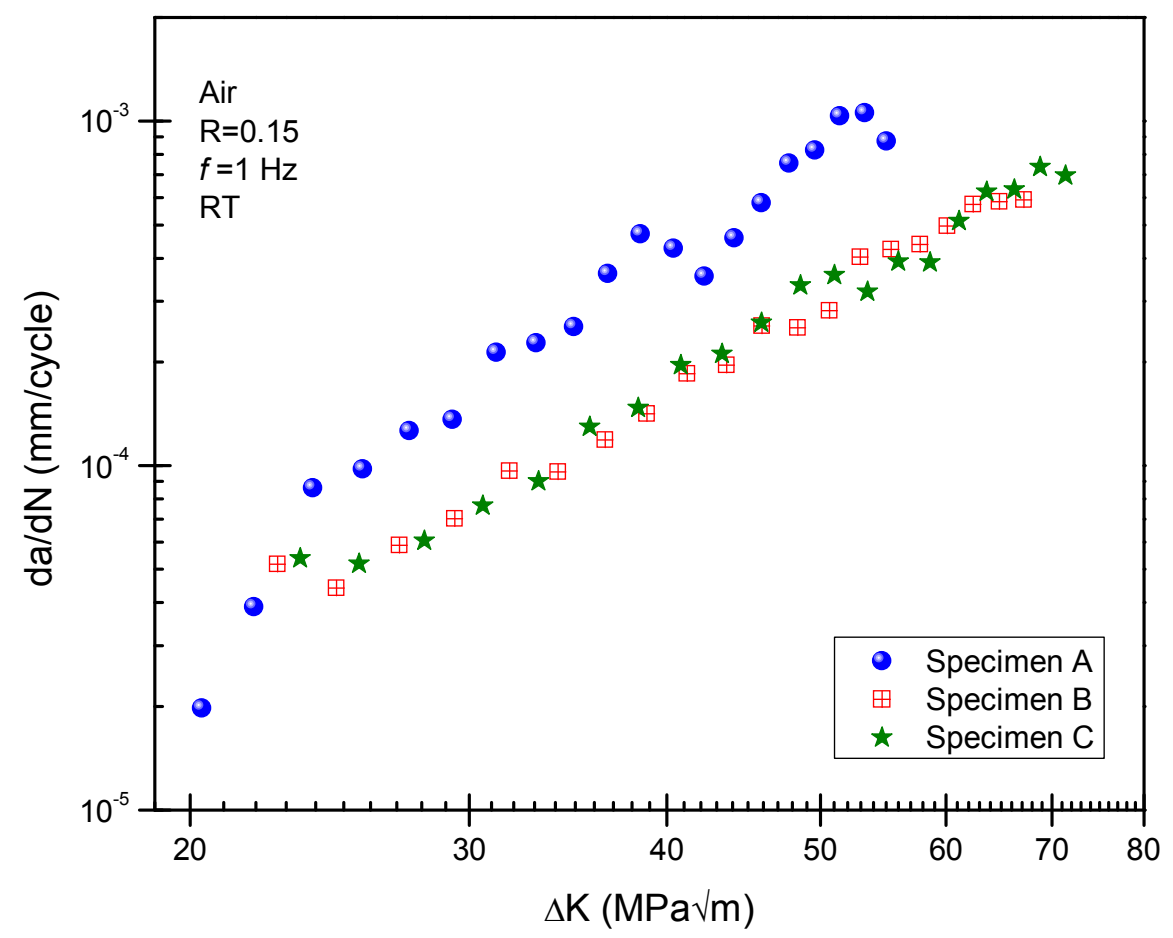

Figure 4.25 Aging treatment comparison in air at RT.

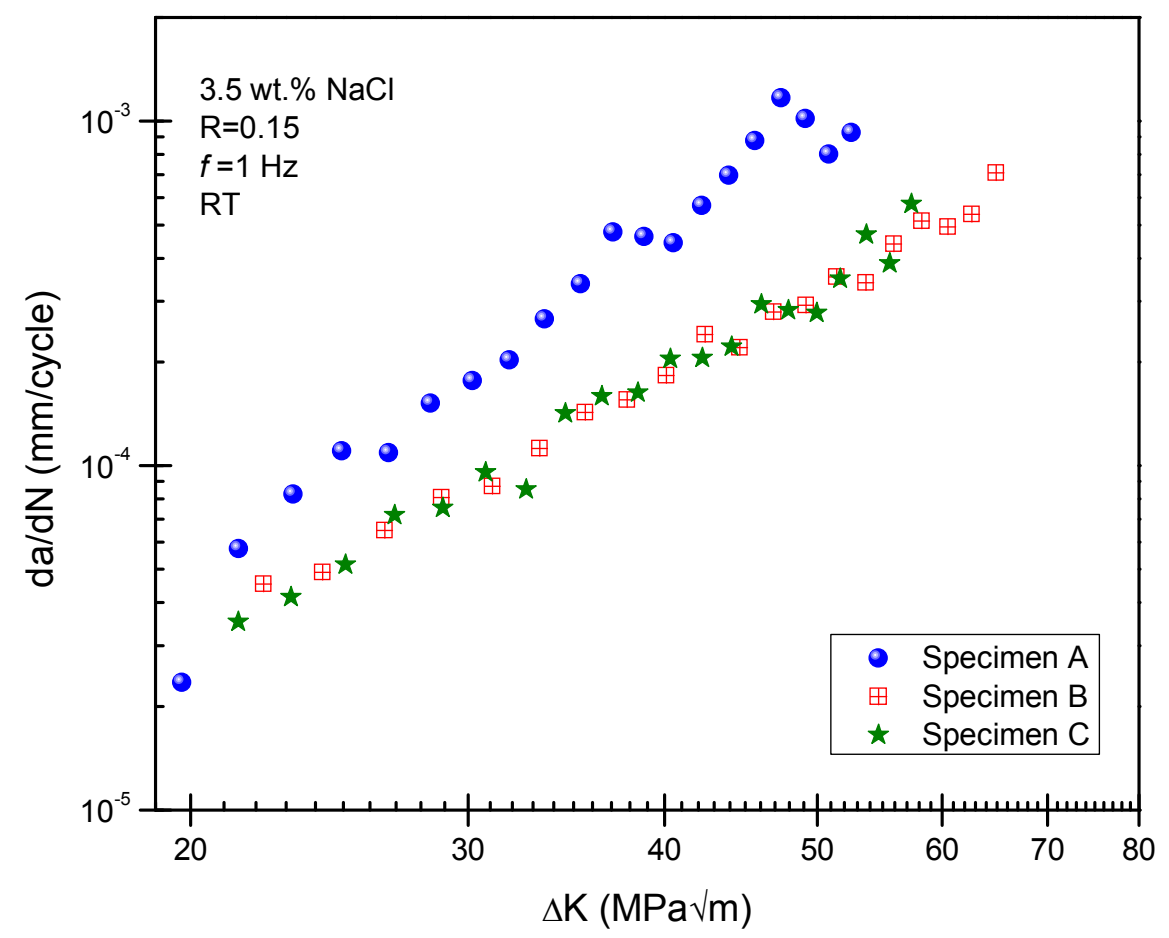

Figure 4.26 Aging treatment comparison in 3.5wt.\% $\mathrm{NaCl}$ at RT. 


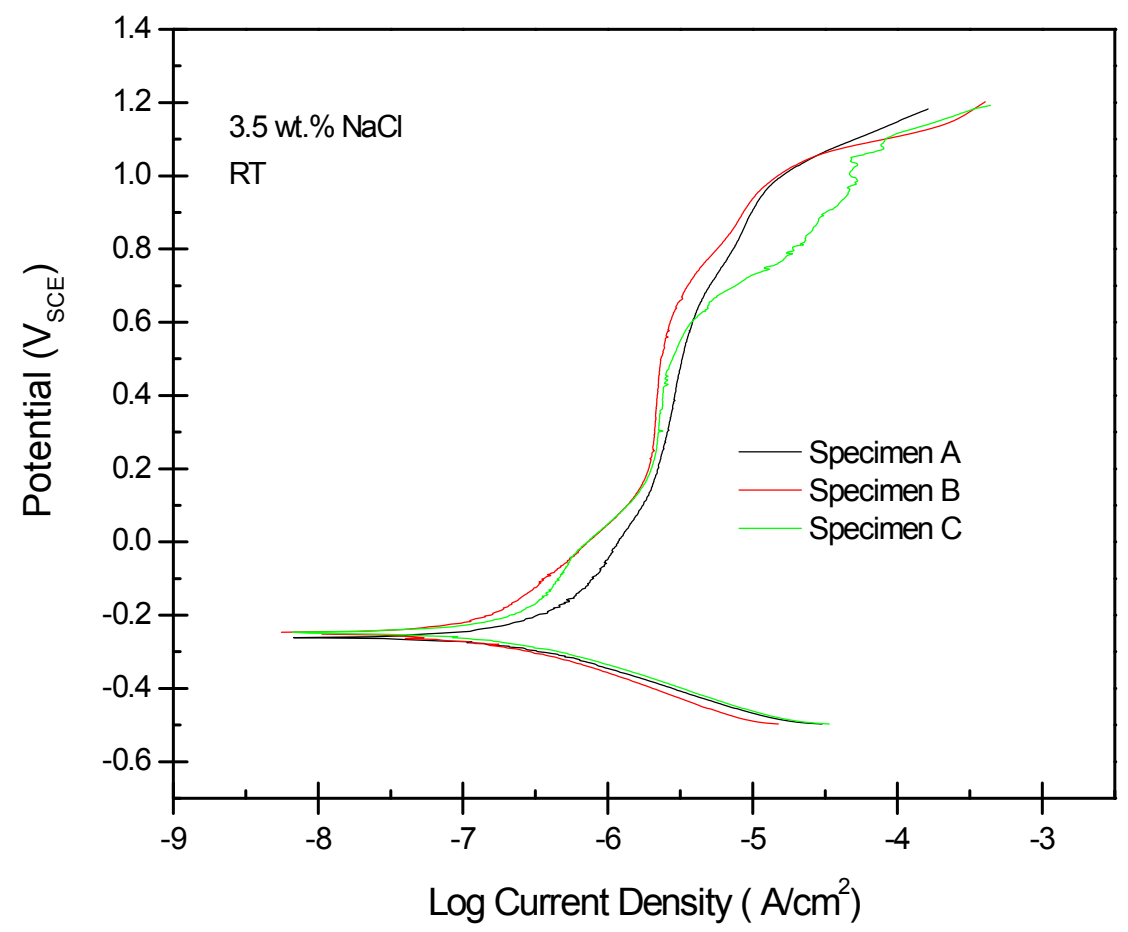

Figure 4.27 Potentiodynamic polarization curves for different aging treatments in $3.5 w t \% ~ N a C l$ at RT.

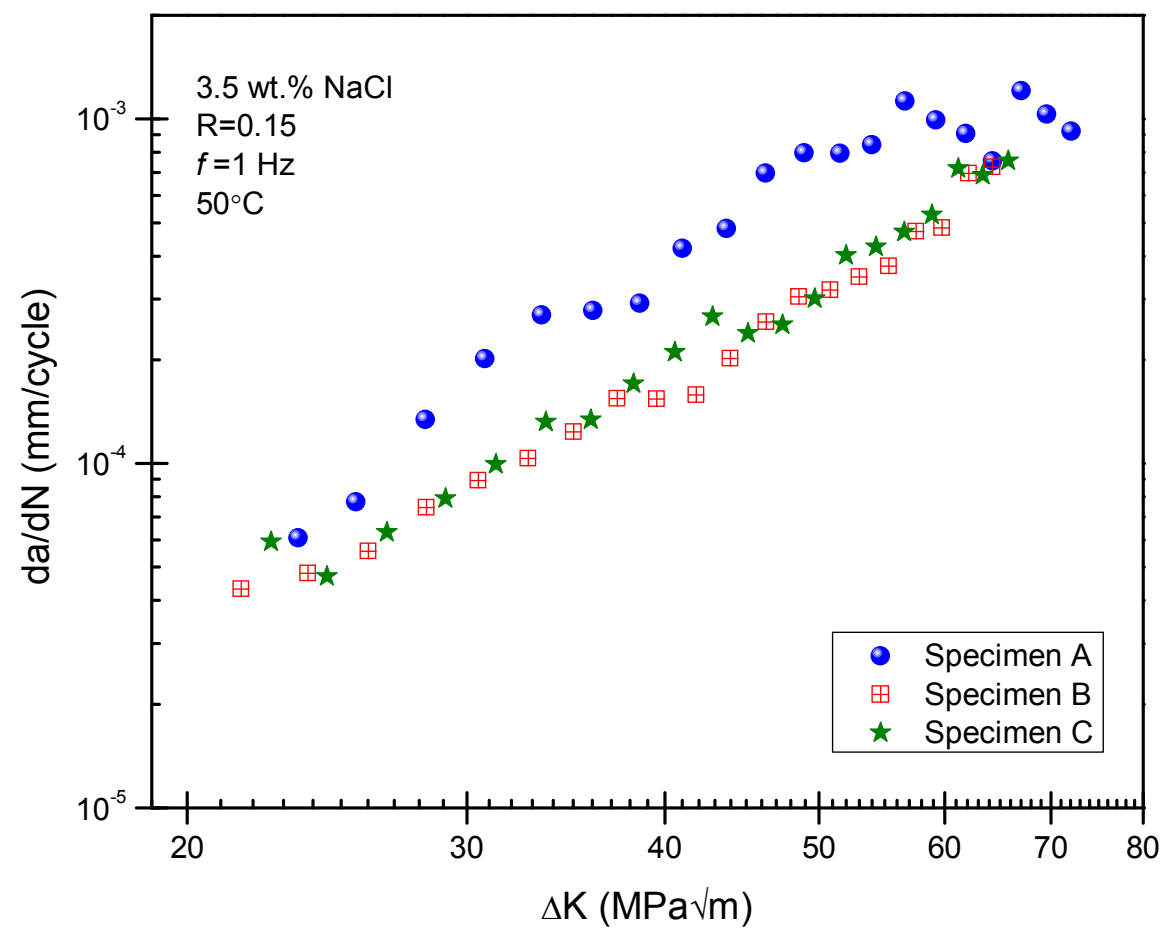

Figure 4.28 Aging treatment comparison in $3.5 \mathrm{wt} . \% \mathrm{NaCl}$ at $50^{\circ} \mathrm{C}$. 


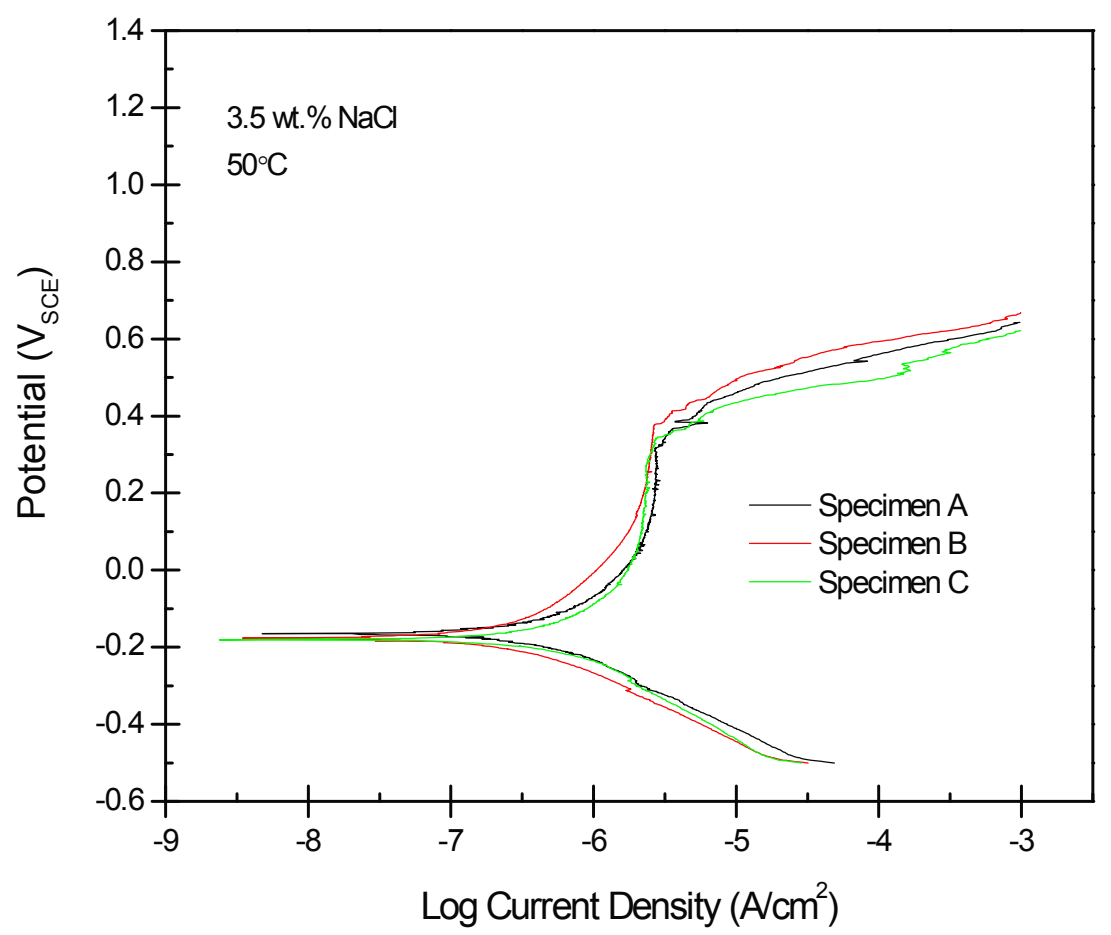

Figure 4.29 Potentiodynamic polarization curves for different aging treatments in $3.5 \mathrm{wt} \% \mathrm{NaCl}$ at $50^{\circ} \mathrm{C}$.

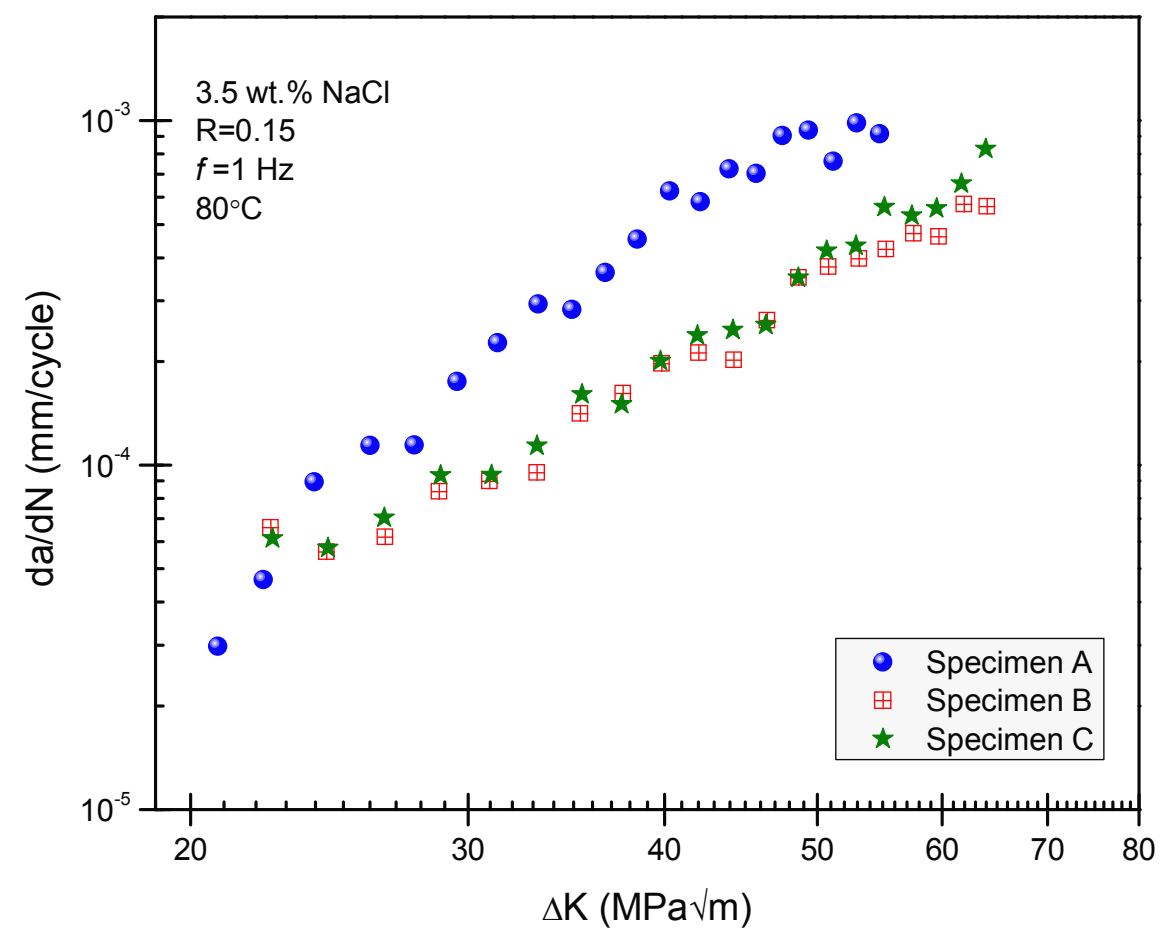

Figure 4.30 Aging treatment comparison in $3.5 \mathrm{wt} . \% \mathrm{NaCl}$ at $80^{\circ} \mathrm{C}$. 


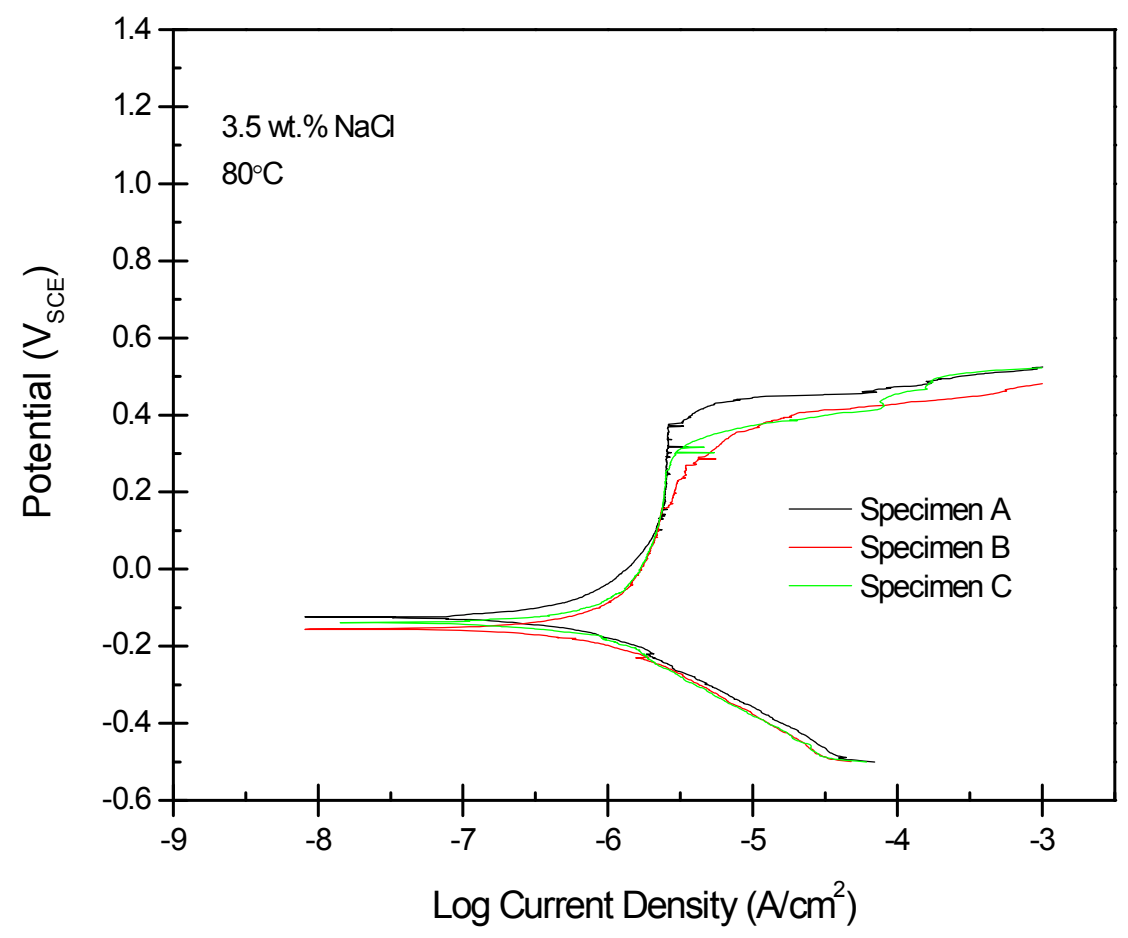

Figure 4.31 Potentiodynamic polarization curves for different aging treatments in $3.5 \mathrm{wt} \% \mathrm{NaCl}$ at $80^{\circ} \mathrm{C}$.

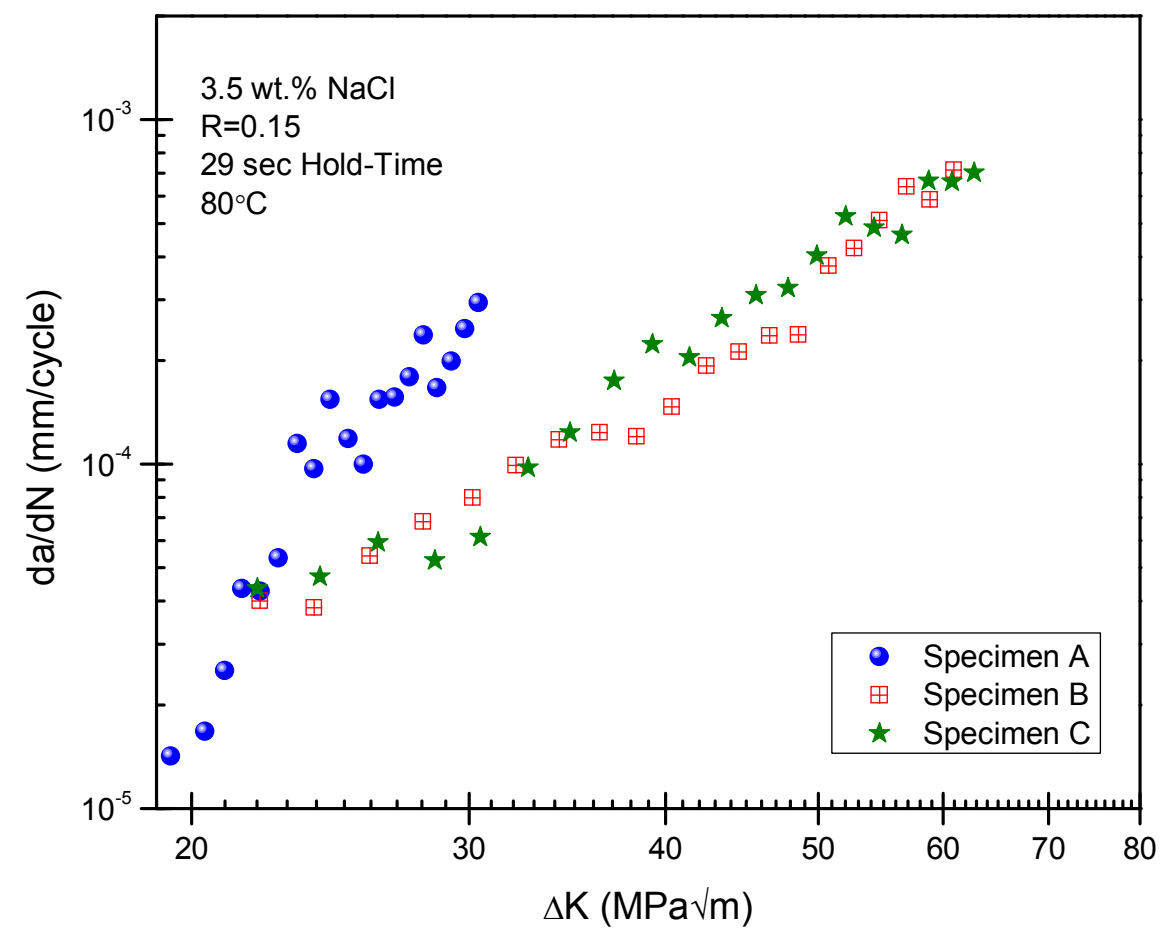

Figure 4.32 Aging treatment comparison under trapezoidal waveform in $3.5 \mathrm{wt} . \% \mathrm{NaCl}$ at $80^{\circ} \mathrm{C}$. 


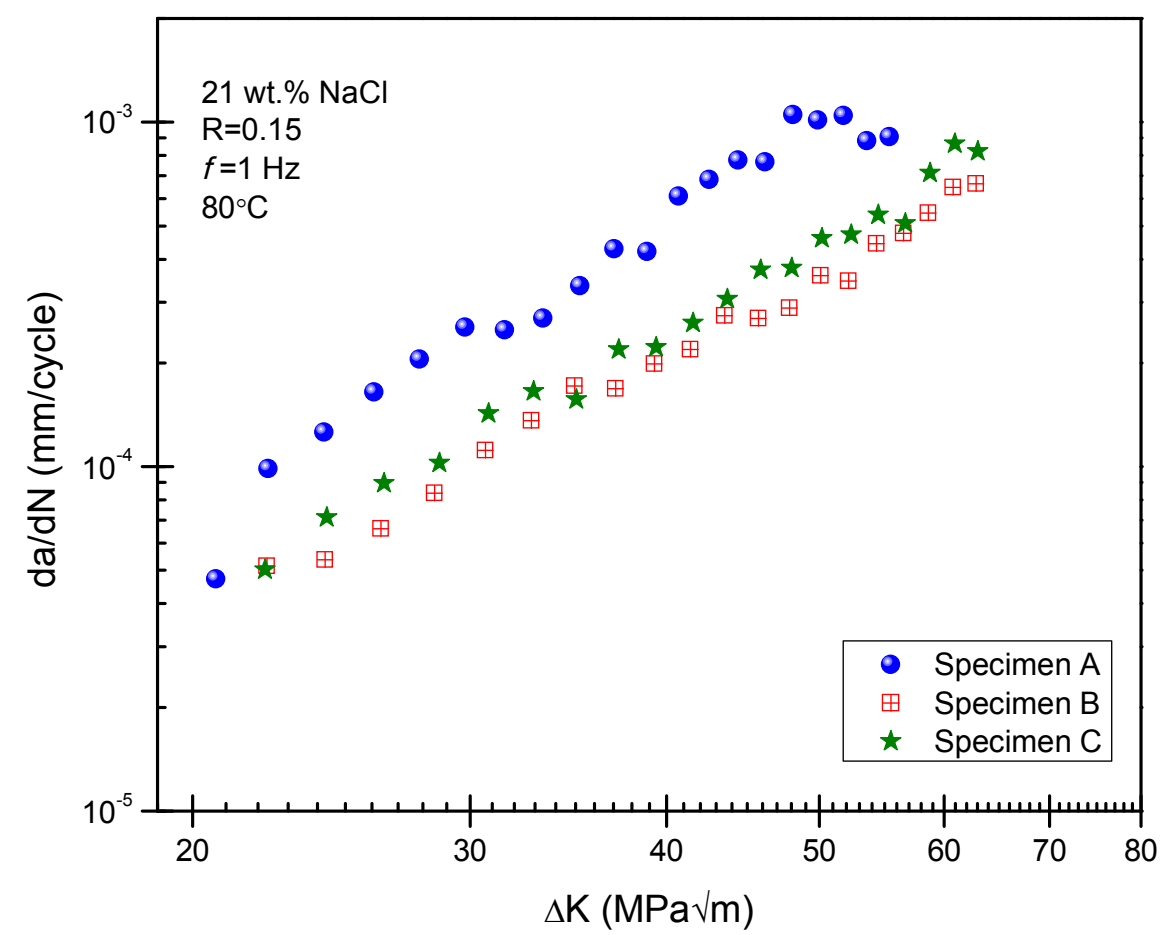

Figure 4.33 Aging treatment comparison in $21 \mathrm{wt} . \% \mathrm{NaCl}$ at $80^{\circ} \mathrm{C}$.

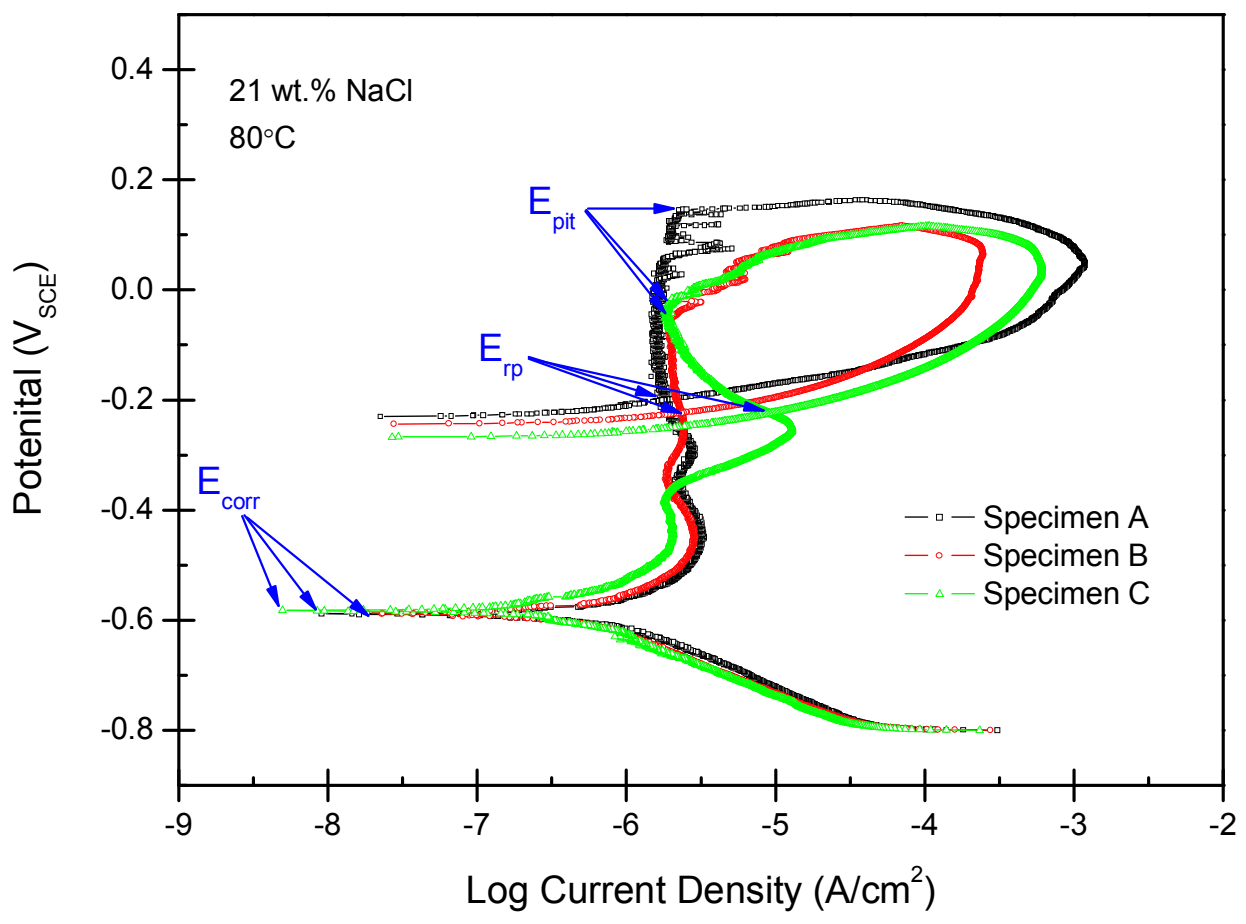

Figure 4.34 Potentiodynamic polarization curves of the different aging treatments in 21 wt.\% NaCl at $80^{\circ} \mathrm{C}$. 


\subsection{Fractography}

Scanning electron microscopy (SEM) observations show that the cracks propagated by a transgranular mode under all testing conditions. The fracture surfaces for Specimens A, B, and C in 3.5 wt.\% $\mathrm{NaCl}$ at $80^{\circ} \mathrm{C}$ under triangle and trapezoidal waveforms are shown in Figure 4.35, Figure 4.36, and Figure 4.37 respectively. As the crack propagates from left to right, striations corresponding to the crack growth rate were observed along the $\{111\}$ crystallographic fracture planes shown in Figure 4.38 for Specimen $\mathrm{A}$ under triangular waveform loading in $3.5 \mathrm{wt} . \% \mathrm{NaCl}$ at $80^{\circ} \mathrm{C}$. Striations were also observed for Specimen A under trapezoidal waveform loading in the same conditions shown in Figure 4.39. These features were prevalent as well as smooth and planar facets for all of the tested specimens. These results are typical for alloy 718 at this temperature range [71-75]. More detailed investigations on the role of slip mode on CFCP and SCC can be found in references [72, 74-79].

(a)

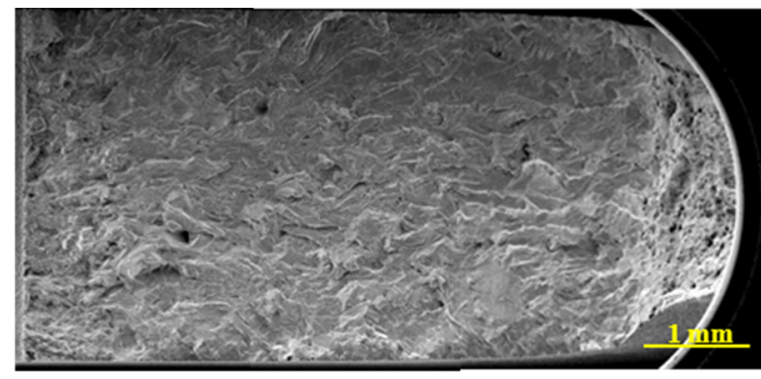

(b)

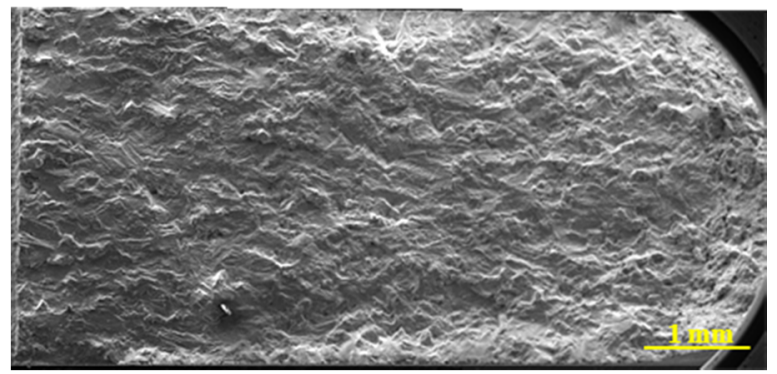

Figure 4.35 Fracture surface of Specimen A in $3.5 \mathrm{wt} . \% \mathrm{NaCl}$ at $80^{\circ} \mathrm{C}$ under (a) triangle waveform and (b) trapezoidal waveform loading. 
(a)

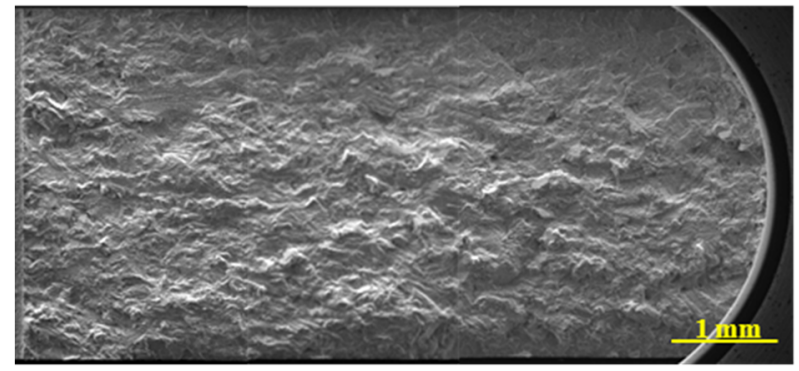

(b)

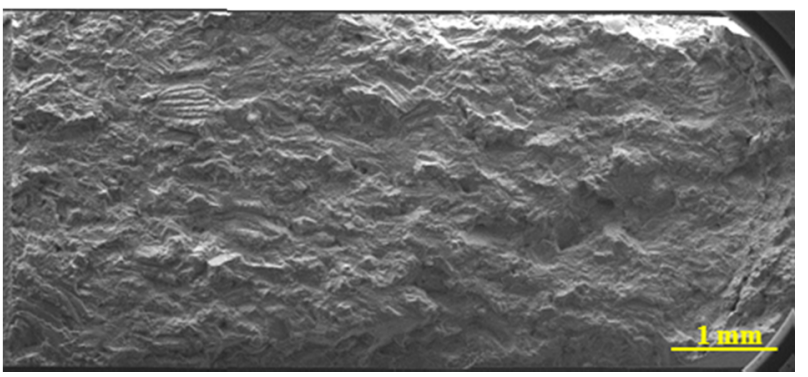

Figure 4.36 Fracture surface of Specimen B in $3.5 \mathrm{wt} . \% \mathrm{NaCl}$ at $80^{\circ} \mathrm{C}$ under (a) triangle waveform and (b) trapezoidal waveform loading.

(a)

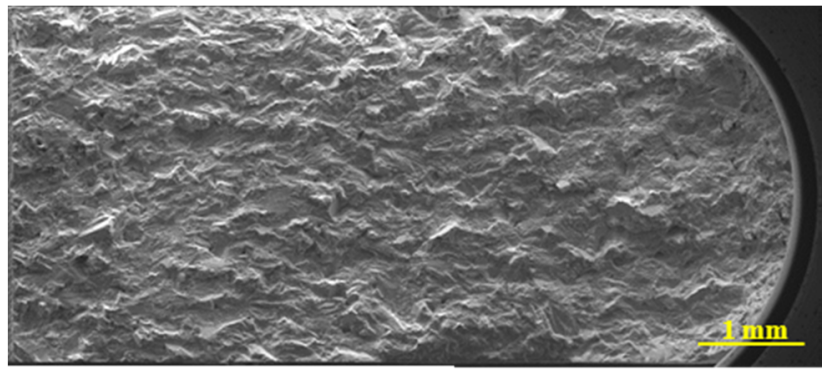

(b)

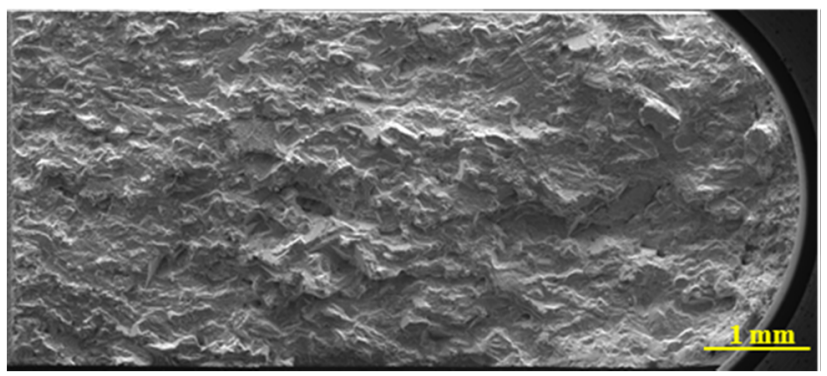

Figure 4.37 Fracture surface of Specimen $\mathrm{C}$ in $3.5 \mathrm{wt} . \% \mathrm{NaCl}$ at $80^{\circ} \mathrm{C}$ under (a) triangle waveform and (b) trapezoidal waveform loading. 

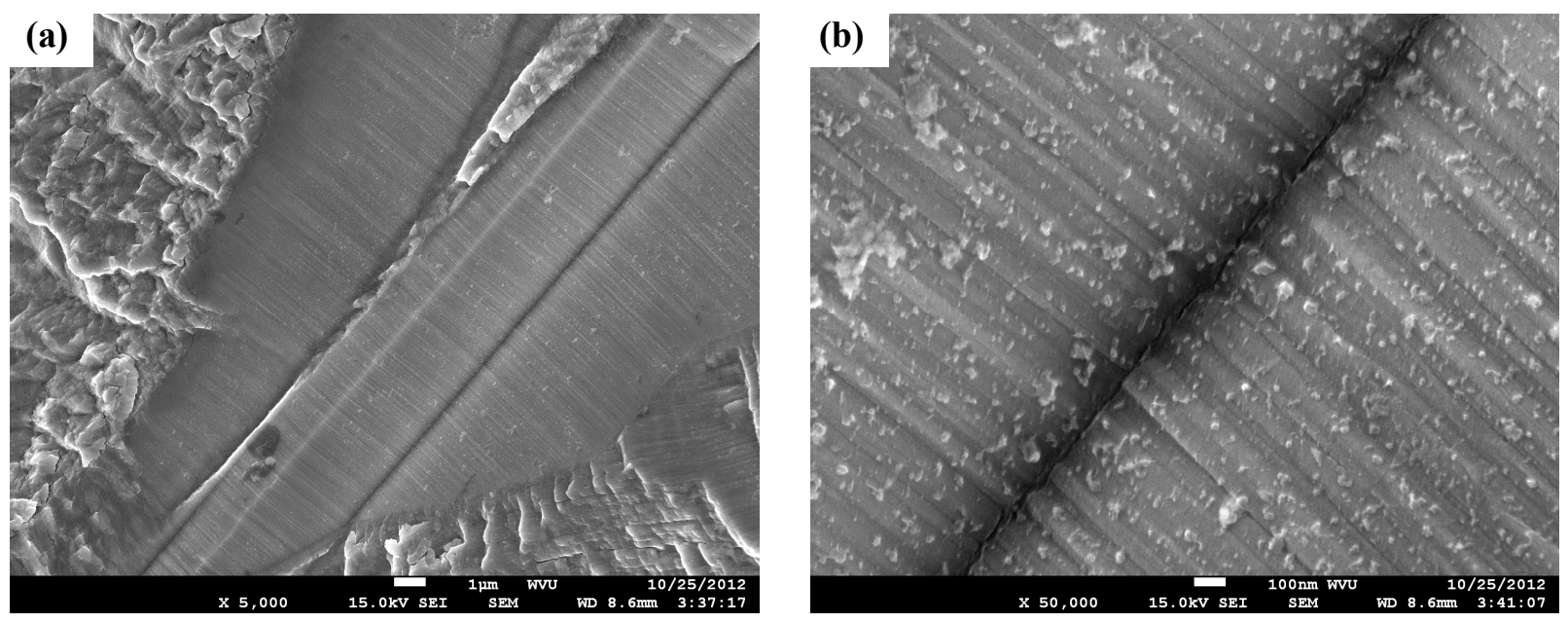

Figure 4.38 SEM of striations on Specimen A fracture surface observed at $80^{\circ} \mathrm{C}$ in $3.5 \mathrm{wt} . \% \mathrm{NaCl}$ under triangle waveform loading at (a) 5,000x and (b) 50,000x magnification.
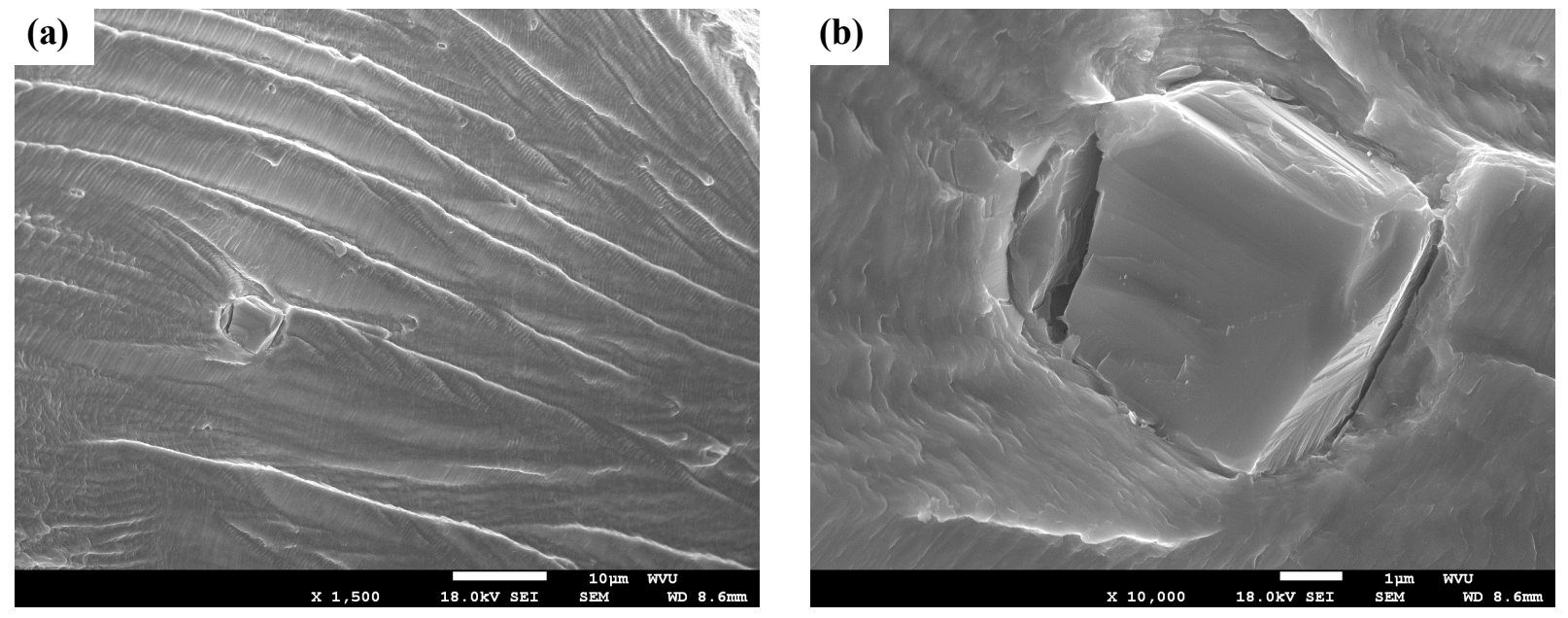

Figure 4.39 SEM of striations near an inclusion on Specimen A fracture surface observed at $80^{\circ} \mathrm{C}$ in 3.5 wt.\% NaCl under trapezoidal waveform loading at (a) 1,500x and (b) 10,000x magnification. 


\section{Chapter 5: Conclusion}

The microstructure revealed sparse amounts of inclusions spread throughout the grains and grain boundaries including nitrides, carbides and globular delta phases for all aging treatments. After aging treatment, gamma prime and double prime precipitates were formed in the gamma matrix, as well as, discontinuous platelet shaped delta phases formed along the grain boundary. However, the precipitations are much smaller for the two-step aging treatment than the one-step aging treatment.

The CFCP results show that there is no obvious effect of $3.5 \mathrm{wt} . \% \mathrm{NaCl}$ solution on the CFCG rates of oil-grade alloy 718 in all three different aged conditions. However, the crack growth rate increased in $21 \mathrm{wt} . \% \mathrm{NaCl}$ for all of the specimens compared with the tests in air and $3.5 \mathrm{wt} . \% \mathrm{NaCl}$, and are more pronounced in the lower $\Delta K$ regions where the effects of stress and strain on the crack tip are less dominate. Moreover, aging treatments lead to lower CFCG rates of oil-grade alloy 718 in all tested conditions including air. Finally, SEM observations revealed that the cracks propagated by a transgranular mode under all testing conditions. 


\section{References}

[1] D. H. Kang, J. K. Lee, and T. W. Kim, "Corrosion fatigue crack propagation in a heat affected zone of high-performance steel in an underwater sea environment," Engineering Failure Analysis, vol. 18, pp. 557-563, Mar 2011.

[2] S. A. Shipilov, "Mechanisms for corrosion fatigue crack propagation," Fatigue \& Fracture of Engineering Materials \& Structures, vol. 25, pp. 243-259, Mar 2002.

[3] Z. F. Yin, W. Z. Zhao, W. Y. Lai, and X. H. Zhao, "Electrochemical behaviour of Ni-base alloys exposed under oil/gas field environments," Corrosion Science, vol. 51, pp. 1702-1706, Aug 2009.

[4] W. M. Zhao, R. F. Xin, Z. R. He, and Y. Wang, "Contribution of anodic dissolution to the corrosion fatigue crack propagation of $\mathrm{X} 80$ steel in $3.5 \mathrm{wt}$.\% NaCl solution," Corrosion Science, vol. 63, pp. 387-392, Oct 2012.

[5] S. A. McCoy, B. C. Puckett, and E. L. Hibner. (2007, High Performance Age-Harden able Nickel Alloys Solve Problems in Sour Oil and Gas Service. Available:

http://www.specialmetals.com/documents/High\%20Performance\%20Age-

Hardenable\%20Nickel\%20Alloys\%20Solve\%20Problems\%20in\%20Sour\%200il\%20\&\%20Gas\%20

Service.pdf

[6] P. R. Rhodes, "Environment-assisted cracking of corrosion-resistant alloys in oil and gas production environments: A review," Corrosion, vol. 57, pp. 923-966, Nov 2001.

[7] R. Ayer, R. R. Mueller, J. Y. Koo, and M. Watkins, "Acceptability criteria for alloy 718 for use in sour service," in Proceedings of the Thirteenth, J. S. Chung, J. Wardenier, R. M. W. Frederking, and W. Koterayama, Eds., ed, 2003, pp. 75-82.

[8] J. L. do Nascimento, C. Barbosa, and J. L. Fernandes, "Effect of Different Heat Treatment Conditions on the Microstructure and Mechanical Properties of Inconel 718 Nickel Based Super Alloy Used in Petroleum Production," Praktische Metallographie-Practical Metallography, vol. 46, pp. 640-+, Dec 2009.

[9] J. Kolts, "Alloy 718 for the Oil and Gas Industry," presented at the Superalloy 718 Metallurgy and Applications, 1989.

[10] O. A. Onyewuenyi, "Alloy 718 - Alloy Optimization for Applications in Oil and Gas Production," presented at the Superalloy 718 - Metallurgy and Applications, 1989.

[11] R. B. Bhavsar, A. Collins, and S. Silverman, Use of alloy 718 and 725 in oil and gas industry. Warrendale: Minerals, Metals \& Materials Soc, 2001.

[12] J. deBarbadillo and S. K. Mannan, "Alloy 718 for Oilfield Applications," Jom, vol. 64, pp. 265-270, Feb 2012.

[13] "API Standard 6A718," in Nickel-Base Alloy 718 (UNS N07718) for Oil and Gas Drilling and Production Equipment, ed. Washington, DC: API Publishing Services, 2009.

[14] M. J. Donachie, Superalloys: A Technical Guide, Second Edition: ASM International, 2002.

[15] R. C. Reed, The superalloys : fundamentals and applications: Cambridge University Press, 2006.

[16] L. Fournier, D. Delafosse, and T. Magnin, "Cathodic hydrogen embrittlement in alloy 718," Materials Science and Engineering a-Structural Materials Properties Microstructure and Processing, vol. 269, pp. 111-119, Aug 1999.

[17] T. Cassagne, M. Bonis, D. Hillis, and C. Duret, "Understanding Field Failures of Alloy 718 Forging Materials in HP/HT Wells," presented at the EUROCORR 2008, Edinburgh, UK, 2008.

[18] S. Huizinga, B. McLoughlin, W. E. Liek, and J. G. DeJong, "Offshore Nickel Alloy Tubing Hanger and Duplex Stainless Steel Piping Failure Investingations," presented at the Corrosion 2003, San Diego, CA, 2003. 
[19] "Aerospace Material Specification 5662L," in Nickel Alloy Corrosion and Heat Resistant Bars, Forgings, and Rings, ed: SAE, 2000.

[20] B. F. Brown, C. T. Fujii, and E. P. Dahlberg, "Methods for Studying the Solution Chemistry Within Stress Corrosion Cracks," Journal of The Electrochemical Society, vol. 116, pp. 218-219, February 1, 19691969.

[21] K. R. Cooper and R. G. Kelly, "Using capillary electrophoresis to study the chemical conditions within cracks in aluminum alloys," Journal of Chromatography A, vol. 850, pp. 381-389, Jul 30 1999.

[22] K. R. Cooper and R. G. Kelly, "Crack tip chemistry and electrochemistry of environmental cracks in AA 7050," Corrosion Science, vol. 49, pp. 2636-2662, Jun 2007.

[23] V. V. Panasyuk, L. V. Ratych, and I. N. Dmytrakh, "FATIGUE CRACK-GROWTH IN CORROSIVE ENVIRONMENTS," Fatigue of Engineering Materials and Structures, vol. 7, pp. 1-11, 19841984.

[24] G. Sandoz, C. T. Fujii, and B. F. Brown, "SOLUTION CHEMISTRY WITHIN STRESS-CORROSION CRACKS IN ALLOY STEELS," Corrosion Science, vol. 10, pp. 839-\&, 19701970.

[25] A. Turnbull, "Modeling of the chemistry and electrochemistry in cracks - A review," Corrosion, vol. 57, pp. 175-189, Feb 2001.

[26] A. Turnbull, A. S. Dolphin, and F. A. Rackley, "EXPERIMENTAL-DETERMINATION OF THE ELECTROCHEMISTRY IN CORROSION FATIGUE CRACKS IN STRUCTURAL-STEEL IN ARTIFICIAL SEAWATER," Corrosion, vol. 44, pp. 55-61, Jan 1988.

[27] N. J. H. Holroyd and G. M. Scamans, "Stress Corrosion Cracking in Al-Zn-Mg-Cu Aluminum Alloys in Saline Environments," Metallurgical and Materials Transactions a-Physical Metallurgy and Materials Science, vol. 44A, pp. 1230-1253, Mar 2013.

[28] L. Liu, Y. Li, and F. Wang, "Influence of micro-structure on corrosion behavior of a Ni-based superalloy in 3.5\% NaCl," Electrochimica Acta, vol. 52, pp. 7193-7202, Sep 2007.

[29] N. El-Bagoury, M. A. Amin, and Q. Mohsen, "Effect of Various Heat Treatment Conditions on Microstructure, Mechanical Properties and Corrosion Behavior of Ni Base Superalloys," International Journal of Electrochemical Science, vol. 6, pp. 6718-6732, Dec 2011.

[30] J. M. Barsom, "MECHANISMS OF CORROSION FATIGUE BELOW KISCC," International Journal of Fracture Mechanics, vol. 7, pp. 163-182, 19711971.

[31] A. Astarita, A. Scala, A. Squillace, M. lodice, T. Monetta, D. B. Mitton, and F. Bellucci, "A NEW APPROACH IN THE MONITORING OF METAL COUPON SUBJECTED AT FATIGUE LOAD IN AGGRESSIVE SOLUTION," International Journal of Material Forming, vol. 3, pp. 203-206, Apr 2010.

[32] Z. F. Wang, J. Li, J. Q. Wang, and W. Ke, "The influence of loading waveform on corrosion fatigue crack propagation," Corrosion Science, vol. 37, pp. 1551-1565, 1995.

[33] R. P. Gangloff, "Environmental Cracking-Corrosion Fatigue," in Corrosion Tests and Standards: Applications and Interpretation, R. Baboian, Ed., 2nd ed West Conshohocken, PA: ASTM International, 2005, pp. 302-321.

[34] T. Magnin, "Corrosion Fatigue Mechanisms in Metallic Materials," in Corrosion Mechanisms in Theory and Practice, P. Marcus, Ed., ed: CRC Press, 2002, pp. 451-478

[35] X. C. Li, R. L. Eadie, and J. L. Luo, "Influence of plasticity on corrosion and stress corrosion cracking behaviour in near neutral pH environment," Corrosion Engineering Science and Technology, vol. 43, pp. 297-303, Dec 2008.

[36] J. Schijve, "Fatigue as a Phenomenon in the Material," in Fatigue of Structures and Materials, 2nd ed: Springer Science+Business Media, 2009, pp. 13-58.

[37] K. Sadananda and A. K. Vasudevan, "Review of Environmentally Assisted Cracking," Metallurgical and Materials Transactions a-Physical Metallurgy and Materials Science, vol. 42A, pp. 279-295, Feb 2011. 
[38] H. Sheng, C. F. Dong, K. Xiao, X. G. Li, and L. Lu, "Anodic dissolution of a crack tip at AA2024-T351 in 3.5wt\% $\mathrm{NaCl}$ solution," International Journal of Minerals Metallurgy and Materials, vol. 19, pp. 939-944, Oct 2012.

[39] A. I. Asphahani and N. Sridhar, "CORROSION FATIGUE OF NICKEL AND NICKEL-BASE ALLOYS," Corrosion, vol. 38, pp. 587-595, 19821982.

[40] B. G. Ateya and H. W. Pickering, "THE DISTRIBUTION OF ANODIC AND CATHODIC REACTION SITES DURING ENVIRONMENTALLY ASSISTED CRACKING," Corrosion Science, vol. 37, pp. 14431453, Sep 1995.

[41] L. Liu, Y. Li, and F. H. Wang, "Influence of micro-structure on corrosion behavior of a Ni-based superalloy in 3.5\% NaCl," Electrochimica Acta, vol. 52, pp. 7193-7202, Sep 2007.

[42] R. Rungta and J. A. Begley, "EFFECT OF CATHODIC POTENTIAL ON CORROSION FATIGUE CRACK GROWTH-RATES OF A NI-CR-MO-V TURBINE DISK STEEL IN ROOM-TEMPERATURE CAUSTIC ENVIRONMENT," Metallurgical Transactions a-Physical Metallurgy and Materials Science, vol. 11, pp. 821-830, 1980.

[43] W. T. Tsai and C. H. Chou, "Corrosion fatigue crack growth behavior of nickel base alloys in sodium thiosulfate solution," Materials Science and Engineering a-Structural Materials Properties Microstructure and Processing, vol. 288, pp. 5-11, Aug 312000.

[44] J. M. Barsom, "Corrosion-fatigue crack propagation below KISCC," Engineering Fracture Mechanics, vol. 3, pp. 15-25, 1971.

[45] C.-K. Lin and C.-H. Chiu, "Low-cycle fatigue behavior of AISI 347 stainless steel in salt water," Journal of Materials Science, vol. 42, pp. 40-49, Jan 2007.

[46] A. Saxena, P. K. Liaw, and J. D. Landes, "THE INFLUENCE OF WAVE-FORM AND LONG HOLD TIME ON THE CORROSION FATIGUE CRACK-GROWTH BEHAVIOR OF AN AUSTENITIC STEEL," Materials Science and Engineering, vol. 95, pp. 137-143, Nov 1987.

[47] C. K. Lin, W. C. Fan, and W. J. Tsai, "Corrosion fatigue of precipitation-hardening martensitic stainless steel," Corrosion, vol. 58, pp. 904-911, Nov 2002.

[48] O. Vosikovsky, W. R. Neill, D. A. Carlyle, and A. Rivard, "THE EFFECT OF SEA-WATER TEMPERATURE ON CORROSION FATIGUE-CRACK GROWTH IN STRUCTURAL-STEELS," Canadian Metallurgical Quarterly, vol. 26, pp. 251-257, Jul-Sep 1987.

[49] H. Sun, X. Wu, and E.-H. Han, "Effects of temperature on the protective property, structure and composition of the oxide film on Alloy 625," Corrosion Science, vol. 51, pp. 2565-2572, Nov 2009.

[50] S. Y. Cho, C. H. Kim, and D. H. Bae, "A study on the corrosion fatigue characteristics of $12 \mathrm{Cr}$ alloy steel," in Fracture and Strength of Solids, Pts 1 and 2. vol. 183-1, W. Hwang and K. S. Han, Eds., ed, 2000, pp. 993-998.

[51] Y. Nakai, A. Alavi, and R. P. Wei, "EFFECTS OF FREQUENCY AND TEMPERATURE ON SHORT FATIGUE CRACK-GROWTH IN AQUEOUS ENVIRONMENTS," Metallurgical Transactions a-Physical Metallurgy and Materials Science, vol. 19, pp. 543-548, Mar 1988.

[52] J. B. Duh, W. T. Tsai, J. T. Lee, and H. Chang, "EFFECT OF POTENTIAL ON THE CORROSION FATIGUE CRACK-GROWTH RATE OF FE-AL-MN ALLOY IN 3.5-PERCENT-NACL SOLUTION," Corrosion, vol. 46, pp. 983-988, Dec 1990.

[53] A. D. B. Gingell and J. E. King, "The effect of frequency and microstructure on corrosion fatigue crack propagation in high strength aluminium alloys," Acta Materialia, vol. 45, pp. 3855-3870, Sep 1997.

[54] V. Schroeder and R. O. Ritchie, "Stress-corrosion fatigue-crack growth in a Zr-based bulk amorphous metal," Acta Materialia, vol. 54, pp. 1785-1794, Apr 2006.

[55] L. Weng, J. Zhang, S. Kalnaus, M. Feng, and Y. Jiang, "Corrosion fatigue crack growth of AISI 4340 steel," International Journal of Fatigue, vol. 48, pp. 156-164, Mar 2013. 
[56] J. T. Ho and G. P. Yu, "FATIGUE BEHAVIOR OF ALLOY-600 IN NACL SOLUTION AT ROOMTEMPERATURE," Journal of Nuclear Materials, vol. 226, pp. 226-237, Oct 1995.

[57] F. Menan and G. Henaff, "Influence of frequency and exposure to a saline solution on the corrosion fatigue crack growth behavior of the aluminum alloy 2024," International Journal of Fatigue, vol. 31, pp. 1684-1695, Nov-Dec 2009.

[58] F. Menan and G. Henaff, "Influence of frequency and waveform on corrosion fatigue crack propagation in the 2024-T351 aluminium alloy in the S-L orientation," Materials Science and Engineering a-Structural Materials Properties Microstructure and Processing, vol. 519, pp. 70-76, Aug 302009.

[59] F. Menan and G. Henaff, "Synergistic action of fatigue and corrosion during crack growth in the 2024 aluminium alloy," in Fatigue 2010. vol. 2, P. Lukas, Ed., ed, 2010, pp. 1441-1450.

[60] R. S. Piascik and R. P. Gangloff, "ENVIRONMENTAL FATIGUE OF AN AL-LI-CU ALLOY .1. INTRINSIC CRACK-PROPAGATION KINETICS IN HYDROGENOUS ENVIRONMENTS," Metallurgical Transactions a-Physical Metallurgy and Materials Science, vol. 22, pp. 2415-2428, Oct 1991.

[61] J. S. Warner and R. P. Gangloff, "Alloy induced inhibition of fatigue crack growth in agehardenable Al-Cu Alloys," International Journal of Fatigue, vol. 42, pp. 35-44, Sep 2012.

[62] T. P. Hoar, "The Production and Breakdown of the Passivity of Metals," Corrosion Science, vol. 7, pp. 341-355, 1967.

[63] S. H. Zhang, T. Shibata, and T. Haruna, "Inhibition effect of metal cations to intergranular stress corrosion cracking of sensitized Type 304 stainless steel," Corrosion Science, vol. 47, pp. 10491061, Apr 2005.

[64] ThyssenKrupp. (March 2003). Nicrofer 5219 Nb - Alloy 718. Available: http://www.outokumpu.com/SiteCollectionDocuments/VDM\%20Data\%20Sheet\%20Nicrofer\%2 05219\%20Nb_e.pdf

[65] X. Liu, J. Xu, E. Barbero, W.-D. Cao, and R. L. Kennedy, "Effect of thermal treatment on the fatigue crack propagation behavior of a new Ni-base superalloy," Materials Science and Engineering a-Structural Materials Properties Microstructure and Processing, vol. 474, pp. 30-38, Feb 152008.

[66] X. B. Liu, B. Kang, and K. M. Chang, "The effect of hold-time on fatigue crack growth behaviors of WASPALOY alloy at elevated temperature," Materials Science and Engineering a-Structural Materials Properties Microstructure and Processing, vol. 340, pp. 8-14, Jan 2003.

[67] T. L. Anderson, Fracture Mechanics: Fundamentals and Applications, 2 ed.: CRC Press Inc, 1995.

[68] H. Tada, P. C. Paris, and G. R. Irwin, The Stress Analysis of Cracks Handbook, 2nd ed. St. Louis, MO: Paris Prodctions, Inc, 1985.

[69] M. Khan. (2009). Search closest value in a vector [MATLAB Function]. Available: http://www.mathworks.com/matlabcentral/fileexchange/15088-search-closest-value-in-avector

[70] B. MacDougall, "EFFECT OF CHLORIDE-ION ON THE LOCALIZED BREAKDOWN OF NICKEL-OXIDE FILMS," Journal of The Electrochemical Society, vol. 126, pp. 919-925, 1979.

[71] M. Clavel and A. Pineau, "FREQUENCY AND WAVE-FORM EFFECTS ON FATIGUE CRACK GROWTHBEHAVIOR OF ALLOY 718 AT 298-K AND 823-K," Metallurgical Transactions a-Physical Metallurgy and Materials Science, vol. 9, pp. 471-480, 19781978.

[72] D. L. Davidson and J. Lankford, "FATIGUE CRACK-GROWTH IN METALS AND ALLOYS MECHANISMS AND MICROMECHANICS," International Materials Reviews, vol. 37, pp. 45-76, 19921992.

[73] D. Gopikrishna, S. N. Jha, and L. N. Dash, Influence of microstructure on fatigue properties of alloy 718, 1996. 
[74] C. Mercer and W. O. Soboyejo, Fatigue crack growth mechanisms in a forged IN 718 nickel-based superalloy, 1996.

[75] W. J. Mills and C. M. Brown, Fatigue fracture surface morphology for Alloy 718, 2001.

[76] S. Kalluri, K. B. S. Rao, G. R. Halford, and M. A. McGaw, DEFORMATION AND DAMAGE MECHANISMS IN INCONEL-718 SUPERALLOY, 1994.

[77] M. Sundararaman, P. Mukhopadhyay, and S. Banerjee, PRECIPITATION AND ROOM TEMPERATURE DEFORMATION BEHAVIOUR OF INCONEL-718, 1994.

[78] M. Sundararaman, P. Mukhopadhyay, and S. Banerjee, Carbide precipitation in nickel base superalloys 718 and 625 and their effect on mechanical properties, 1996.

[79] A. K. Vasudevan and K. Sadananda, "Role of Slip Mode on Stress Corrosion Cracking Behavior," Metallurgical and Materials Transactions a-Physical Metallurgy and Materials Science, vol. 42A, pp. 405-414, Feb 2011. 
Appendix 1

Data Processing

MATLAB Code 
ㄱared S. Nutter

oMaster's Thesis Project:

oCorrosion Fatigue Crack Propagation of Oil-Grade Alloy 718 in NaCl Solution

\%West Virginia University

Department of Mechanical and Aerospace Engineering

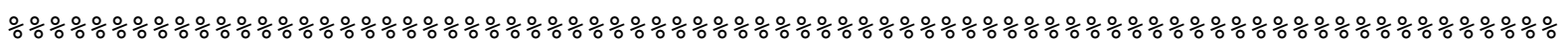

clc; close all; format compact; format long; clear all;

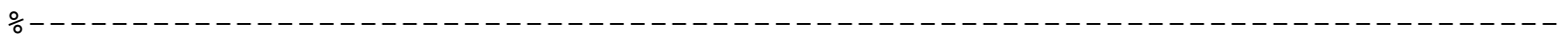

\%Required inputs from the sample, test, and data file names:

-Data Recording

$\mathrm{dn}=0.5$; $\%$ Number of cycles between FCG data points

dn_pre $=5$; №mber of cycles between pre-crack data points

a)_pre $=0.15$; $\%$ Pre-cut length (in)

ㄴoads

p_min_pre $=0.75$; \%Minimum load during pre-crack (kip)

p_max_pre $=1.45$; $\circ$ Maximum load during pre-crack (kip)

p_min $=0.3$; $\%$ Minimum load during fatigue test (kip)

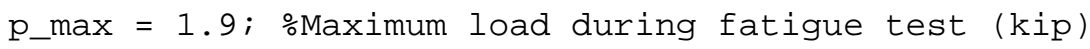

○ Sample Geometry

$y=0.015 ;$ oHalf probe span (in)

$\mathrm{w}=0.75 ; \% \mathrm{Width}$ (in)

$t=0.125 ;$ oThickness (in)

o Select crack region graphing options:

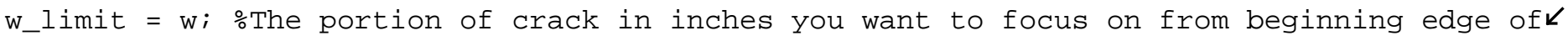
sample. (Enter "w" for entire crack)

del $=0$; $\%$ The number of RAW data points deleted from the beginning of the test.

del_dp $=0 ;$ 응 The number of averaged data points deleted from beginning of "limit" plot.

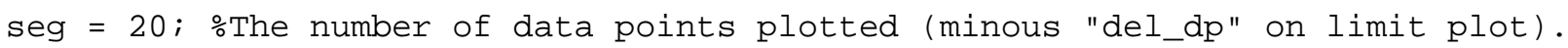

seg_length $=0.01 ;$ oDesired crack length between delta $\mathrm{K}$ points. (MUST set seg = 0)!!!!

oImports the pre-crack and FCG data from pure numeric .txt files (aka you must delete $\boldsymbol{L}$ the

oheadings in the . dat file and save as a .txt file)

data_pre = importdata ('MPM326_N2180_31_pre_NUM.txt') ;

data = importdata ('MPM326_N2180_31_cfcg_NUM.txt') ;

disp ('data loading complete')

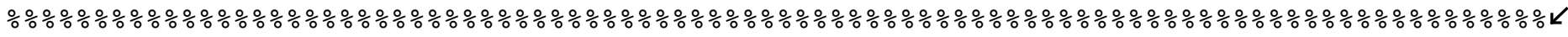

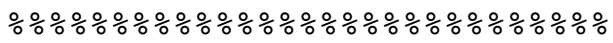

$\operatorname{disp}('$ ' )

uo_pre = data_pre $(1,1) / 1000 ;$ oDefines the starting voltage for the pre-cut length.

u_raw_pre $=$ data_pre $(:, 1) / 1000$; $\frac{0}{D e f i n e s ~ r a w ~ v o l t a g e ~ m a t r i x ~ f r o m ~ d a t a ~ f i l e . ~}$

n_pre = data_pre $(:, 3) / 2$; $\frac{0}{D e f i n e s ~ c y c l e ~ m a t r i x ~ f r o m ~ d a t a ~ f i l e . ~}$

\% a0_pre $=$ a0_pre*0.03937; \%Converts a0 from $\mathrm{mm}$ to in. 


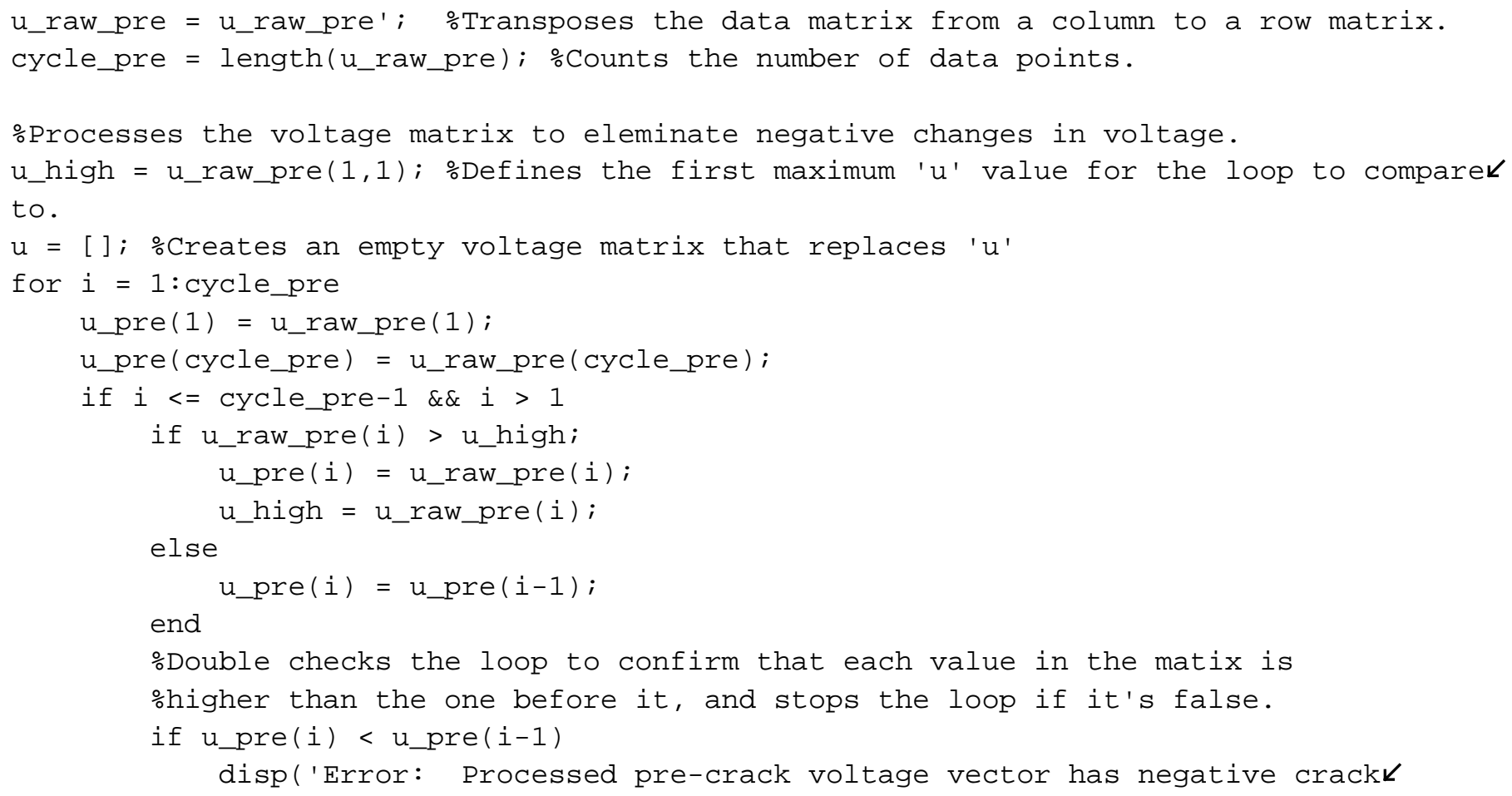


end

end

$$
\text { end }
$$

disp('pre-crack da complete')

k_max_pre $=[] ;$

k_min_pre $=[] ;$

dk_pre $=[]$;

for $i=1$ :cycle_pre

theta_pre $(i)=\left(p i * a \_p r e(i)\right) /(2 * w)$;

k_max_pre $(i)=\left(p \_m a x \_p r e /(t * \operatorname{sqrt}(w))\right) *\left(\operatorname{sqrt}\left(2 * t a n\left(t h e t a \_p r e(i)\right)\right) / \cos (\right.$ theta_pre $\left.(i))\right) k$

$*(0.752+2.02 *($ a_pre $(i) / w)+0.371 *(1-\sin ($ theta_pre $(i))) \wedge 3)$;

k_min_pre $(i)=($ p_min_pre $/(t * \operatorname{sqrt}(w))) *(\operatorname{sqrt}(2 * \tan ($ theta_pre $(i))) / \cos ($ theta_pre $(i))) \boldsymbol{K}$

$*\left(0.752+2.02 *\left(a \_p r e(i) / w\right)+0.371 *(1-\sin (\right.$ theta_pre $\left.(i))) \wedge 3\right)$;

dk_pre (i) = k_max_pre(i) -k_min_pre (i) ;

end

disp ('pre-crack dk complete')

disp('Pre-Crack data processing complete')

$\operatorname{disp}(', ')$

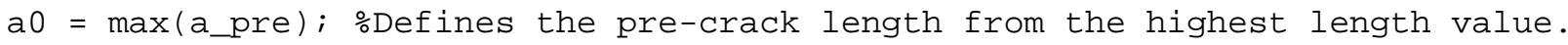

$\mathrm{u} 0=$ data $(1,1) / 1000 ;$ Defines the starting voltage for the pre-crack length calculated $\boldsymbol{K}$ above.

u_raw $=$ data $(:, 1) / 1000 ;$ Defines raw voltage matrix from data file.

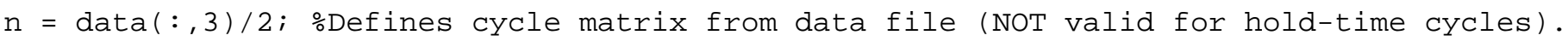

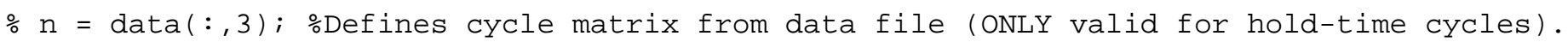

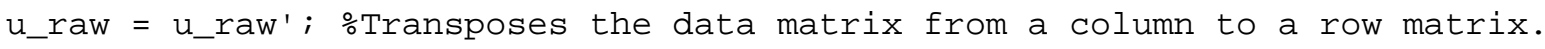

cycle = length(u_raw); ocounts the number of data points.

응은 This is only for the "BAD COUNT" hold-time data tests (T7-T10)!!!!!!!!!

$\circ \mathrm{N}=(\mathrm{cycle}-1) * \mathrm{dn}$;

$\div \mathrm{dN}=\operatorname{round}(\mathrm{cycle} / \mathrm{N})$;

$\circ \mathrm{n}=\operatorname{ones}(1$, cycle $)$;

$\circ \mathrm{n}((\mathrm{cycle}-\mathrm{dN}+1):$ cycle $)=\operatorname{ceil}(\mathrm{N})$;

for $i=d N+2: d N: c y c l e-d N$

$\mathrm{n}(i: i+\mathrm{dN})=((i-2) / \mathrm{dN})+1$;

응 end

OProcesses the voltage matrix to eleminate negative changes in voltage.

u_high = u_raw $(1,1)$; $\frac{0}{D e f i n e s}$ the first maximum 'u' value for the loop to compare to.

$\mathrm{u}=[]$; $\%$ Creates an empty voltage matrix that replaces 'u'

for $i=1:$ cycle

$$
\begin{aligned}
& \text { u (1) = u_raw (1); } \\
& u(\text { cycle) = u_raw (cycle); } \\
& \text { if } i<=\text { cycle-1 \&\& } i>1 \\
& \text { if u_raw(i) > u_high; } \\
& u(i)=u \_r a w(i) \text {; } \\
& \text { u_high = u_raw (i); } \\
& \text { else } \\
& u(i)=u(i-1) \text {; }
\end{aligned}
$$


end

oDouble checks the loop to confirm that each value in the matix is

ohigher than the one before it, and stops the loop if it's false.

if $u(i)<u(i-1)$

disp('Error: Processed FCG voltage vector has negative crack growth!!!!') end

end

end

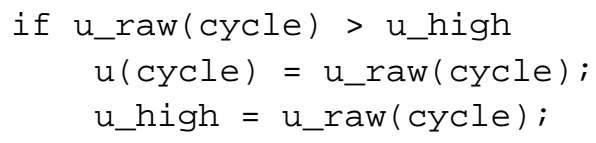

else

$\mathrm{u}(\mathrm{cycle})=\mathrm{u}(\mathrm{cycle}-1) ;$

end

if $u($ cycle $)<u($ cycle-1) ||$u(2)<u(1)$

disp('Error: Processed FCG voltage vector has negative crack growth at the $\boldsymbol{K}$ beginning or ending!!!!')

break

end

disp('Voltage process complete')

oCalculates the crack length and change in crack length from the voltage omatrix.

$\mathrm{a}=[] ;$ \%Creates an empty crack length matrix 'a'

da_cmp $=[]$; $\%$ Creates an empty change in crack length matrix 'da_cmp'

for $i=1:$ cycle

if $i<=$ cycle -1

$\mathrm{a}(1)=\left(\left(2{ }^{*} \mathrm{w}\right) / \mathrm{pi}\right) * \operatorname{acos}\left(\cosh \left(\left(\mathrm{pi}{ }^{*} \mathrm{y}\right) /\left(2{ }^{*} \mathrm{w}\right)\right) / \cosh \left((\mathrm{u}(1) / \mathrm{u} 0) * \operatorname{acosh}\left(\cosh \left(\left(\mathrm{pi}{ }_{\mathrm{y}}\right) / \boldsymbol{L}\right.\right.\right.\right.$

$\left.\left.\left.\left.\left(2 \star_{\mathrm{w}}\right)\right) / \cos \left(\left(\mathrm{pi} \star_{\mathrm{a} 0}\right) /\left(2{ }^{*} \mathrm{w}\right)\right)\right)\right)\right)$;

$\mathrm{a}(\mathrm{i}+1)=\left(\left(2 \star_{\mathrm{w}}\right) / \mathrm{pi}\right){ }^{*} \operatorname{acos}\left(\cosh \left(\left(\mathrm{pi}{ }^{\star} \mathrm{y}\right) /\left(2{ }^{*} \mathrm{w}\right)\right) / \cosh \left((\mathrm{u}(\mathrm{i}+1) / \mathrm{u}(\mathrm{i})){ }^{*} \operatorname{acosh}\left(\cosh \left(\left(\mathrm{p} i{ }^{*}\right) \boldsymbol{K}\right.\right.\right.\right.$

$\left.\left.\left.\left./\left(2 \star^{*}\right)\right) / \cos \left((p i \star a(i)) /\left(2 \star^{*}\right)\right)\right)\right)\right)$;

da_cmp $(i)=(a(i+1)-a(i)) / d n ; \% d a / d n$

if da_cmp(i) $<1 e-10$

da_cmp $(i)=0$;

end

end

end

$\mathrm{k} \_\max =[] ;$

k_min $=[] ;$

$\mathrm{dk} \_\mathrm{cmp}=[] ;$

for $i=1:$ cycle

theta $(i)=(p i * a(i)) /(2 * w) ;$

$k \_\max (i)=\left(p \_\max /(t * \operatorname{sqrt}(w))\right) *(\operatorname{sqrt}(2 * \tan (\operatorname{theta}(i))) / \cos (\operatorname{theta}(i))) *(0.752+2.02 *(a k$

(i) $/ \mathrm{w})+0.371 *(1-\sin ($ theta $(i))) \wedge 3)$;

$k \_\min (i)=($ p_min $/(t * \operatorname{sqrt}(w))) *(\operatorname{sqrt}(2 * \tan (\operatorname{theta}(i))) / \cos (\operatorname{theta}(i))) *(0.752+2.02 *(a k$

(i) $/ \mathrm{w})+0.371 *(1-\sin (\operatorname{theta}(i))) \wedge 3)$;

$\mathrm{dk \_ cmp}(i)=\mathrm{k} \_\max (i)-\mathrm{k} \_$min $(i)$;

end 


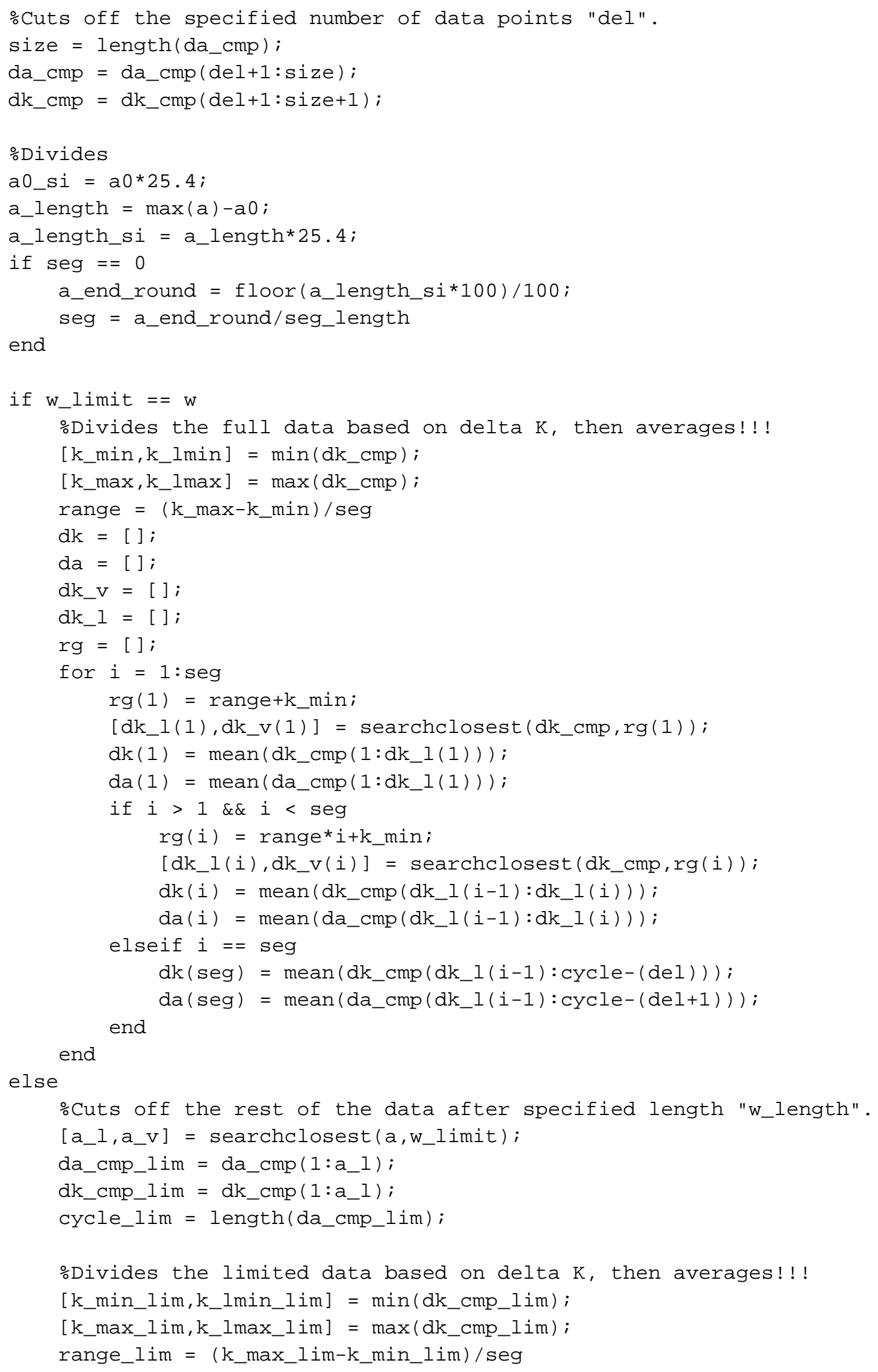




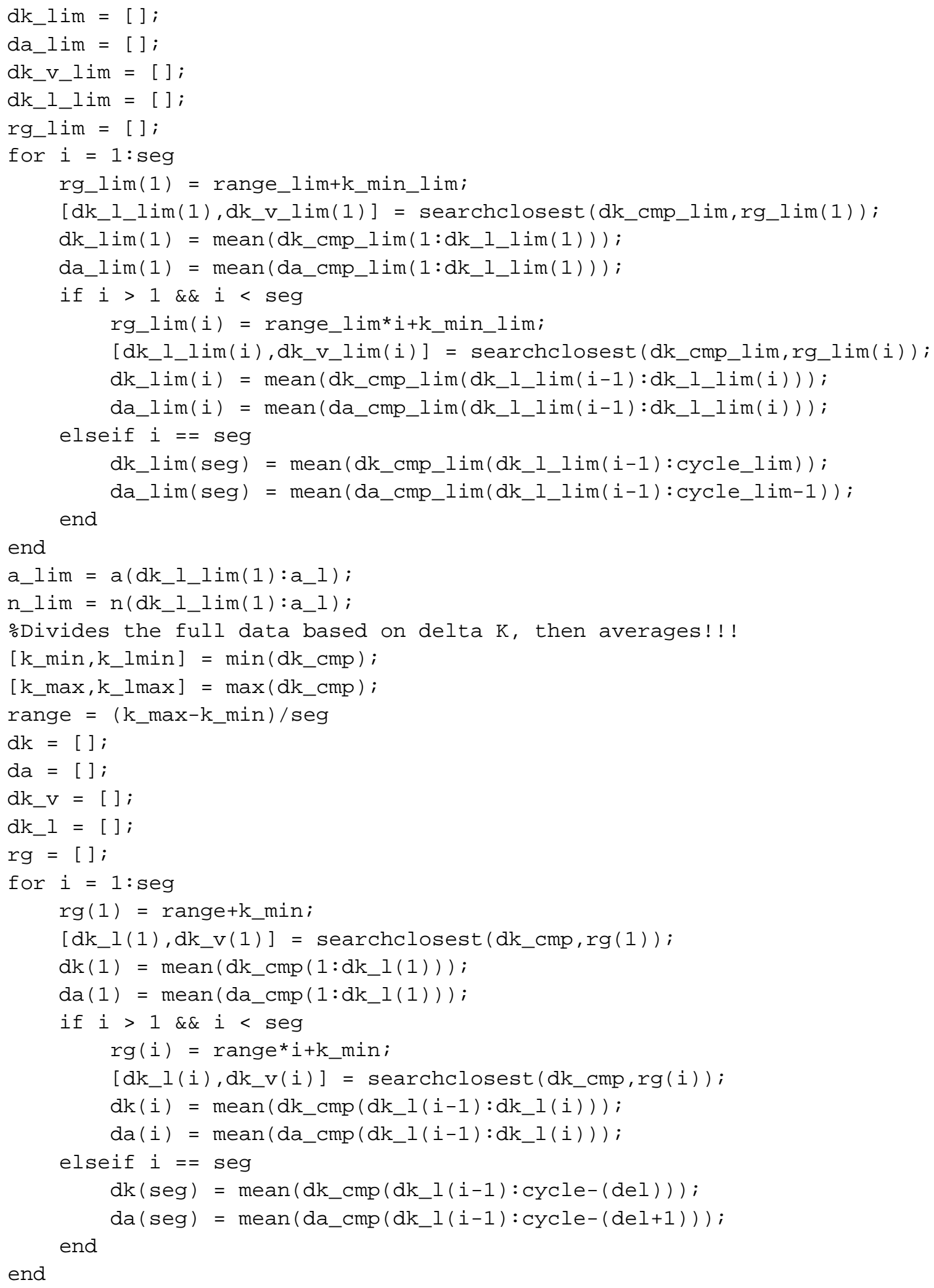




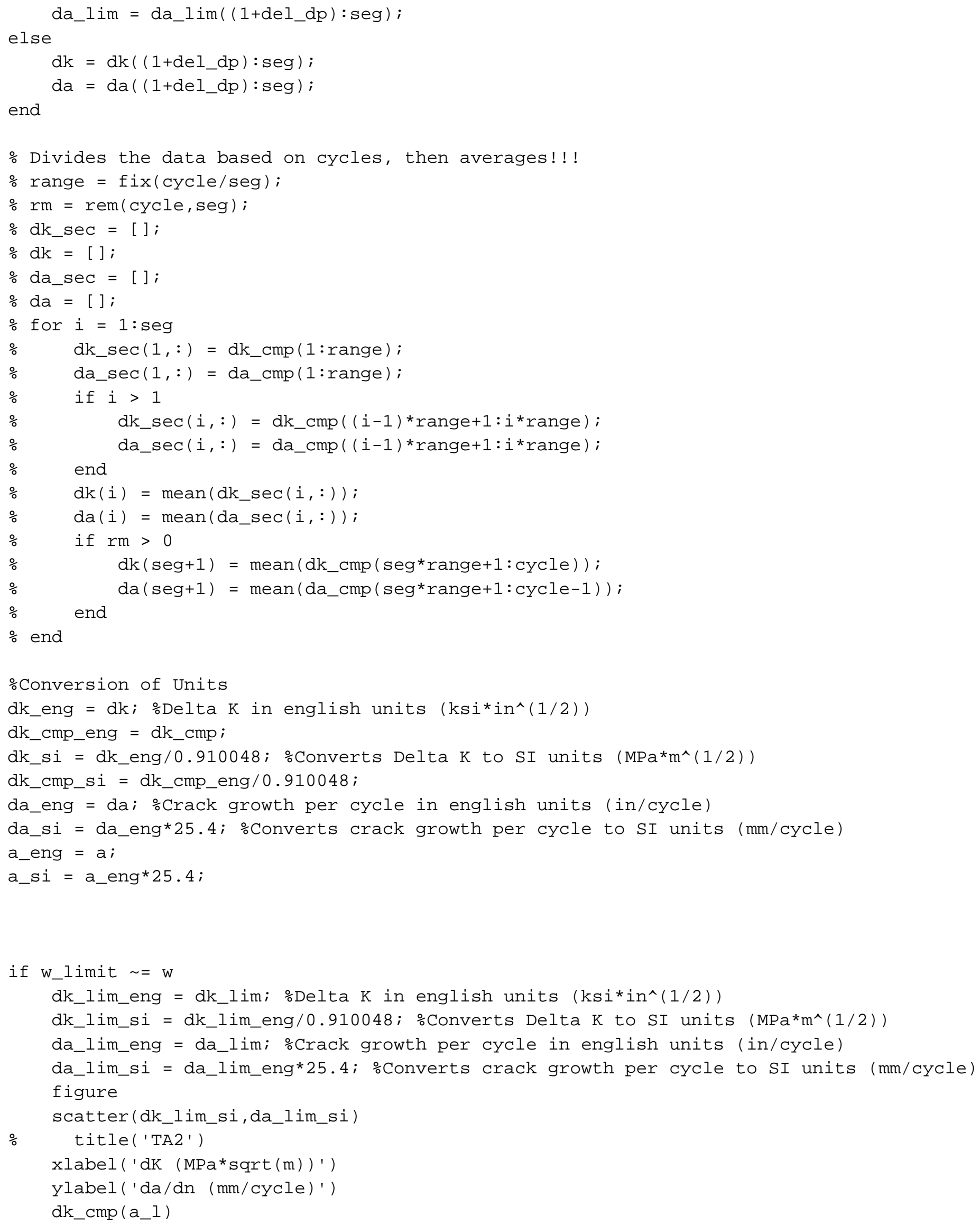




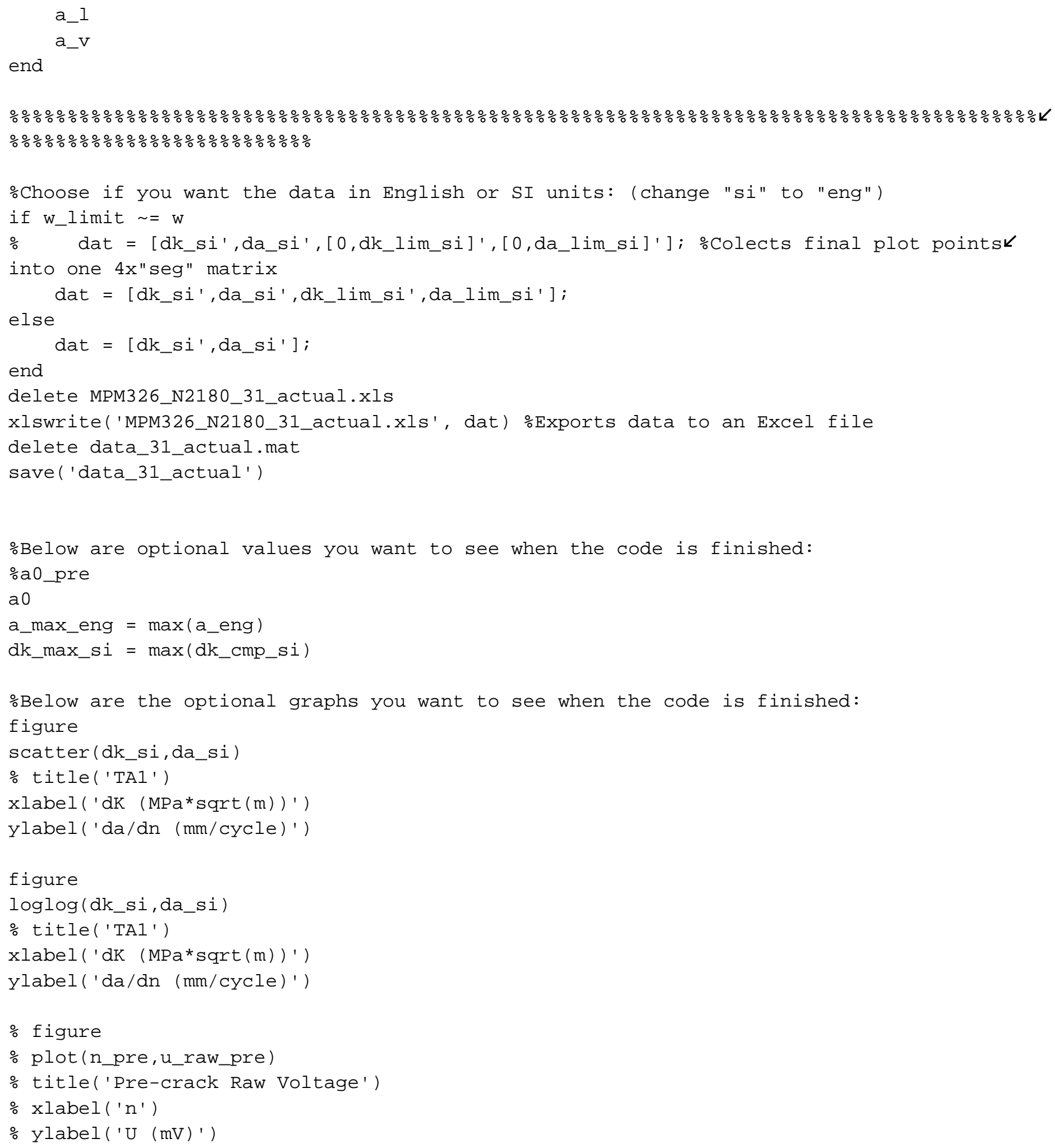


Appendix 2

SearchClosest

MATLAB Function [69] 


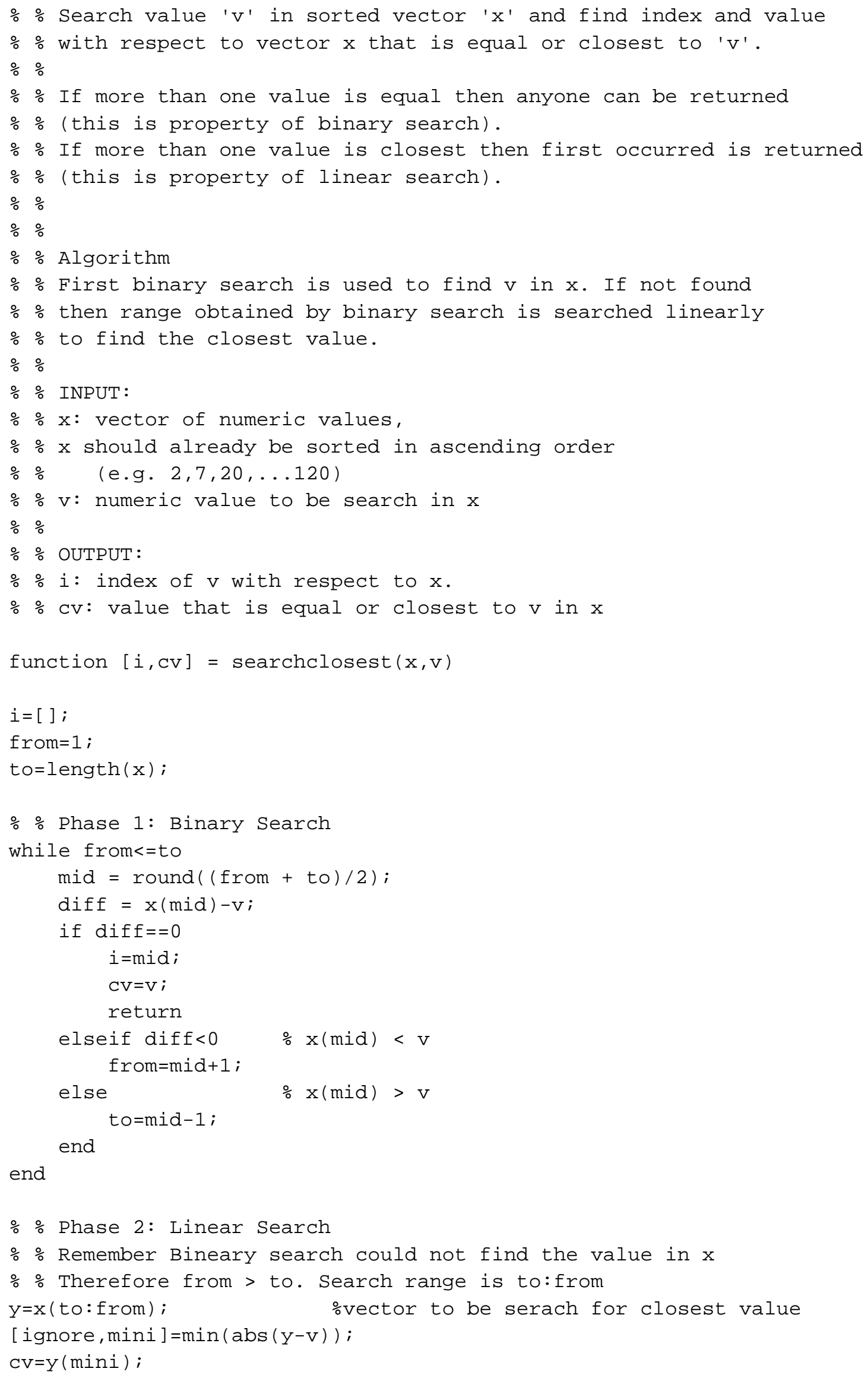




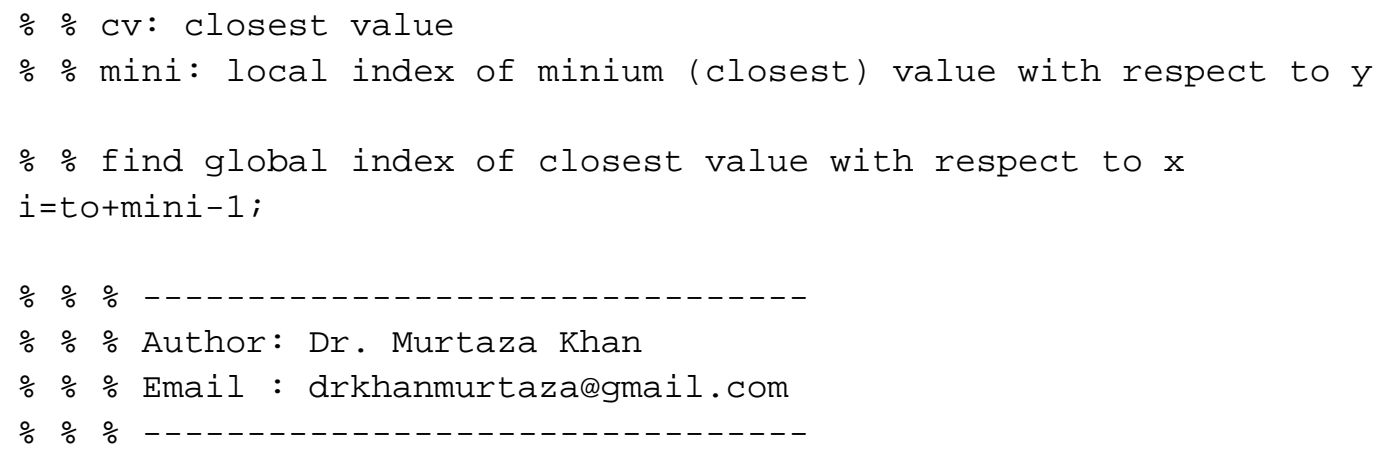

